Rapporter från Åldrande och Social Förändring No. 5

\title{
Late working life, exclusion and inequality -National policies and political-economic context in Germany
}

EIWO Working Paper No. 4

\section{Gerhard Naegele}

${ }^{1}$ TU Dortmund University, Germany

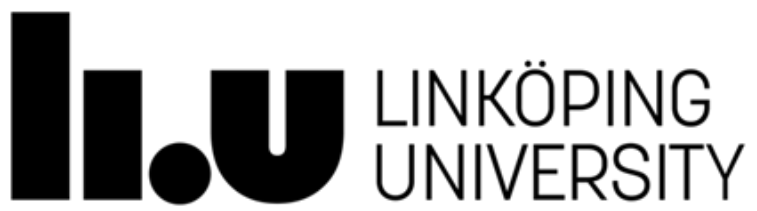




\section{EIWO \\ Exclusion and Inequality \\ in Late Working Life}

Rapporter från Åldrande och Social Förändring No. 5

Late working life, exclusion and inequality -National policies and political-economic context in Germany

Gerhard Naegele

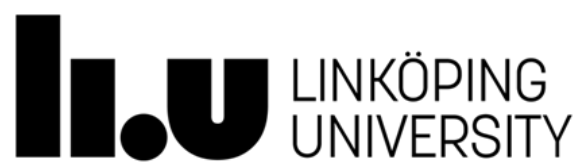

Department of Culture and Society

Division of Ageing and Social Change

Linköpings University, SE-581 83 Linköping, Sweden

Linköping 2021 
(C) Gerhard Naegele, 2021

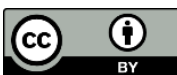

This work is licensed under the Creative Commons Attribution 4.0 International License. To view a copy of this license, visit http://creativecommons.org/licenses/by/4.0/.

Publisher: Linköping University Electronic Press 2021

ISBN 978-91-7929-200-3 (PDF)

https://doi.org/10.3384/9789179292003

ISSN 2004-2655 


\section{Contents}

$1 \quad$ Preface

2 Overview of context in which policies concerning EWL are framed ....................7 2.1 Brief historical background - Germany as the 'world-champion' in early retirement.

2.1.1 Early retirement in the service of labour market policy.......................7

2.1.2 Promoting early retirement as a result of a 'grand societal coalition of interests' 8

2.2 The paradigm shift from early retirement to 'working longer again' and EWL 10

2.2.1 The driving forces........................................................................

2.2.2 Financial pressure on the social security systems............................ 11

2.2.3 Ageing and shrinking of the workforce and (skilled) labour shortage11

2.2.4 The amplifiers - new images of old age in the world of labour..........12

2.2.5 EWL - a 'necessary' shift of paradigm ................................................ 13

2.2.6 How the paradigm shift began ............................................................. 14

2.3 Policy and scientific discourses around EWL ............................................ 15

2.3.1 Moral cushioning of EWL through concepts such as Active Ageing, potentials, resources, and productivity in old age .............................................16

2.3.2 EWL in the context of changed life-courses......................................... 16

2.3.3 The view of Germany's gerontologic community: strengthening negative age images versus humanisation of working life for (highly workloaded) older workers ...................................................................................18

2.3.4 Socio-political discourses pertaining to the Hartz IV reforms............ 19

3 Key macro demographic and social and political and economic national regime characteristics in the EWL context ...................................................................... 20

3.1 Demographic profile of Germany during the paradigm shift .................. 20

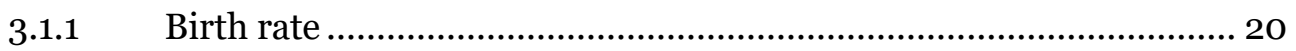

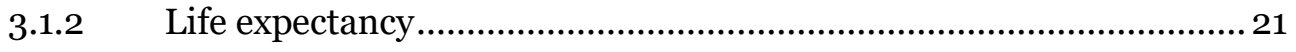

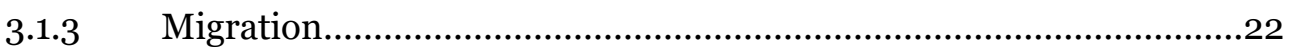

3.1.4 Future total population and 'demographic burden' scenario..............23

3.1.5 The ageing of society as a whole as 'triple ageing' ...............................24 
3.2 Fragmentation instead of comprehensive approaches in demographic policies

3.2.1 Employment policies in the framework of a conservative-corporatist

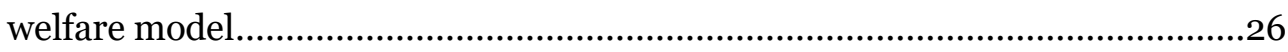

3.2.2 EWL as a horizontal political task .29

3.2.3 Co-ordination of policies in the context of Subsidiarity and Federalism

3.2.4 Collective bargaining-autonomy - a fundamental right for social partners 30

3.3 A new approach: the Federal Demographic Strategy (2012-2018) 30

3.4 Interim conclusion - problems and discrepancies in coordination and governance of policy approaches aiming at EWL.

4 Germany - a success model for integration older workers? A critical overview from the perspective of social inequalities

4.1 Increasing employment rates in all age groups ........................................33

4.1.1 The shift of paradigm to EWL - a German success-model? ...............33

4.1.2 Hardly new recruitments, rather increases due to retention factors .34

4.1.3 Decline in general unemployment rates, but not for older unemployed 35

4.1.4 The German 'success model' as a result of various interwoven

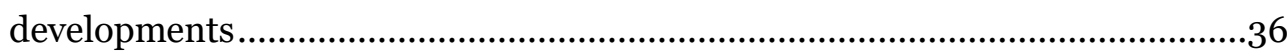

4.2 However, social inequalities are preventing achievement of EWL .........36

4.2.1 Privileges consolidate.........................................................................36

4.2.2 Medium and highly-skilled older workers with higher employment rates 37

4.2.3 No 'age-neutral' labour market structures .37

4.2.4 Growing financial inequalities as effects of the paradigm shift ........ 38

4.3 Unemployment among older workers decoupled from general trends .....39

4.3.1 Increased unemployment among older workers.................................39

4.3.2 Older unemployed: low risk of entry, but high risk of remaining ..... 40

4.4 Who are Germany's 'silver workers'?...................................................... 40

4.4.1 'Silver work' has always existed.......................................................... 40

4.4.2 Increase since the change of paradigm - voluntary or forced?..........41

4.4.3 Social inequalities in the distribution of 'silver work' ..........................41

4.5 The participation of older women in the labour market in Germany ........43

4.5.1 The West German 'breadwinner' model................................................43

4.5.2 The increase in the female employment rate ...................................43 
4.5.3 Gainful employment increasingly in conflict with private care obligations

4.5.4 Atypical and/or precarious employment among (not only older) female workers..

5 Profile of EWL policies and inequalities therein

5.1 Overview

5.2 Fields and areas of action and emerging social inequalities in the wake of EWL policies...

5.2.1 Key threats from social inequalities .48

5.3 The core of EWL policies - state retirement age policies and financial incentives that close or complicate early retirement pathways. .51

5.3.1 Overview........................................................................................ 51

5.3.2 Social inequalities in achieving the objectives of 'pension at 67 ' .......56

5.4 Reducing and/or complicating disability pensions $(2001,2012)$.............. 61

5.5 Redesigning the transition process into retirement ................................62

5.5.1 Introduction of gradual retirement in 1996 and its abolishment in $2009 \quad 62$

5.5.2 'Improving' the unsuccessful partial pension scheme introduced 1992 62

5.5.3 Flexible pension act (Flexirentengesetz) (2017) ..............................62

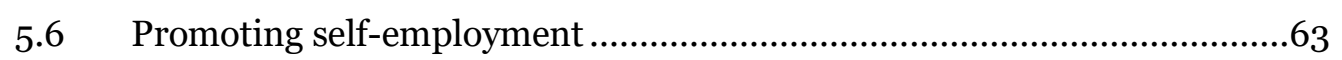

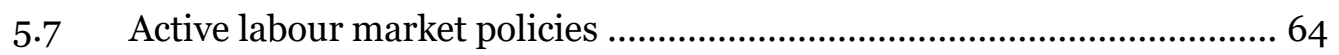

5.7.1 Active and passive labour market policies ........................................ 64

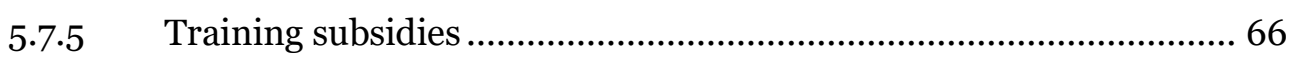

5.7.6 Unemployment reforms following the Hartz commission (20042018) 67

5.7.7 The Federal Initiative '5oplus' (2005-2015)

5.7.8 Mixing of existing legal instruments and priorities in employment promotion for older worker, the current instrument of the Federal Employment Agency 69

5.8 EWL-aimed learning and training - Germany on the way to an institutionalised vocational life-long-learning (LLL) .......................................... 71

5.8.1 Vocational LLL in the service of EWL ................................................ 71

5.8.2 Facts about continuing vocational learning ........................................72

5.8.3 Recent participation and funding figures ....................................... 72

5.8.4 Protection of qualifications in Germany's social law .........................73

5.8.5 Supported further education according to Social Code Book III and II

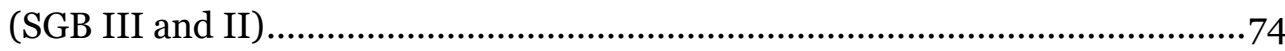


5.8.6 Promotion of further training during employment............................74

5.8.7 The National Continuing Education Strategy (2018) ........................75

5.8.8 The Qualification Opportunities Act (2018) ....................................76

5.8.9 Latest news from Germany`s adult education policy (12/2021)........76

5.9 Health promotion, prevention, protection and rehabilitation.................... 77

5.9.1 Premature reduction/loss of health-related earning capacity

(Minderung der Erwerbsfähigkeit) ..................................................................77

5.9.2 Terms and objectives of health promotion, prevention, protection and

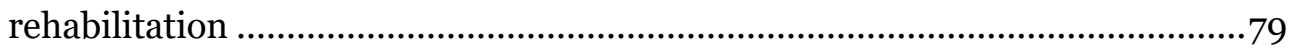

5.9.3 Prevention Act, a new law to strengthen health promotion and prevention (2015) ..........................................................................................79

5.9.4 Common German Strategy for Occupational Safety, or GDA

(Gemeinsame Deutsche Arbeitsschutzstrategie) ............................................ 80

5.9.5 Mental health diseases, a new health-risk factor ............................. 80

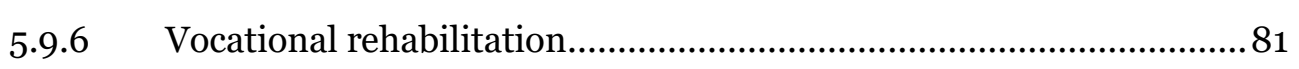

5.9.7 Company-based operational integration management (BEM)......... 82

5.9.8 Personal health promotion through practicing health competence.. 82

5.10 Corporate HR (CHR) strategies and corporate management of age and ageing 83

5.10.1 CHR as a tool to promote EWL ........................................................ 83

5.10.2 Corporate management's tool box for age and ageing ...................... 84

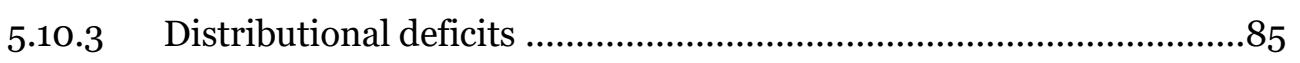

5.10.4 The new credo of a life-cycle oriented personnel policy .....................85

5.10.5 Who benefits from corporate and/or social partner activities

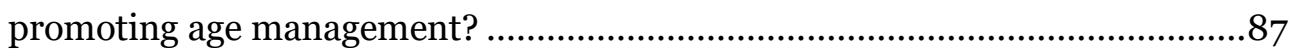

5.11 Provisions for workers with private care obligations (mainly older women) 89

5.12 General strategies aiming at sensitization, education, and raising

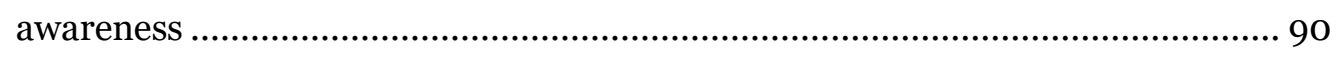

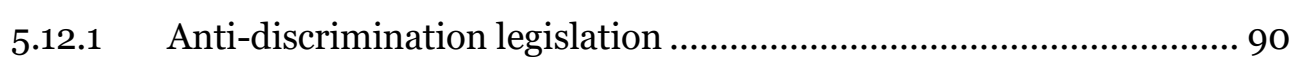

5.12.2 Parliamentary Inquiry Commission on Demographic Change (19892002) 91

5.12.3 The Federal Government's Reports on Ageing in Germany ..... . .92

5.12.4 INQUA and DDN - National attempts to better equip companies to handle demographic change ...............................................................................92

5.12.5 The demography network (DDN) …….............................................93

5.12.6 BMAS/INQUA's new initiative 'Working 4.0'................................... 94

5.13 Collective agreements to regulate demographic change in companies .....95 
EXCLUSION AND INEQUALITY IN LATE WORKING LIFE

WORKING PAPER 4: NATIONAL POLICIES AND POLITICAL-ECONOMIC

CONTEXT IN GERMANY

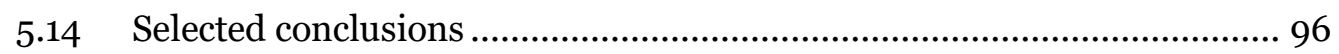

6 A new holistic perspective - news from the EXTEND-project ...........................97

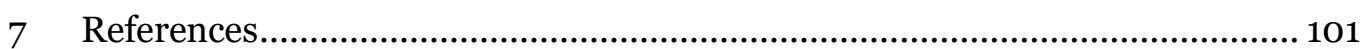

The research programme EIWO is funded by the Swedish Research Council for Health, Working Life and Welfare, grant no. 2019-01245. More information on the research programme and the programme consortium can be found at http://www.eiwoproject.org/.

EIWO Working Papers can be downloaded from the programme's website at http://www.eiwoproject.org/publications.html 


\section{Preface}

The primary task of Work Package 5 is to identify and understand the influence of macro and social changes, population dynamics, cultural swings, and changes in political economy and resulting (social) policy approaches on employment in late life in recent decades. The special focus is on the extent to which different regimes and combinations of policy strategies are associated with different forms and levels of employment in late life and resulting inequalities. For Germany, the focus is on, in particular, the strategic shift from a policy and subsequent practice of promoting early retirement, which lasted from the mid-1970s until about the turn of the millennium (and even longer in some sectors and/or regions) and has since been replaced by a policy aimed at extension of working life (EWL).

\section{Overview of context in which policies concerning EWL are framed}

\subsection{Brief historical background - Germany as the 'world- champion' in early retirement}

After the Second World War, the German economy started to grow rapidly in the early 1950 (Wirtschaftswunder; 'economic miracle') and needed every possible worker, hence, had high employment rates in all age groups and all qualifications, at least amongst men (Ebbinghaus 2006). In the 1960s, economic growth slowed and international competition from Asia, in particular Japan, and the oil crisis in the 1970 forced the large and important production sector in Germany to reduce costs. Shedding labour costs by laying off workers was one tool and, in particular, because of the de facto seniority wages, comparably expensive older workers were pushed into unemployment. Figure 1 gives an overview of the development of unemployment of all age groups between 1975 und 2018 (see also section 2.1.1).

\subsubsection{Early retirement in the service of labour market policy}

To avoid even greater unemployment, politicians, employers, and trade unions began a policy of redistributing labour at the expense of older workers by using the instrument of early retirement in the late 1970s/mid-1980s (Kohli 1990; Kohli et al. 1991; Naegele 1992); among researchers, this trend is often described as 'devocationalisation of old age' ("Entberuflichung des Alters", Naegele 1992; Tews 1993). Older workers were offered various options for retiring well before the official retirement age ( 65 for men, 60 for women at that time) with comparably low 
and very often no pension deductions (Naegele 1992; Bauknecht \& Naegele 2015). Main early exit routes were the early retirement options for long-term contributors to the German statutory old age income security system and the unemployment insurance (Radl 2007; BMFSFJ 2010). Employers used the early retirement policy to cut costs in a socially acceptable manner and often complemented the public early retirement options with generous payments (Hofäcker, Hess \& Neumann 2015). Older workers, driven and very often supported by like-minded German trade union initiatives, willingly accepted this 'golden hand-shake' and early retirement (e.g. before the statutory retirement ages of $60(\mathrm{w})$ and $65(\mathrm{~m})$ ) became the 'normal' exit route out of paid labour.

Figure 1: Unemployed and unemployment rates in Germany, 1975-2018

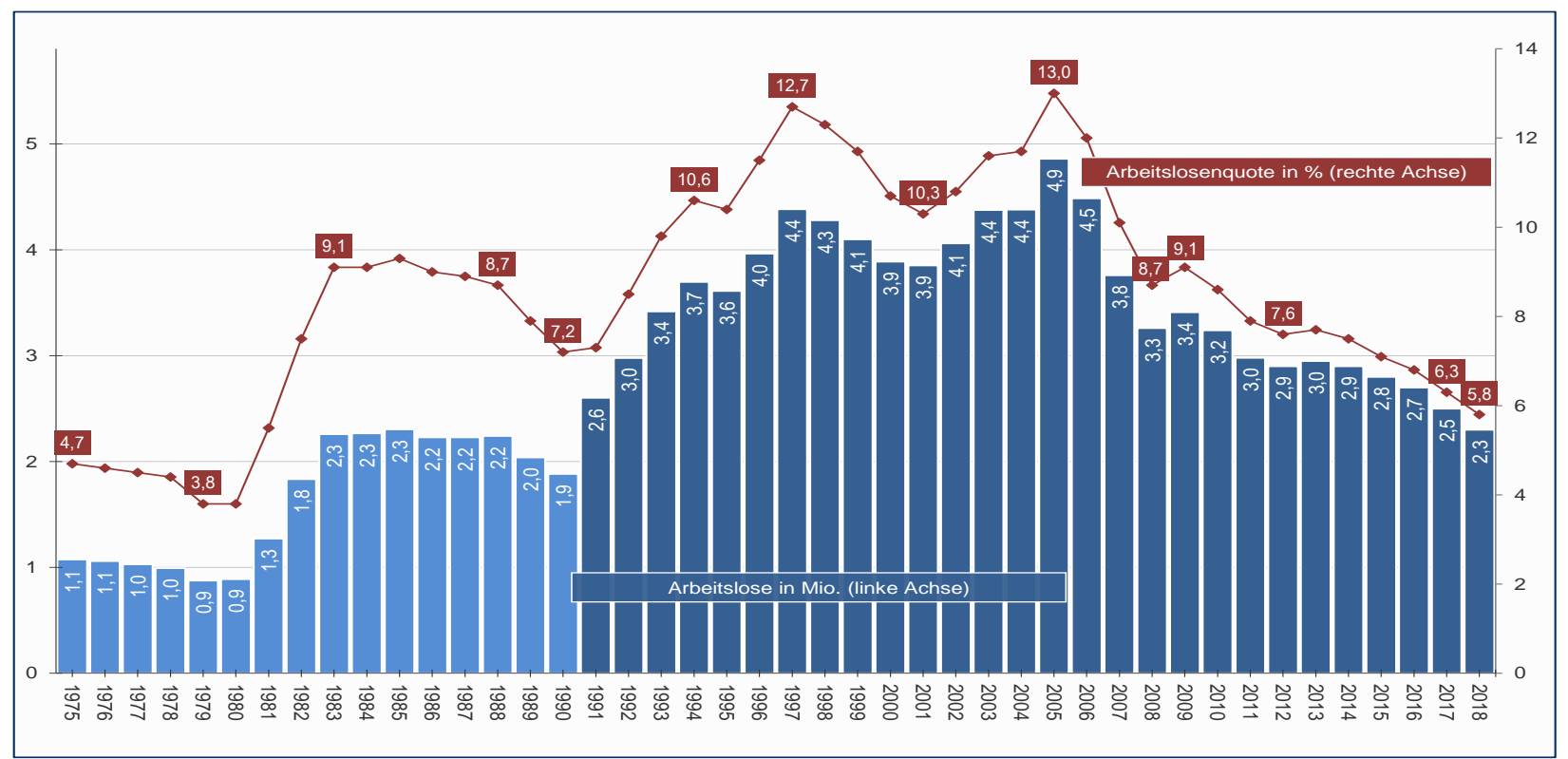

Unemployment rate related to dependent civilian labour force up to 1990: old Federal states, from 1991: Germany.

Red line: officially registered unemployed (in \%) right axis

Blue text: unemployed in mio. (left axis)

Source: Statistics of the Federal Employment Agency (2019): Unemployment over time.

\subsubsection{Promoting early retirement as a result of a 'grand societal coalition of interests'}

The early exit of older workers quickly developed into a 'great coalition of interests' of all stakeholders, in which the main actors (government, social partners like trade unions and employers' associations, the statutory pension funds, and the statutory unemployment insurance) and both the companies and older workers themselves 
were actively involved. In the years to come, early retirement became regarded the 'normal' way of exiting the labour market mainly for men, while retirement at or after 65 became a very rare. The older workers concerned were not themselves uninvolved. They were by no means 'victims' of an externalisation policy, but for the most part (thanks to the generous financial incentives) active drivers of their own premature de-occupationalisation, due to an increasingly widespread 'early retirement consciousness', often according to the motto 'the earlier, the better' (Naegele 1992). As a consequence, most older employees (and most trade unions) saw earlier retirement both as a significant tool to humanize working conditions for older workers and, particularly against the background of long working careers in often- stressful jobs, not seldom as a 'social right' ('fair earnings for a lifelong high commitment to a company and/or the economy') or as 'a legal claim in a normal employee biography'. Kohli (1987) referred to these ideas as part of his concept of "the moral economy of a working society."

\subsubsection{Early retirement as a key instrument for adjusting the East German labour markets to the economic transformation}

After German reunification in 1990/91, the 'proven' instrument of early retirement was transferred to the territory of the former German Democratic Republic (GDR) to better adjust the labour markets there to the new situation and to the collapse of large parts of the former East German economy. Prior to this change, GDR state policies encouraged high level of employment and long working hours for both (older) women and older workers. Due to the notorious shortage of labour in the former GDR, the employment rates for women (and mothers) were extremely high compared to West Germany, and supported by an efficient system of social infrastructure (e.g. day nurseries and kindergartens, after-school care, all-day schools). It was also common for older employees to stay in working life significantly longer than their West German counterparts, and (forced) early retirement was unknown. Older workers were praised as deserving 'veterans of labour' (Ernst 1995) as a way to provide moral support and ensure that the labour needs for even older people were met.

After the "Wende" (Germany`s reunification), this high regard for older workers ended quickly. Following the West German model, most of East Germany's older workers were offered an attractive early exit option called 'Old Age Transition Scheme' (Altersübergangsgeld) that let them retire at 55 if they became unemployed (Bönke, Schröder \& Schulte 2009). The idea of the 'lump-of-labour' policy makers was that if the older workers left the labour market by retiring,

\footnotetext{
${ }^{1}$ See Naegele, G. and Walker, A. (2021): EIWOWorking Paper I: EIWO's Theoretical Perspectives. Final report on EIWO wp 1. EIWO-website.
} 
younger workers could take their jobs and the unemployment rate would decrease ('generational contract') (which could never be empirically confirmed by research).

\subsection{The paradigm shift from early retirement to 'working longer again' and EWL}

Alongside efforts to combat unemployment 'on the backs of older workers', in the initial phase of the paradigm shift, concerns about the long-term stability of social security systems were also used as justifications for early retirement. Based on both individual labour market participation and the Bismarck-ian social insurance system based on the 'pay as you go' principle, and financed by individual contributions, the argument was made that the increasing discrepancy between income (decreasing contributions) and (early exit-related) rising expenditures (pensions) would sustainably threaten the stability of the public pensions funds. This discourse dominated the debate on the sustainability of old-age security systems for decades (and it does even today), but soon extended to the entire system of social security according to the Bismarck-ian social insurance model. Moreover, the rising labour costs on the employers' side (social security contributions are traditionally shared by employers in Germany) were a thorn in the side of both the representatives of the 'pure' market economy theory as well as among many leading stakeholders and/or policy makers close to them. Additionally, arguments were presented about intergenerational justice and the fear that the generational contract might collapse, and that younger generations should not be paying for the pensions of the older without receiving old age income when they themselves became old (Hess, Naegele \& Bauknecht 2020).

\subsubsection{The driving forces}

To keep the pensions and sustain the 'proven' social insurance system was (and is still is today) the prime driving force for the paradigm shift to working longer again and EWL. However, EWL also was increasingly supported by labour market arguments with regard to the imminent threat of a shortage of (skilled) labour, due to the demographically-induced ageing and shrinking of the German workforce. Today, two main policy streams can be distinguished when explaining the change of paradigm towards EWL: (1) financial considerations in connection with pensions and other retirement benefits and increasing labour costs, and (2) labour market policy threat scenarios about an impending ageing and shrinking of the labour force both outside and inside of companies. However, these two key streams have to be seen in a broader context of different influencing factors, which can be summarised as follows (Naegele 2013b; Bauknecht \& Naegele 2015; Naegele \& Bauknecht 2017):

- Ageing of staff due to the forthcoming exit of the 'baby-boomers';

- Fear of declines in Germany's national and international innovative capabilities and competitive position; 
- Raising the employment rates of older workers is seen as a tool to prevent economic downswings;

- Rising appreciation of human capital (including older workers) as a factor of production against the backdrop of a general change in the working landscape;

- EU requirements to raise the employment rates of older workers and to postpone retirement age as embedded in the new dogma of 'Active Ageing' (Walker 2013; Ogg \& Rasticova 2020);

- Long-distance effects of (EU and national) anti-discrimination legislation.

\subsubsection{Financial pressure on the social security systems}

Policymakers and stakeholders started seeing the long-lasting policy of early retirement as a key reason for financial jeopardy mainly in the statutory old age income system (Gesetzliche Rentenversicherung, GRV) (other pension systems like those for the self-employed or for civil servants were equally threatened, but differently financed). The argument for the GRV was that a shrinking number of contributors was facing a growing number of recipients with longer periods of payments due to increasing residual life expectancy. Between 1995 and 2017, for example, the average duration of pension payments rose by about 4 years (men 4.3, women 3.6). In 2017, pensions were being paid for 19.9 years (men) and 21.8 years (women). After 1960, the length of time that pensions have been paid has more than doubled (BMAS 2018a).

Although the need to halt the financial pressure on both the public pension as well as the entire social security systems was already being discussed in the early 1980 s, these discussions did not lead to real policy change in Germany until the late 1980 s and early 1990s, which is at least in part accounted for by the pressure on policy agenda in the wake of German reunification. In this respect, it is justifiable to see the various retirement-age and labour market reforms aimed at extending working life (EWL) in the years to come and until today (see sections 5.3 and 5.4) as part of a more comprehensive reform of the statutory pension systems ('new age policy') which - as many critics have repeatedly stressed - aims at a complete paradigm shift in the hitherto prevailing pension policy, namely in favour of consolidation of finances and contribution rate stability instead of securing living standards and avoiding poverty (Naegele \& Schmähl 2007).

\subsubsection{Ageing and shrinking of the workforce and (skilled) labour shortage}

In Germany, the active workforce is undergoing a noticeable process of both ageing and shrinking: the number of workers aged between 55 and 65 has increased from 9.6 million in 2008 to 12.1 million 2018 (BA 2018) (see Figure 2). A further significant increase is expected in the years to come. This projection is confirmed by a global projection (from 2011) of the development of the total labour force potential. According to this projection, under constant conditions, the labour force 
potential will decline to approximately 35.1 million persons by 2030 (in 2005, the labour force was 44.7 million). However, these numbers do not include increases in immigration to Germany (2015/16). But even with strong immigration surges, the labour force potential is projected to decline to about 41.0 million by 2030 (Brussig 2018).

At the same time, public awareness of the problem as increased, empirically supported by experiences in particularly affected sectors: this demographic change is now reaching the world of work and the companies. Already in the early 2000s, German companies (particularly those in high-technology, health and care, and the craft sector) faced a lack of skilled and experienced workers. In the beginning there was primarily a shortage of engineers, however, soon a lack of skilled labour spread to professions previously unconcerned, e.g. nurses and similar professional careers (Merkel, Holman, Ruokolainen \& Hess 2020; Reichert 2020, 2021). This development is reinforced by the (in a mid-term perspective) expected move of some of the younger 'baby boomers' (at least those born in the 1960s) into the cohort of older workers with retirement entitlements in many lines of industry. This change will entail considerable discrepancies in the formal qualification level between the individual age cohorts, which additionally overlays the feared qualification bottleneck (see Figure 3). Consequently, fears of reinforcing the lack of (skilled) labour, once they reach the retirement age and exit the labour market, are even higher.

Figure 2: Development of population and age structure Germany (1960-2060) by total population and age group (in millions)

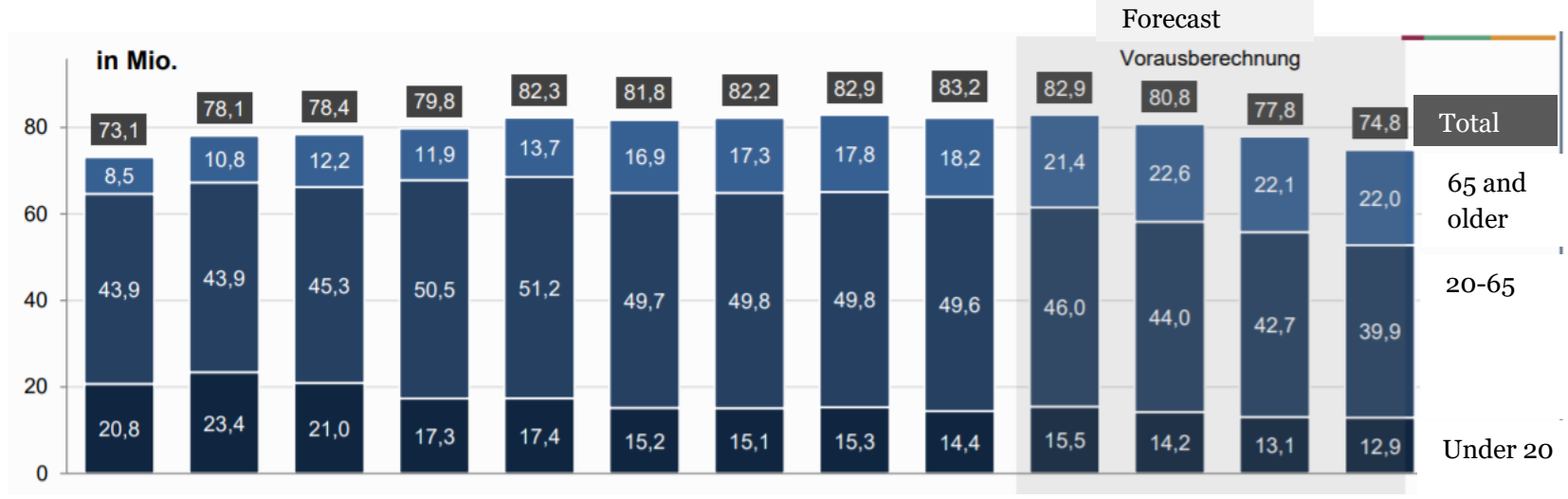

Source: Statistisches Bundesamt (2016, 2019) Bevölkerungsfortschreibung, Fachserie 1, Reihe 1.3.

\subsubsection{The amplifiers - new images of old age in the world of labour}

Today, in many types of businesses, older workers are seen as an important labour market resource by both the state and by many companies. More and more, but as a rule only under certain conditions (above all qualifications and concrete operational 
use value), these workers are being asked to stay longer in the companies and in their specific jobs ('retain factor'). Furthermore, in many companies, special demographic collective agreements have been introduced to regulate the implications of an ageing staff (see section 5.13). Individual companies began to react to the foreseeable lack in the skilled labour through investing in age-friendly human resource measures and age management (see section 5.10). However, the degree of prevalence does not indicate blanket coverage, but rather suggests that older employees in large companies and/or sectors that are strongly protected by trade unions or collective agreements benefit most from these changes (Eitner \& Naegele 2013; Hess, Naegele \& Bauknecht 2020; see also section 5.10.5).

In all, this development has also inspired both new images of ageing and a new treatment of particularly skilled older workers, and thus is also in line with the EU's credo of 'Active Ageing'. Germany`s 6th Federal German Aging Report (2010) stated optimistically that the public image of ageing has changed (see section 5.12.3). In a trenchant interpretation of 'Active Ageing', the report calls for older persons (both within and without the labour world) to not be 'idle' as they age, but realize all their potentials in the society: "With the financing crisis of the welfare state, a new discourse on the productivity of old age began, which was linked to a rediscovery and re-engagement of older people, and not only as consumers. Since then, inactivity in retirement is increasingly regarded as requiring justification, and a 'fulfilled' old age is characterized by the fact that older people contribute all their resources, skills and potential to a new generational contract" (BMFSFJ 2010: 84).

\subsubsection{EWL - a 'necessary' shift of paradigm}

As a result of these developments, Germany's policy makers, supported by many economists, employer's associations and other key stakeholders close to them (but not in the beginning by the trade unions; see section 3.2), considered the hitherto widespread exclusion of older workers from the labour market to be inconsistent with both the economic and social challenges of an ageing and shrinking workforce and with a cohort-typical change in images of old age (BMFSFJ 2010; Dietz \& Walwei 2011). It was repeatedly emphasized that Germany's future economic growth, future competitiveness, and efficiency would depend increasingly on how effectively employers could utilize their ageing staff members. Consequently, older workers were encouraged to take an increasingly active part in economic and technological development (Brussig, Knuth \& Mümken 2016), which was in line with the fact that Germany's economy showed a robust growth since 2000 (soon to mitigated by the financial crisis of 2008/2009), resulting in an increased demand of (mainly skilled) workers. Many employers began seeing older workers as both an overlooked as well as 'neglected' sources of experience. In all, two important cohort effects can be identified as additional 'drivers': first, the new cohorts of older workers are better skilled and healthier than earlier cohorts of older workers (regarding formal vocational qualification, see Figure 3); second, the new cohorts have much higher rates of female employment (see section 4.5). 
To extend working life is now officially acknowledged as being the leading objective of pension and retirement policies as well as a being a key starting point for active labour market policies for older workers (see section 5.7), of collective agreements (see section 5.13), and of company initiatives for managing an ageing workforce (see section 5.2). In 2001, the joint declaration from the Federal Alliance for Jobs and Competitiveness ("Gemeinsame Erklärung”; Frerichs \& Naegele 2008) summed up the need for a paradigm shift (at least in the first phase, this shift was focused on vocational training) as follows:

- raising awareness among businesses and workers about the benefits of lifelong learning;

- promoting vocational training for older workers based on voluntary in-company actions as well as on collective bargaining;

- implementing financial incentives for vocational training of older workers aged 50 and over in small and medium-sized companies.

Figure 3: Educational attainment of the population 2018 by age groups, in \%

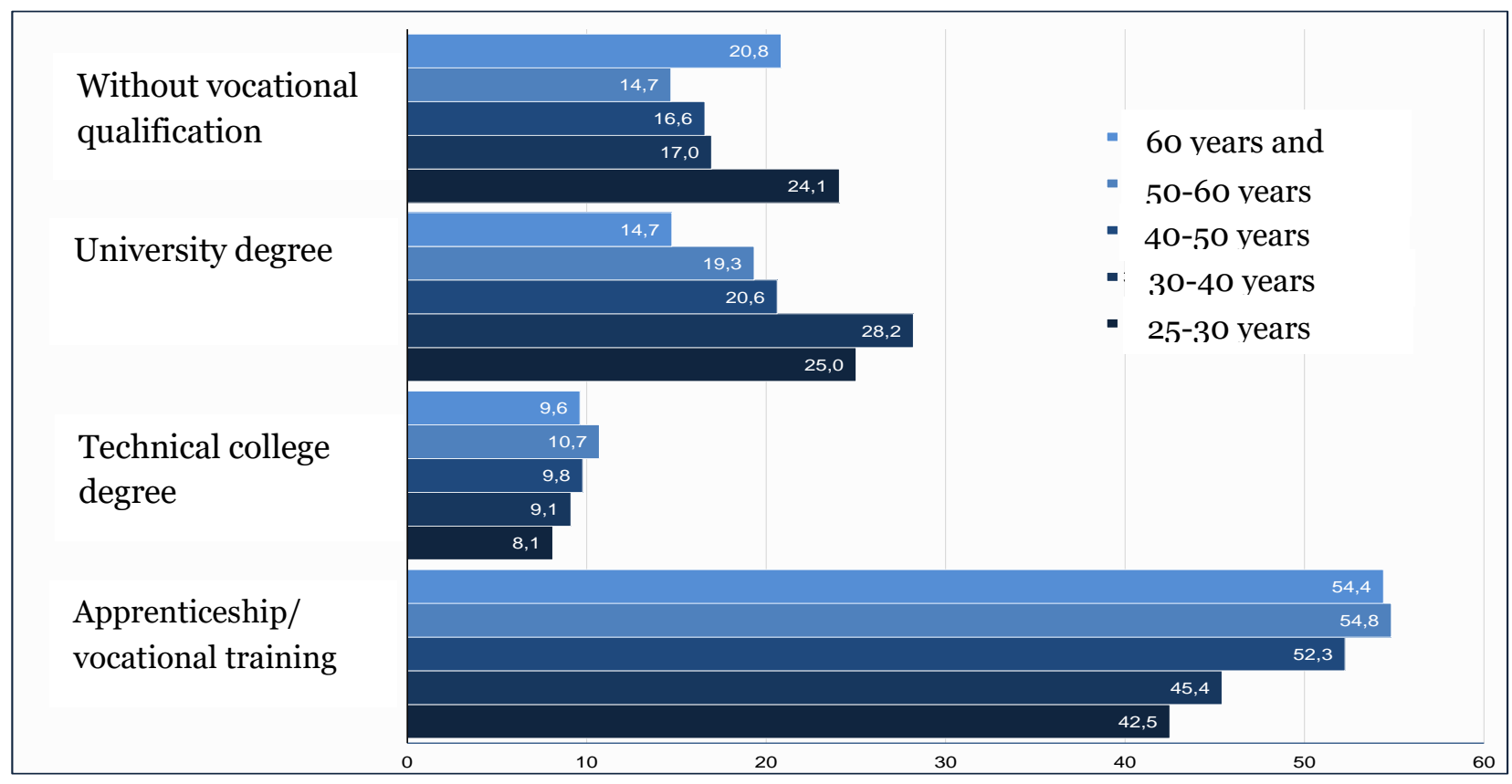

Source: Statistisches Bundesamt (2019): Fachserie 1, Reihe 4.14, Bevölkerung und Erwerbstätigkeit.

\subsubsection{How the paradigm shift began}

The paradigm shift from 'early retirement to working longer again' in public pension and retirement policies started with the first pension reforms in 1989 (these did not come into until 1992) and including restricting early retirement options for women (see sections 4.5 and 5.2), unemployed and people with severe 
health problems who were previously allowed to retire at 60 based on disability pensions. At the same time, both pension reductions (0,3\% per month for early pension recipients who still used the existing early retirement options) and pension increases ( $0,5 \%$ for each month of postponing retirement) were introduced (Bäcker, Naegele \& Bispinck 2020, vol. II). This early retirement option came to an end in 2007 with the Retirement Age Adjustment Act (Altersgrenzenanpassungsgesetz) (2007), which (starting in 2012) aimed at gradually raising the standard retirement age from 65 to 67 ('pension at 67'; see also section 5.3.1). Interestingly, the role of social partners (trade unions, employers' associations, etc.) became less relevant in pension-policy making after the early 2000 s with a more active government and party system acting autonomously on policies about social partners (Romeu-Gordo \& Sarter 2020; see also section 3.4).

The initial focus on qualification issues, training necessities, and so forth was soon extended to policies aimed at older unemployed persons, through attempts to improve their re-integration chances in the labour markets, by for instance encouraging the recruitment of older jobseekers and promoting the sharing of best practices among employers (see section 5.7). The Coalition Agreement signed in 2005 by the governing conservative and social-democratic parties (CDU, CSU \& SPD 2005) stated that industry, social partners, Federal states and regions should put in place measures to maintain and improve the employability of older unemployed people and to reintegrate them into the workforce (Frerichs \& Naegele 2008).

Again a 'grand coalition' (this time with the goal of overcoming early retirement) was gathered through a 'policy network of pension policies' and with hardly any support from Germany's leading trade unions (Deutscher Gewerkschaftsbund (DGB) 2015). In the following years, the objective of sustainability of both the pension systems as well as the welfare state in general was de facto predominating all other social policy action fields and can be regarded more like a unilateral strategy of the government (Busemeyer 2006). In 2004, the Sustainability Pensions law came into force. Among other things, legal retirement ages were raised, early retirement options were abolished, and eligibility criteria were made more rigid, all of which finally led to the more or less complete cancellation of the long-standing societal consensus favouring early retirement (Ebbinghaus 2006; Hofäcker, Hess \& König 2018). From 2012 until today, there has been no possibility of receiving a pension before the age of 65 without accepting high actuarial deductions (Bäcker, Naegele \& Bispinck 2020, vol. II).

\subsection{Policy and scientific discourses around EWL}

The paradigm shift of promoting EWL has been at the centre of various political and scientific discourses from its very beginning. Undoubtedly, the macroeconomic and fiscal policy discourses were the most decisive among them (see section 2.2). However, other discourses were also directly or indirectly involved in seeing and 
promoting EWL as the 'right way'. The most important lines of argumentation and any counter-arguments brought into the discussion are briefly outlined below.

\subsubsection{Moral cushioning of EWL through concepts such as Active Ageing, potentials, resources, and productivity in old age}

The concept of 'Active Ageing' (Walker 2010), which originated in EU debate around the beginning of this millennium, was adopted in Germany and, according to outside observers, coincided remarkably to the paradigm shift towards EWL. Active Ageing was subsequently partly modified and extended to the concepts of 'productivity', 'potentials' and 'resources'. The 5th Federal Report on Ageing focussing the role of old age in the economy and society (BMFSFJ 2006; see also section 5.10) played a prominent role in this context. It dealt with the (often hidden and unused) potential of older people in general (with a special focus on the economic potential) and how this resource could be better used in society as one answer to new demographic challenges. Age was conceptualised as a 'societal resource' that should be included in the social and economic discussions of meeting the challenges of demographic change (e.g. Klös \& Naegele 2013).

Of particular interest were references to the intergenerational obligations of older people in society, both in pay-as-you-go-financed social security systems as well as in their fundamental co-responsibility for reacting to ageing, and better meeting the challenges that affected their own life situations (e.g. self-responsibility, staying independent, being active; BMFSFJ 2006). In this context, working longer was considered a very prominent adjusting screw. However, the optimistic debate about resources did not remain unchallenged, and the idea of 'gerontologic finetuning' was criticized. Reference was made to social inequalities in both availability as well as use of 'potentials', especially among socially weak and very old people. In the debate on 'active ageing' and its application in practice, this was repeatedly criticized and instead demanded to take those older workers who are less "productive" due to several reasons like health and/or skill problems, and try to invest in their "productivity" instead (e.g. by adapting workplaces or reskilling). (Dieck \& Naegele 1993; van Dyck \& Lessenich 2009).

\subsubsection{EWL in the context of changed life-courses ${ }^{2}$}

Demographic and social changes have played major roles in calling into question the current divisions of a life-course and there have been calls for ever-shorter working life and ever-longer retirement. Until those changes happen, the

2 See also Naegele, G. and Walker, A. (2021): EIWO Working Paper I: EIWO's Theoretical Perspectives. Final report on EIWO wp 1. EIWO-website. 
structuring influence of social policy on one's life course ('institutionalisation') had favoured the development of an independent phase of life in old age, which then developed into a far-reaching biographical orientation towards a socially organised exemption from gainful employment. In the literature on the sociology of ageing, the previous practices of early retirement (and also the change of paradigm to EWL) were thought to be the beginning of the dissolution of the classic division of the life course into three parts, and as the beginning of a gradual de-standardization of the 'normal' employment biography (Kohli 1985, 1987, 1990; Kohli et al. 1991; Naegele et al. 2002).

From a demographic perspective, the prolongation of life expectancy, especially of healthy life expectancy (see section 3.1), has favoured a revision of such biographical orientations and is supported by the increase in importance of a wellknown dimension of the 'structural change of old age' ('Strukturwandel des Alters"), namely the 'rejuvenation of old age' ("Verjüngung des Alters”, Tews 1989). According to this viewpoint, over the last decades, there has been a growing discrepancy between a subjective self-assessment of age and actual chronological age (workers now 'feel' themselves to be up to 10 years younger than their actual age). The question arose, why shouldn't people who subjectively feel younger and younger (and are objectively also healthier) work longer (Klös \& Naegele 2013)? This question corresponds to what Alan Walker once described as the 'old age paradox' (Walker 2010), which is the contradiction between increasingly early retirement and better cohort-typical starting conditions for working longer in the age groups as they age, whereby positive cohort effects, especially at the levels of health and qualification, have been emphasized repeatedly.

Important dimensions of societal change also had considerable influence on the EWL discourse, influencing the discussion about the justification of fixed retirement ages and variable (gliding) transitions. Technological and economic developments, changing patterns of education, work, consumption, life, and leisure (Clemens 2010) have all profoundly changed the life courses of successive cohorts and the expectations tied to certain phases of life, such as the idea of 'well-deserved retirement' (as a 'moral obligation of the working society', Kohli 1987) associated with the age phase. As results of increased 'early retirement consciousness' and the 'rejuvenation of old age', the age phase has turned into a phase of 'late freedom' (Rosenmayr 1988) in the assessment of many, mainly younger elderly people ('the young old'), thus fostering an 'awareness of retirement' that has supported the desire of many to leave the workforce as early as possible. On the other hand, an increasing variability in life courses can be observed, resulting in changed biographies (including later marriage, later births, childlessness, longer educational careers, more women in traditional male employment, etc.; Clemens 2010). For an increasing number of older workers, these changes have been accompanied by a $\mathrm{n}$ perspective that favours choosing the 'right time to leave work' in accordance with private living conditions in the sense of 'linked lives', e.g. in a couple and/or household context, financial obligations, costs of raising children, and so forth, 
irrespective of the of the (later) legal retirement ages. In retrospect, it could be argued that the demand for EWL was partly favoured by the increasing variability of life courses and the changed goals in later life phases.

\subsubsection{The view of Germany's gerontologic community: strengthening negative age images versus humanisation of working life for (highly work-loaded) older workers}

In the narrower (mainly psychologically-dominated) gerontologic debate, criticism was initially directed primarily at the continued practice of early retirement. The starting point for these debates was the results of basic gerontologic psychological research from the Bonn School around Hans Thomae and Ursula Lehr (Lehr 1988), which suggested that early retirement by no means corresponded to the changed performance capabilities of older people. On the contrary: early retirement was to be regarded as a 'Danaer-gift' contributing to the premature 'scrapping of old age'. This position is based on widespread of criticism of the 'deficit model of old age', which is strongly represented by psychological gerontology. The idea here is that early retirement would contribute to the spread and reinforcement of negative stereotypes of old age.

As a counter-proposal, mainstream gerontology in Germany in particular pressed for the dissemination of positive and later 'realistic images of old age', especially in the world of work. The 6th Federal Old-Age Report with the main topic 'images of old age in society' (BMFSFJ 2010; see also section 5.12.3) is a prominent part of this position. Here, this development is described as being responsible for substantial changes in the hitherto dominating images of age: "Following the increase in unemployment in 1967/68 and especially after the first oil crisis in 1973, pressure increased on older workers to retire in favour of younger people.

Retirement became a socio-historically completely new interpretation as 'deserved retirement'. [...] Age became in a certain way synonymous with idleness and was thus placed in sharp contrast to the values of the working society" (BMFSFJ 2010: 84).

In contrast, another counter position was presented very early on, which was represented in particular by the Cologne School of Gerontology centred around Otto Blume and colleagues (Neumann (ed.) 1979). Strongly influenced by the traditional life-situation research on older workers, especially in the iron and steel and processing industries but also in social services such as nursing care (Frerichs (ed.) 2016), attention was drawn to the negative effects of physically and mentally stressful working conditions, often experienced over decades, on both ability to work and on health. In this view, early retirement ages or other options for early exit from working life were considered by many to be important instruments for the humanisation of work, especially for highly stressed groups of mainly blue-collar older workers. Later, this argument was repeatedly put forward both when 'pension 
with 67' ("Rente mit 67") was introduced (2005) as well as in the context of its partial revision in 2014 (see section 5·3.1).

Many opponents of Rente mit 67, especially those with trade-unionist positions, regarded these arguments to be the most important counter-argument against a blanket increase in retirement ages, and in particular, workers from stressful occupations and sectors loudly and effectively expressed their doubts about its feasibility at all (see Figure 3). Rente mit 67 still today is repeatedly opposed among many (not only older) workers, emphasising that a large group of older workers particularly in physically demanding jobs will not be able to stay employed until 67, and will therefore face severe pension cuts (DGB 2015); these criticisms apply especially to many working women (Heien et al. 2008; see also section 5.3.2).

\subsubsection{Socio-political discourses pertaining to the Hartz IV reforms}

Socio-political discussions entered the agenda particularly about the social and financial consequences of implementing the new concept of 'support and demand' in the wake of introducing the Hartz IV reforms (see section 5.7). Older long-term unemployed (with regional focus on the territories of the former GDR) were long regarded as the main 'victims' of the Hartz reforms. Their poverty rates increased substantially in what, for a long time, was the cause of massive, publicly voiced criticism of the welfare state in Germany (again, particularly in the areas of the former GDR). The Government's 'Agenda 2010' including among other things the implementation of the Hartz IV reforms, which were partly responsible for the Federal election defeat of Chancellor Schröder in 2005 and contributed to the founding of the party called 'The Left' with strong support mainly in former GDR regions, at least in the beginning. ${ }^{3}$ In order to counteract both the ongoing public criticism as well the persistent hardening of long-term unemployment, a partial reversal of the restrictive orientation of SGB II was implemented around 2016. Special programmes of the Federal Government and, in particular, new funding regulations in SGB II were designed to offer the long-term unemployed and longterm benefit recipients employment and participation opportunities and to make substantial funding available for this purpose (Bäcker, Naegele \& Bispinck 2020, vol. I; see also sections 5.7).

\footnotetext{
${ }^{3}$ Since this time, "The Left' has lost enormously in its position as an explicit representative of East German interests in the public discourse. Recent election results in eastern states (i.e., the former GDR) indicate that the right-wing party 'Alternative for Germany' (AFD), which according to majority opinion represents radical right-wing and nationalist positions, has taken over this role, and the party's greatest recent electoral successes have been in the eastern German states.
} 


\section{Key macro demographic and social and political and economic national regime characteristics in the EWL context}

\subsection{Demographic profile of Germany during the paradigm shift ${ }^{4}$}

For Germany, as for all developed countries, the dual effect of a persistently low birth rate and an increase in life expectancy has led (and will continue to lead) to a decline in the total population, and at the same time, to a fundamental shift in the age structure of the population. Since the older generation is among the primary recipients of benefits in the welfare state (Bäcker, Naegele \& Bispinck 2020, vol. I), this demographic upheaval is having a particular impact here: the number of older people is growing, while at the same time the number of middle-aged, active people who are able to work and have to provide funding for the social systems is declining.

In order to determine the dimensions of future development, longer-term model calculations of the German population have been carried out. These population projections are based on assumptions about expected demographic trends and are therefore subject to a high degree of uncertainty. They should not be regarded as forecasts in the true sense of the word. Demographic model calculations essentially depend on factors birth rate, life expectancy, and immigration.

\subsubsection{Birth rate}

In 2018, the birth rate was about 1.6 children per woman of childbearing age. The birth rate in western German states (alte Bundesländer) has been relatively stable since the mid-1970s (after a marked decline in the second half of the 1960s), while in the eastern, former GDR (neue Bundesländer) states, it fell dramatically after unification, but recovered quickly and levelled off at the same level as the western German states (alte Bundesländer) (see Figure 4).

\footnotetext{
${ }^{4}$ The following section is based primarily on Bäcker, Naegele \& Bispinck 2020, vol. I, II.
} 
Figure 4: Birth rates 1980-2018, average number of children per woman of childbearing age

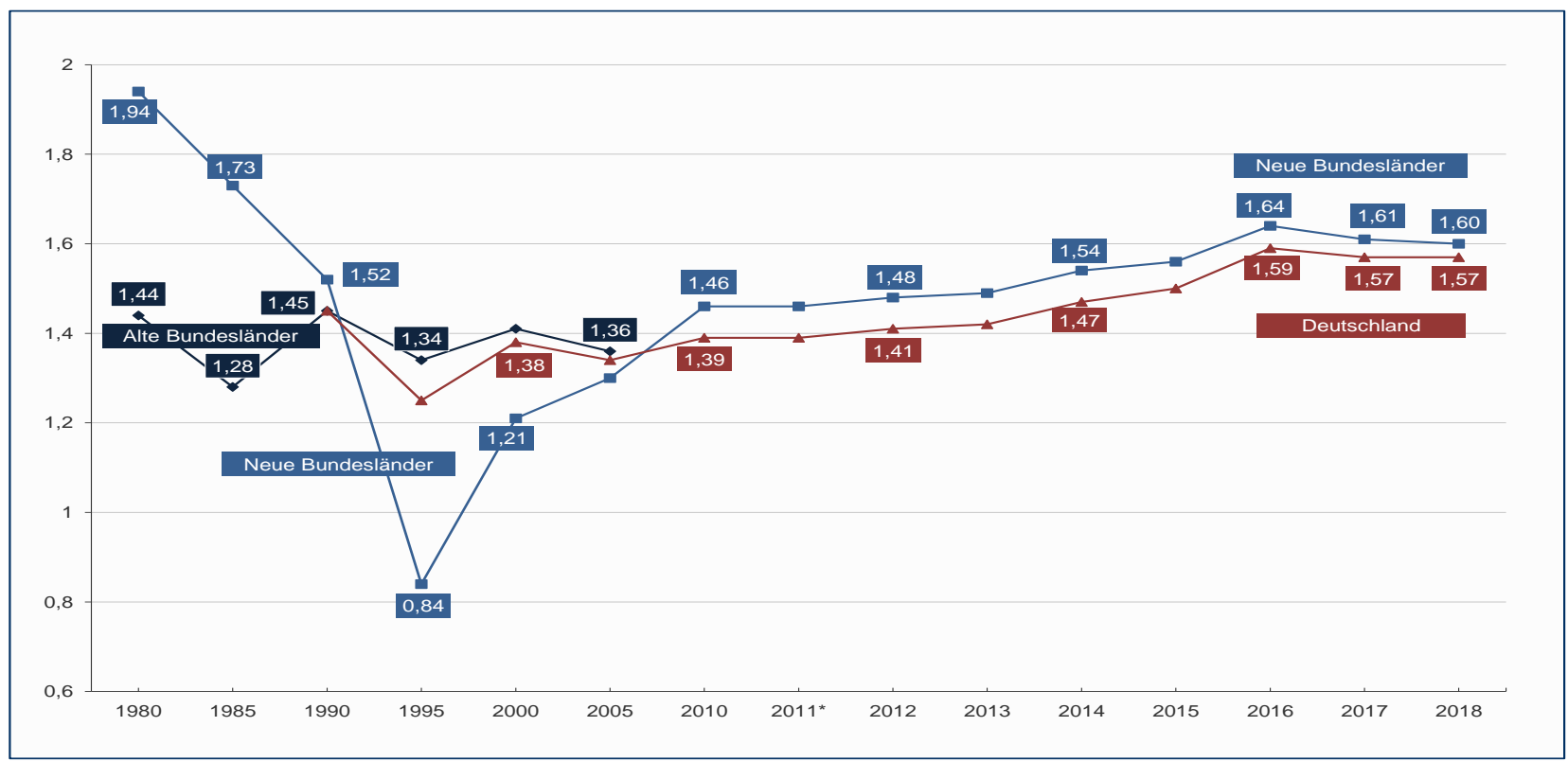

Calculated according to the year of birth method.

Source: Statistisches Bundesamt (2019).

Although birth rates have risen slightly since 2000, with a view to the future, there is little to suggest that there will be an overall fundamental and lasting change in generative behaviour that could by itself ensure a constant population (the required birth rate would be about 2.1).

\subsubsection{Life expectancy}

Socio-political considerations of life expectancy and mortality need to take into account both the average life expectancy (in relation to a new-born child) and the further life expectancy (average remaining life expectancy of persons who have already reached a certain age). The average life expectancy provides information in particular on the population number: the higher the life expectancy, the larger the population, partly compensating for a low birth rate. The further life expectancy provides information about the remaining years of life, and it is the most important measure for socio-political purposes (from age 65 and onwards), providing information about the number of older people who are no longer employed, as well as on the number of retirees and - above all - on the expected pension payment durations. Life expectancy in all developed countries in the Global West is characterised by a long-term increase. Average life expectancy in 2015/2017 was 78.4 years (men) and 83.2 years (women); the further life expectancy of 65-year- 
olds was 17.8 years (men) and 21.0 years (women). A further slow increase can be assumed for the future. The (most probable) projections of the Federal Statistical Office assume that, in 2060, the further life expectancies will increase by as much as 20.4 years (men) and 23.2 years (women) for those over 65, meaning that men would have an average age of 85.4 years and women 88.2 years (see Figure 5).

Figure 5: Further life expectancy at age 65 in years, 1901-2060

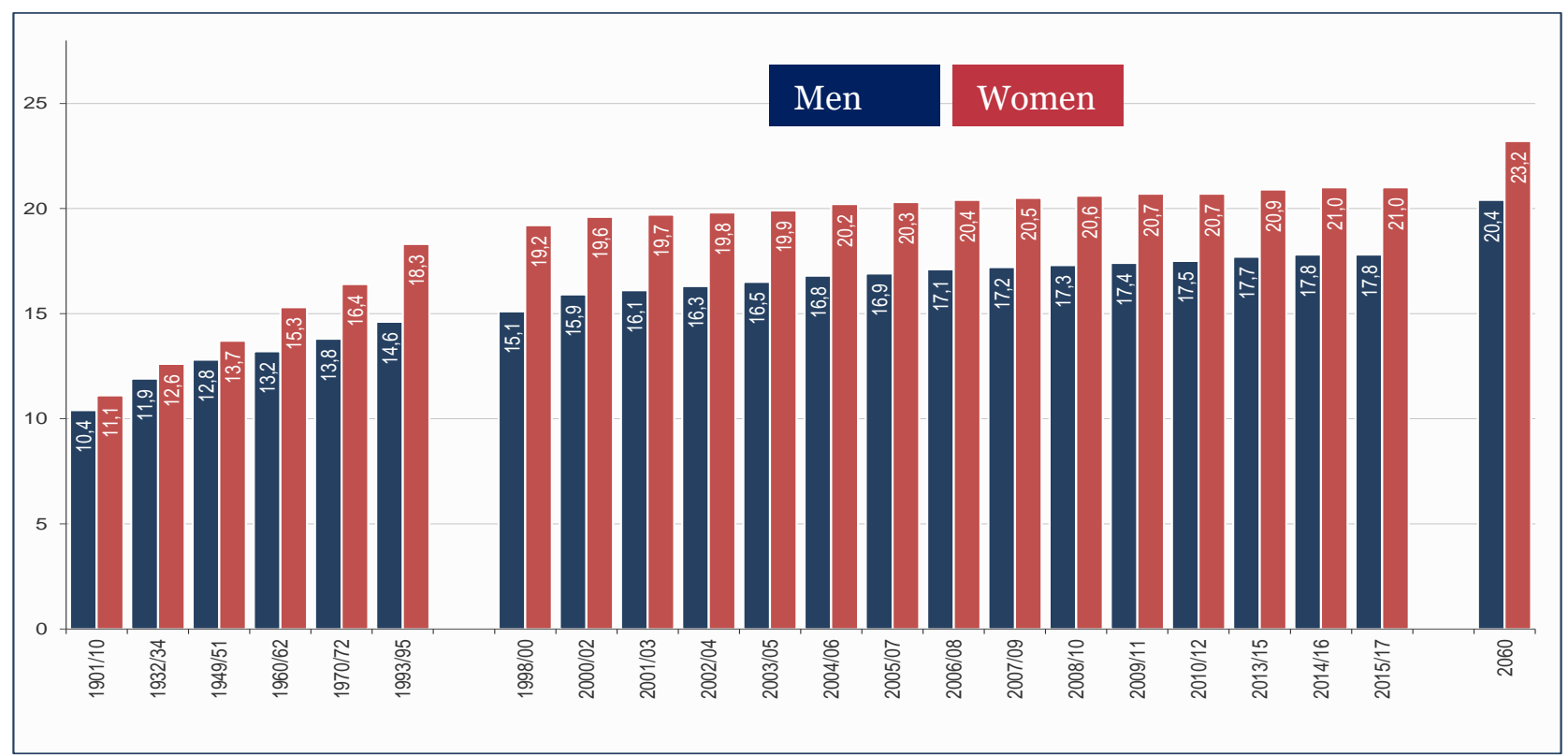

Up until 1932/34: German Reich; 1949/51 to 1980/82: old federal states; from 1991/93: Germany; 2060: assumptions of the 14th coordinated population projection (variant L1: 'small increase').

Source: Federal Statistical Office (last 2019), mortality table; 14th coordinated population projection.

\subsubsection{Migration}

The expected changes in the size and age structure of the population will also be strongly influenced by net immigration (immigration to Germany minus outward and return migration). In the past, immigration has more than compensated for the annual birth deficit (balance of deaths and births), so that the population of Germany as a whole has risen from 78 million (1970) to around 83 million (2018). The future assessment of net immigration is proving to be particularly difficult, as it is determined to a large extent by external decisions, regulations, and political events. However, even in Germany (which is essentially an open immigration country in the heart of Europe that is highly attractive for those wishing to immigrate), net immigration also depends on economic, labour market, and social 
conditions. It is therefore hardly possible to make reliable forecasts that extend well into the middle of this century.

A distinction would have to be made between different groups of immigrants: for instance, there are asylum seekers, labour migrants, family reunifications from third countries, immigration of EU foreigners, and all these would also have to be parsed according to their age, gender, and qualifications. The age structure of immigrants and emigrants is therefore of interest, since younger people tend to migrate, while older people tend to leave. All in all, all the signs indicate that the positive migration balance, which in Germany between 1950 and 1995 amounted to over 8 million people, will continue, not least when the rapidly growing world population is considered. For the year 2021, for example, the Federal Statistical Office calculates a net immigration balance of around 200,000, meaning crossborder immigration minus cross-border emigration. In its latest population projection a further immigration in a similar order of magnitude is considered likely. 5

\subsubsection{Future total population and 'demographic burden' scenario}

According to the Federal Statistical Office's projection (most probable variant), the total resident population will decline from 83 million (2018) to 80.7 million in 2040 and to 74.8 million in 2060 (see

Figure 2: Development of population and age structure Germany (1960-2060) by total population and age group (in millions)). Under the assumptions of this variant, the decline in the total population is thus kept within narrow limits. The fact that the population decline is only comparatively weak, despite the low birth rate, is a consequence of both immigration and rising life expectancy. The number of older people $\left(65^{+}\right)$will rise sharply, from 18.5 million in 2018 to 22.6 million in 2040, and remain roughly constant thereafter. It is precisely the younger baby boomers who will reach retirement age after 2020. Of greater significance, however, is that the share of the $65^{+}$population in the total population will constantly increase, from about 21\% (2018) to about 30\% (2060). In other words, the average age of the population is rising, and by 2060, almost one in three will be part of the older generation. It should be kept in mind that as life expectancy increases, so do the number of years spent in good health, but of course, also the number of years for which the next generation will have to finance pensions. This fact is all the more significant because the number of very old people (80 years and older) will increase in particular.

5 Federal Statistical Office (2021): Pressemitteilung Nr. 016 vom 121. Januar 2021: 2020 voraussichtlich kein Bevölkerungswachstum (Press Release No. 016, January 121, 2021: No population growth expected in 2020). 
A statistic called the old-age dependency ratio is calculated by putting the older population in relation to the population of working age people (defined as 20 to under 65 years). According to the model calculation, this ratio will be $55.2 \%$ in 2060 and thus more than double what this ratio was in 2000. There will then be about 81 older people for every 100 people of working age. This pattern corresponds to a common thesis in the field of pension insurance, which claims that a far-reaching reduction in the pension level is necessary if a rapid increase in contribution rates and an overburdening of the younger generation is to be avoided. The old-age dependency ratio also explains the most popular reason for the extension of working life, because it cannot only be a question of the ratio of young to old, but also of the ratio of 'active' to 'inactive' as a whole, i.e. the problem of what proportion of value added must be transferred to all those persons who have no income from gainful employment. According to this thesis, the higher the retirement age is raised, the greater the relief for the old-age dependency ratio. However, in the future, it can be expected that employment will increase beyond the age of 65 (partially as 'silver work', see section 4.2).

Generative behaviour, mortality, and immigration are important, but not the only determinants of the long-term development of the welfare state. With regard to the occupation of the 'active' generation, it is not the number of people capable of working that is important, but the number of people actually in employment. In this respect, the future development of the population's labour force participation is of crucial importance. Demographic calculations must therefore be combined with forecasts about the development of the labour market, and unemployment and employment levels. To do so goes beyond the scope of this paper. However, it is still important to refer to the predicted future age structure and to raise the question of how it is possible to proactively shape labour market participation and, above all, labour force size among different age groups within the framework of an active labour market policy that can respond appropriately to the challenges of demographic change.

\subsubsection{The ageing of society as a whole as 'triple ageing'}

'Triple ageing' means

- an increase in the absolute number of older people,

- a growing proportion of older people in the total population, and

- a sharp rise in the number of very old people aged 80 years and over.

The population of older people is constantly increasing. The number of people aged 65 and older in Germany rose from 13.7 million (16.6\% of the population) in 2000 to 17.8 million (21.5\% of the population) in 2018 . A particularly strong increase can be seen in the number of people 80 and over, which rose from over 3.1 million in 2000 (3.8\% of the population) to just under 5.4 million ( $6.5 \%$ of the population) in 2018 (). One of the main reasons for the strong increase in 'triple ageing' is the 
longer life expectancy and that people older than 80 years are living much longer than they used to.

Figure 6: Population aged 8o years and older, 1950-2060

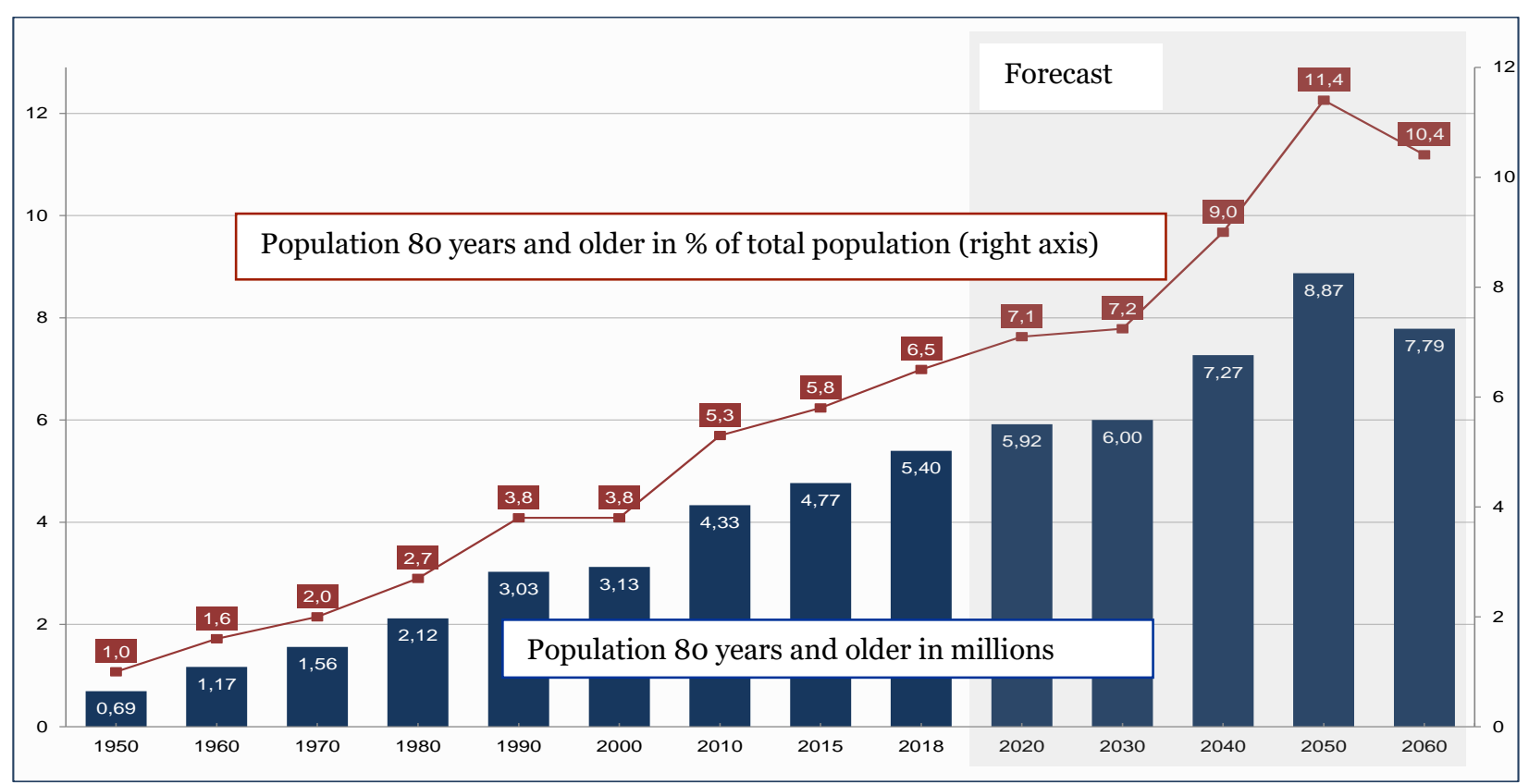

Assumptions of the projection: Option 15 - see Table II.10 in Chapter 'Economic principles and financing'.

Source: Federal Statistical Office (2018), Population extrapolation, Fachserie 1, Reihe 1.3; Federal Statistical Office (2019), 14th coordinated population projection.

This trend of a shift in the age structure, which can also be observed in all developed countries, will continue into the future, as the projections of the Federal Statistical Office show both for the number of older and very old people, and for their respective shares in the total population. According to these projections, the number of people aged 65 and older will increase to 22.0 million in 2060 and the proportion in the population as a whole will rise to $29.4 \%$. In other words, almost one in three people will then be part of the older generation, if the $65^{+}$age threshold continues to be taken as the benchmark in the future. The very old population is showing a particularly steep increase: both the number and the proportion of people aged 80 and over in the total population will rise in the forecast period to $10.4 \%$ in 2060 . The proportion of the total population over 90 will increase from $0.6 \%$ to $2.9 \%$, i.e. almost five times as much. 


\subsection{Fragmentation instead of comprehensive approaches in demographic policies}

The German welfare regime has been characterised as 'conservative-corporatist' (Esping-Andersen 1990). The conservative (or continental European) welfare states are shaped by Bismarck's social security model. Insurance benefits are in the foreground here. The strong link between wage labour and social entitlements means, among implications, that women who are not in employment are often excluded from these benefits. ${ }^{6}$

\subsubsection{Employment policies in the framework of a conservative-corporatist welfare model $^{7}$}

With respect to the concrete design of employment relationships and the various labour market policies, it has to be taken into account that the conservativecorporatist model favours strong job protection for all employed adults and active employment or training policies. This preference is based on the view that paid work, as an essential source of income for the majority of the population, serves not only to provide social and material security for individuals and their families, but is also a decisive factor in the allocation of social status. This view is reflected in the strong differentiation of individual social security systems and regulations in Germany according to occupational groups (e.g. dependent workers, civil servants, self-employed, farmers, craftsmen, etc., Bäcker, Naegele \& Bispinck 2020, vol. I, II).

In contrast to liberal and social-democratic regimes, unemployment in conservative-corporatist regimes is also strongly managed by labour supply reduction including, in particular, early retirement, a strategy that is reflected in the German government's intervention in retirement policy, e.g. setting incentives for early retirement (see section 2.2 and further arguments below). This corresponds to the principle of 'solidarity between the generations' that is constitutive for the German welfare model: older people make room for younger ones so that the succeeding generations can build up their own social security. On the other hand, the active workforce and younger people also have to fulfil their part of the generational contract, mainly through life-long working and perhaps even EWL if basic conditions of the labour market (like the demographics of the active workforce) fundamentally changes (Bäcker, Naegele \& Bispinck 2020, vol. I; see also section 3.1).

\footnotetext{
${ }^{6}$ See also Naegele, G. and Walker, A. (2021): EIWO Working Paper I: EIWO's Theoretical Perspectives. Final report on EIWO wp 1. EIWO-website.

${ }^{7}$ This sub-section was written in collaboration with Frerich Frerichs.
} 
The decline of labour force participation rates among older workers in Germany in the 1980 s and 1990 s did not only mirror strategic personnel policy measures of German enterprises, but was also the result of a long-lasting broad social consensus among different stakeholders, institutions, and groups regarding early retirement (the 'grand coalition of interests'; see also section 2.1). This decline can be interpreted as overcoming the otherwise strict separation of responsibilities between the state and its institutions on the one hand (pension insurance institutions, Federal agency of employment, etc.) and the social partners (trade unions, etc.) and their sub-organisations on the other hand, and this strategy has even reached down to the company level. This reach was made possible because many companies have implemented (mostly for purely micro-economic reasons) what the 'grand coalition' has prescribed.

Despite the general trend to curtail early exit provisions and to raise the retirement ages for statutory pensions, there were and still are several residual means by which older workers can retire early. The Part-time Retirement Law (Altersteilzeitgesetz, ATG) enacted in 1996 and enabling companies to receive funding was abolished as recently as 2009 (see section 5.5), and early-retirement by company-led schemes and hidden tax-incentives still occur to varying degrees in Germany. ${ }^{8}$ These incentives are partly supported by longer duration of unemployment benefits for older workers, though such was not the intended effect of the measure (Frerichs 2009). Even more striking in this respect is the introduction of early pensions for long-term and particularly long-term insured persons who can retire starting as young as 63 (see section 5.3.1). Due to the widespread use of this measure (in particular by male workers), the retirement age in Germany has stagnated at 64,3 for male workers since 2013 (Kaboth \& Brussig 2019).

Nevertheless, active labour market policies aimed at the reintegration of the unemployed are pronounced in Germany and can be seen more commonly in the German conservative-corporatist welfare regime than in liberal welfare regimes (Frerichs 2009). General long- and short-term training measures, wage subsidies, job creation schemes, and promotion of self-employment are in place as well as selected measured targeted at the older unemployed in particular (for details, see section 5.7). Labour market policies in Germany also have, to a certain extent, preventive components, such as the funding of training measures for older workers in small and medium enterprises (SMEs) or the requirement to register dismissals at employment agencies as soon as they have been announced. Just recently, the

${ }^{8}$ See for example Handelsblatt 2019: 2; although specific studies on this phenomenon are not readily available for Germany. 
'Qualification Opportunities Act' (see section 5.10) was introduced, aiming at strengthening the preventive component.

All these measures seem to form a comprehensive approach on behalf of the Federal Government to increase labour market participation of older workers. In fact, the Federal Government stresses that it works on different levels to fulfil the demands of the European Employment Guidelines with respect to older workers. Announced changes in paradigm and in recent Coalition Agreements show that demographic changes witnessed in the last few years have been acknowledged as important policy issues by almost all relevant political actors in Germany.

However, structural exclusion of older workers from employment promotion and job placement schemes still exist as an after-effect of the early retirement policy practised in the past, with a particular tendency to exclude older workers from advanced training (Frerichs 2009, Brussig, Knuth \& Mümken 2016; Kaboth \& Brussig 202ob; see also section 4.4). From this point of view, active labour market policy for older workers is still taking a conservative, corporatist direction with the objective of reducing supply. At the same time, a general shift towards an 'activating' labour market policy has also led to a tendency towards exclusion, especially of permanently unemployed older workers who are difficult to place. These potential workers have been, above all, excluded from placement activities on the part of the employment agencies, but also from training and qualification measures, and this group has been put at a further disadvantage by the cutbacks in job provisions (see section 5.7). Considering the necessity of maintaining employability throughout the life-course, life-course approaches such as sustained life-long learning are underdeveloped or completely absent.

With respect to the regulation of the labour market, a core feature of conservative-corporatist welfare state policies in contrast to liberal regimes is a higher employment protection. However, in addition to other possible ambiguities, counter-effects with regard to early-retirement can be stated. When there are high levels of job-protection (Frerichs 2009), employers tend to offer early retirement for those older workers with higher salaries and longer job tenure that cannot be dismissed by other means (Möhring \& Bennett 2015).

All in all, the prevailing trends of an ageing and shrinking workforce and the contemporary labour market problems facing older workers have only recently been included in plans for reform on the level of governmental labour market policy, and this response to overarching trends can be summarised as follows (see also section $5 \cdot 7)$ :

- The last two decades (1998 to 2018) saw a multitude of transformative changes which cannot only be assessed as 'simple' retrenchment, but justify to talk of a paradigm shift (Blank 2020). Generosity of de-commodifying transfers was reduced and policies moved partly away from the goal of status maintenance in particular concerning pensions, employment benefits, and training measures. 
- Nevertheless, the conservative-corporatist welfare-regime in Germany and its ambiguities concerning the employment promotion of older workers still prevail: (residual) early-retirement incentives and low participation of older workers in active labour market measures stand in contrast to high pressure for staying in employment until the regular, steadily increasing pension age has been reached.

\subsubsection{EWL as a horizontal political task}

According to the broad scope and understanding of social security in Bismarck's social insurance model, a typical feature of the German welfare regime organisation (and for public social policy as a whole) is the institutionalised segmentation of social-political responsibilities. With respect to demographic policies and policies for the elderly generation (and particularly for policies aiming at EWL, which is a classical horizontal task), the following governmental departments are included: economy, pensions, labour market, education, health, family, women, and migration.

On the executive level, the issue of meeting the challenges of demographic change is divided among various ministries and departments, which do not always co-operate with each other. Usually, segmentation in policies creates barriers when cross-cutting issues such as the political shaping of demographic change are on the policy agenda. What is particularly true for shaping demographic change as a typical cross-cutting task calls for integrated, i.e. holistic concepts (Hüther \& Naegele 2013). In Germany, on the Federal level as well as on state level, each of these policy areas is assigned to different ministries, each of which has a limited partial (department specific) responsibility. Depending on the specific dimensions affected (e.g. regionality, research, foreign workers), other ministries may be added if necessary. It goes without saying that integrated policy concepts have to be 'organised' in sometimes long and complicated coordination processes, which is not an easy task to pursue in a fragmented political system. This institutionalised segmentation according to policy fields applies equally to pension and old-age policy, which makes it all the more difficult to design a 'one-stop shop' pension policy that takes up the different dimensions equally. This difficulty applies in particular to the often conflicting policy objectives of economic, labour-market, and social policy in retirement and pension issues, which in a growing number of cases are partly responsible for emerging social inequalities in the context of early retirement (Naegele \& Hess (eds.) 2020; see also section 5.3.2).

\subsubsection{Co-ordination of policies in the context of Subsidiarity and Federalism}

A third typical feature of the German welfare model is the separation of policy responsibilities and areas into a state and a federal level (with the Länder and municipalities each having their own clearly defined responsibilities; e.g. the municipalities are responsible for the local dimensions of 'social welfare', together 
with the acknowledged welfare organisations, i.e. the Federalism Principle). However, employment issues do not immediately fall within their competence, but within that of the social partners, for whom other regulations apply ('collective bargaining autonomy'), although in reality these are rarely touched; the still unsatisfactorily-regulated issue of reconciling work and care (see section 5.11), which has led to new social inequalities in the pension system has very serious causes as well (Reichert 2020, 2021).

\subsubsection{Collective bargaining-autonomy - a fundamental right for social partners}

A further considerable separation of responsibilities can be seen in the roles of the state and the social partners (trade unions and employers' associations) in employment issues. For their part, the social partners are responsible within the framework of the collective bargaining system for the concrete formulation of company working and employment conditions. From a social-philosophical point of view, both Federalism and collective bargaining autonomy are applications of the principle of Subsidiarity, which is typical of German social policy. According to this principle and with respect to its relationship to the social partners, the state (as a superordinate political regulatory unit) does not consider its task to be setting concrete wage and working conditions. These concerns are left to the parties to collective agreements that are familiar with the subject matter, and these parties are thus granted their own kind of competence in economic and social policy (Bäcker, Naegele \& Bispinck 2020 vol. I). It is obvious that the fragmentation of responsibilities and actors makes the implementation of objectives such as EWL a difficult and highly complex political design task that cannot necessarily be assessed as 'successfully' institutionalised in Germany.

\subsection{A new approach: the Federal Demographic Strategy (2012- 2018)}

In 2012, the issue of the greying of the workforce has been taken up officially within the framework of the government's Federal Demographic Strategy (2012-2019) ('every age counts') under the auspices of the Federal Ministry of the Interior (BMI). The Federal Demographic Strategy refers to different policy areas affected by overarching demographic developments and resulting policy challenges of national importance, and it takes an explicit cross-sectional view. The overall objective is to mobilize individual life chances throughout a longer life and to open up social development perspectives in the demographic change. In this context, ageing in the world of work and the associated policy challenges are treated as an integrated part of a policy to strengthen economic growth. The main reasons for implementing the Federal Demographic Strategy are described as follows (BMI 2016): 
- public awareness of collective aging and the increasing longevity of the population,

- the need for better integration of migrant population,

- the impact on various economic and financial subsystems,

- the expected pressure on social security systems,

- the foreseeable labour shortage,

- doubts about further realizing the existing national added value,

- fear of losing international competitiveness.

The work was mainly carried out in inter-ministerial working groups that included the ministries responsible for the various areas and mostly supported by external scientists. The work results have been repeatedly discussed at public 'demographic summits'. The work ended 2018 provisionally with recommendations with respect to the following fundamental topics9:

- to strengthen family as a community,

- to promote motivated, qualified and healthy working,

- to promote self-determined living in old age,

- to promote quality of life in rural areas and to secure integrative city policy,

- to ensure the foundations for sustainable growth and prosperity,

- to secure the capacity of action for the state.

With regard to the issues surrounding the demographic challenges in the world of work, the following recommendations were adopted. ${ }^{11}$ The Federal Demography Report (BMI 2012) states: "A mix of measures is required: a long-term personnel policy, company health promotion, a better work-life balance and lifelong qualification and further training. The basis for the success of all measures is a corporate culture that focuses on the participation of and communication with all employees.” The following objectives and measures were named (among others), and these relate to securing the demand for labour while also targeting older workers:

- utilisation of unused reserves (e.g. conversion of part-time to full-time jobs),

- activation of job seekers/activating labour market policy,

- increasing the participation of women in the labour market,

- $\quad$ increasing the labour force participation of older people (e.g. 50+),

\footnotetext{
${ }^{9}$ These were summarised under the heading "strengthen economic growth".

${ }^{11}$ Although it remains to be seen how they will be implemented in practice. At least in the current political debate (2020/2021), they play no de facto role.
} 
- $\quad$ increasing the labour market participation of people with an immigrant background,

- $\quad$ promotion of age and ageing-appropriate working conditions (e.g. in the framework of the INQUA work (see section 5.12),

- $\quad$ expansion of workplace health promotion and illness prevention (see section 5.9),

- promoting the participation of people with disabilities in employment,

- $\quad$ continuing vocational training and lifelong learning.

\subsection{Interim conclusion - problems and discrepancies in coordination and governance of policy approaches aiming at EWL}

In Germany, the initiatives and legal measures of the various ministries involved aimed at EWL are not centrally coordinated, and sometimes repeat or even contradict each other, despite some joint awareness campaigns and the overarching coalition agreements. In general, there is no explicit and integrated public 'older Workers Policy' in Germany despite the fact that the 'Alliance for Jobs, Training and Competitiveness' soon after the turn of the millennium launched a skills strategy for older workers, which became partly enacted in the 'Job-Active Law', despite older workers being one main target group in Social Security Code III, the former Employment Promotion Law. An ad hoc, fragmented policy approach still prevails.

Currently, challenges linked to the 'greying of the workforce' and issues that older workers face have not been taken up by particular legislation nor by national action plans for employment, so there is nothing comparable to, for example, the Finnish National Programme for aging workers (FINPAW) (1998) (Ankril et al. 2002), which was highly regarded in Germany at the time and even received an award from the highly-reputable Bertelsmann Foundation (2006). FINPAW had the explicit aim of promoting workplace health both programmatically and practically throughout the country by combining various measures and supporting organisations. FINPAW was very successful in that it made it possible to both increase the employment rates of older workers and raise the age at which they leave the labour market.

Questioning the areas of responsibility for demographic policy, which is typical of the German welfare model, has, together with the similarly fractional responsibility of social partners for company employment policy, led to the introduction of new retirement regulations on the state side (raising retirement ages, closing or making it more difficult to use existing early retirement schemes), without at the same time creating the de facto conditions for EWL at the company level. It remains to be seen whether the newly-established Federal Demographic Initiative will lead to a paradigm shift. There is much empirical evidence available 
(and presumably, in the wake of the corona virus crisis, there will be even more confirmation) that older workers are still pushed or encouraged to leave the labour market, whereas at the same time policy aims at convincing companies to recruit older jobseekers (Brussig 2018, 2021). It would be unfair to say that there is no connection at all between curtailing early exit provisions and promoting labour market integration of older workers. However, this connection is not at the forefront of current policies and is not dealt within a systematic and comprehensive way.

\section{Germany - a success model for integration older workers? A critical overview from the perspective of social inequalities}

\subsection{Increasing employment rates in all age groups}

\subsubsection{The shift of paradigm to EWL - a German success-model?}

Not a day goes by without politicians and other key figures in public and business life claiming the successes of the paradigm shift in the labour market (as seen in the rising labour force participation rates in the group of older workers from 2005 onwards), either for themselves or as the success of appropriate policy incentives. Across the EU, Germany gained the reputation as 'success model' in older worker's labour market policies. Starting from very low employment rates in the mid- and end of the 1990s, significant increases in employment rates for both men and women have taken place. For women, even higher rates of increase have been recorded, and their current labour force participation is the same as that of men 10 years ago. For men, these changes were mainly due to the previous practice of early retirement; for women, these increases were due to the due to reduced influence of the male breadwinner-model. Even in the $60+$ age group, labour force participation has increased.

The employment rate of workers aged 55 to 64 has almost doubled from $38.1 \%$ in 1998 to 75,9 \% in 2018 (Statistisches Bundesamt 2019), with a marked difference between women $(72,1 \%)$ and men (79,6\%) (see Figure 7, Figure 8). However, it must also be conceded that for many older workers, the retirement age in the statutory old age income security system (GRV) has risen faster than they have been able to extend their individual working lives (Brussig 2018). Further, the rising employment rates of older workers have to be seen and assessed in the context of a generally positive development of the German labour market (see section 4.1). 
Figure 7: Employment rates for older people in Germany by age (2012-2018)

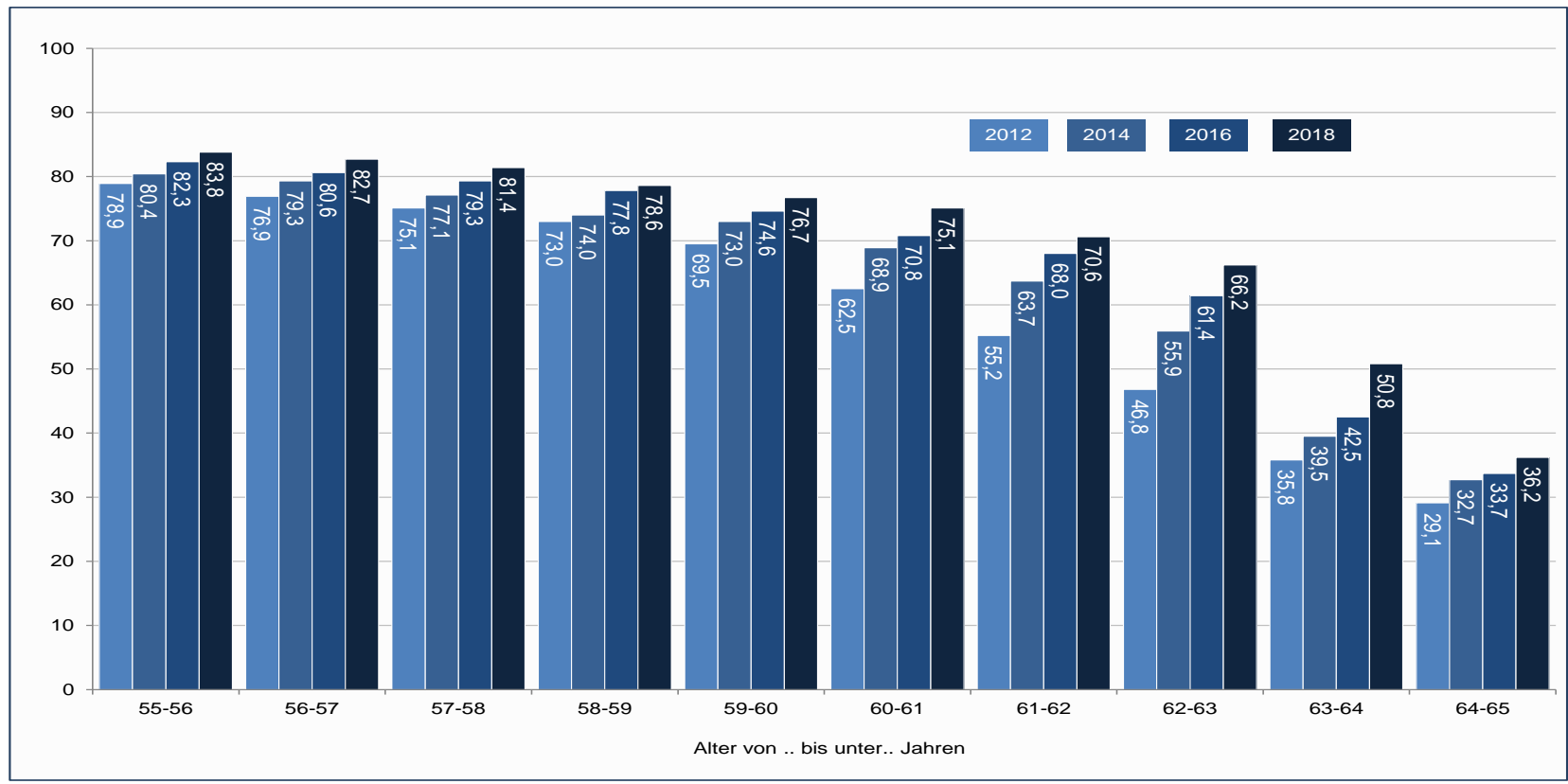

Source: Statistisches Bundesamt (2019): Mikrozensus.

\subsubsection{Hardly new recruitments, rather increases due to retention factors}

However, it should be noted that the rising employment rates of older workers have only been due in a small degree to new recruitments of older jobseekers or the previously unemployed. Rather, companies have increased the employment of their older workers by retaining those employees who have already been in their jobs before, i.e. they have moved up into the group of older members of the workforce by being convinced to stay longer by means of certain 'retention' measures (Brussig 2018; Bauknecht, Hess \& Naegele 2020). This is in particularly true for female workers, who not only reduced their periods of non-employment, but also stayed longer in their jobs, many of them in part-time work (see section 4.4). 
Figure 8: Changes in labour force participation by age group between 1999 and 2017 (EXTEND countries $\mathrm{Dk}, \mathrm{D}, \mathrm{NL}, \mathrm{Fi}, \mathrm{UK}$ )

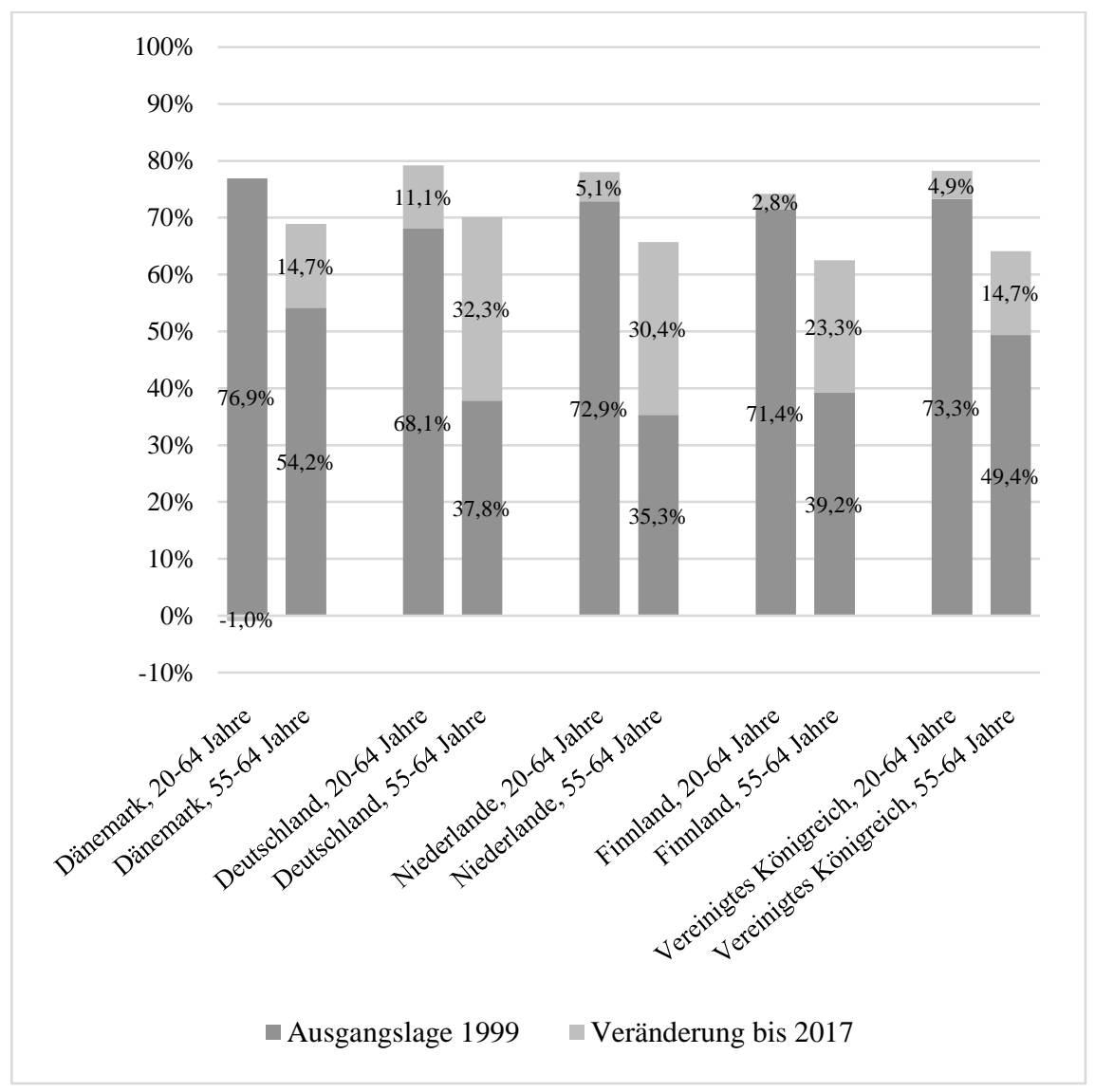

Source: European labour force survey (EU-LFS); Stiemke 2020.

\subsubsection{Decline in general unemployment rates, but not for older unemployed}

Parallel to the rising employment rate among older workers after 2005, there was also a fundamental change in the trend of steadily rising unemployment. This trend could be stopped and partially reversed, however not among older unemployed. In 2018, the number of unemployed was 'only' 2,3 million compared to over 4,9 million in 2005, which is a change in rate from $13 \%$ to $5.8 \%$. Compared to 2005 , figures and rates have more than halved (see Figure 1). However, this development must be looked at differently for older unemployed. Although their numbers declined, their rate increased. In other words, the upswing in the overall labour market largely missed the sub-market of older unemployed and experts speak of a 'decoupling' (Kaboth \& Brussig 2020a; for more details see section 4.3).

This decoupling is particularly evident in the development of recent years and exemplified by the situation in September 2018. It is true that at that time there had 
never been so many older workers in regular employment (subject to social security contributions), numbering almost 2.67 million employees aged over 60. Regarding the general situation in the labour market, in just a few years, Germany developed from the 'sick man of Europe', who had to struggle with the greatest labour market problems, to a 'model pupil', as almost all EU member states have worse, in some cases dramatically worse, unemployment figures.

\subsubsection{The German 'success model' as a result of various interwoven developments}

Despite the fact that older unemployed people in particular have not benefited from the upswing, one can generally state that the development in older workers' employment rate is positive, because it leads to higher tax and social security revenues and relieves the welfare state from monetary pressures while providing the labour market with skilled and experienced workers. However, the German 'success model' must be assessed as the result of several supporting developments which are complex and interwoven, and not just a result of targeted public EWL policies (as described in section 5). It is difficult to say how much of the increase can be allocated to one specific policy measure, which is also true in a EU perspective (Jensen 2020; see also section 6). Three other reasons also contributed to this trend, as stated by Naegele (2013a: 42):

- A general improvement in the employment prospects particularly of qualified older workers due to the economic upswing, in particular between 2005 and 2008, but strongly embedded in the effects of (skilled) labour shortages (see section 2.2);

- $\quad$ The long-term trend towards increasing female employment, among them many in part time jobs (see section 4.4);

- Introduction of various modes of 'de-normalisation' of work ('precarious employment') (like solo self-employment, gig work, mini-jobs, and fixed term employment, and involuntary part-time work; see section 4.4).

It should also be noted that the effects of 'pension at 67 ' did not came into force before 2012, but the increase in gainful employment in old age began much earlier.

\subsection{However, social inequalities are preventing achievement of EWL}

\subsubsection{Privileges consolidate}

The German 'success model' has not had only positive effects; it took place with a simultaneous (unintended) increase of social inequalities in the possibilities and chances to achieve EWL and to profit from the different types of incentives 
(Hofäcker 2015; Brussig 2018, 2021; Naegele \& Hess (eds.) 2020). Already privileged workers with high socio-economic status clearly profited more than lowskilled workers. The latter, who in the past had used the early retirement options, are now facing a tough choice to either retire due to bad health or to delay their retirement for financial reasons. If they retire early, they will incur large pension losses and might even face poverty in old age. If they delay retirement, however, they do so in often harsh, physically and psychologically demanding working conditions. In addition, they are not the main target group of the age-friendly human resources measures, as they normally do not have the skills and qualifications that companies need.

\subsubsection{Medium and highly-skilled older workers with higher employment rates}

In contrast, highly-skilled workers have clearly benefited from increases in employment rates (see Figure 9). They are generally healthier and better skilled than the past cohorts of older workers, and, hence, most of them are able to work longer. Their working conditions are also superior to those of their low-skilled peers. And because employers want to retain them in the companies, in some cases they even improve their conditions. In addition, due to higher contributions, they also have higher pension claims in the public pension and are more often covered by occupational and private pensions, and, thus, have a comparably high overall pension income. So for them, retirement before the official retirement age is not as problematic from a monetary point of view, and (perhaps even more importantly) they have a choice. In contrast, low-skilled workers seem either to retire due to bad health or to delay their retirement for financial reasons (see various contributions in Naegele \& Hess (eds.) 2020).

\subsubsection{No 'age-neutral' labour market structures}

The conclusion of all the evidence presented so far in this section is that Germany's demographic development will not meet an 'age-neutral' labour market, but rather, there are specific segmentations, and some serious age-related labour market risks exist for older workers (Brussig 2018, 2021; Hofäcker, Hess \& König 2018). 
Figure 9: Employment rates of 55-64 years old by education

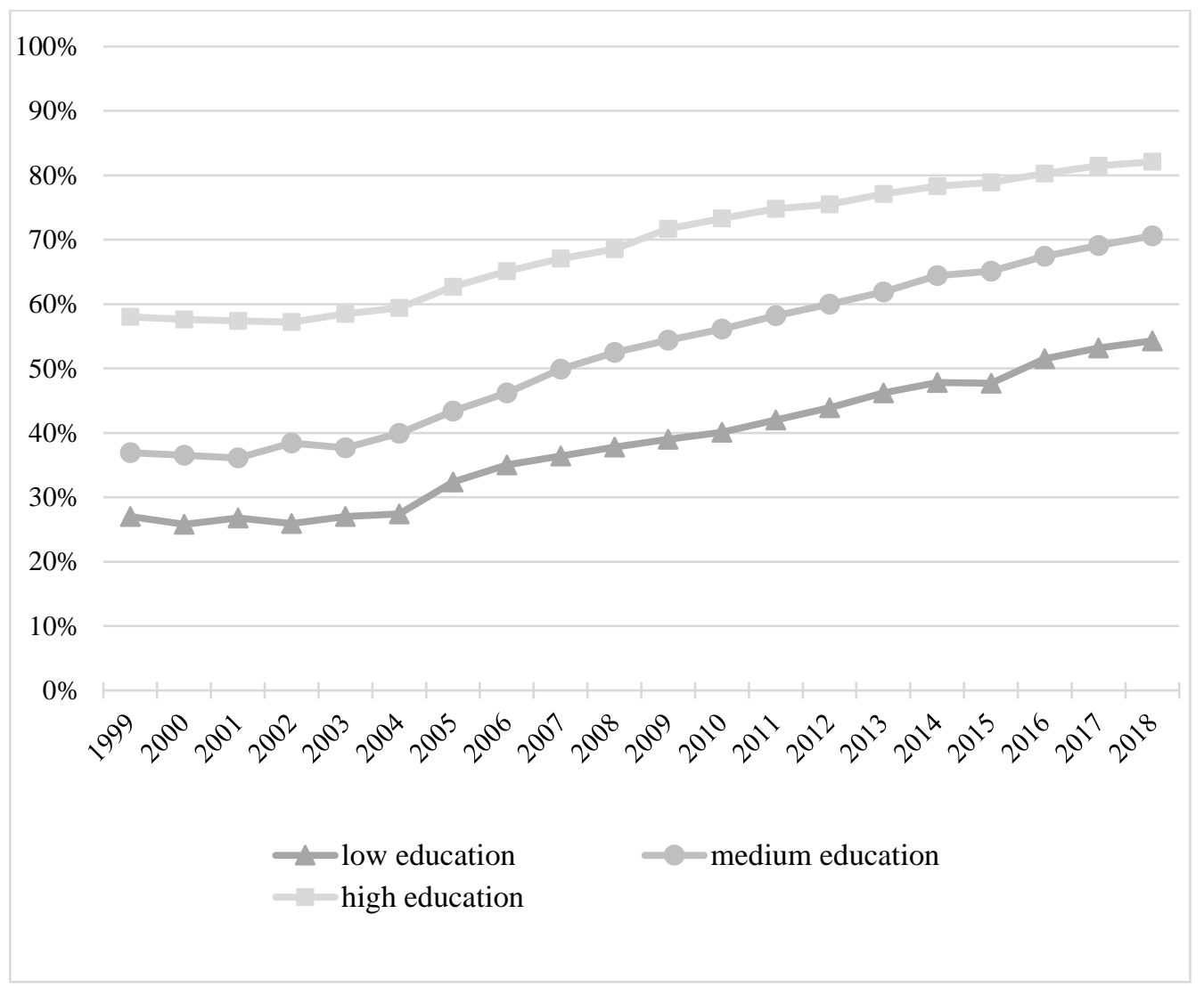

Source: OECD, own calculations, in: Hess, Naegele \& Bauknecht (2020): 70.

Furthermore, there is a distinct segmentation of the labour market for older workers according to gender and skills (Dietz \& Walwei already 2011). In particular, the employment rate of male workers aged 60 to 65 is still rather low at $63,7 \%$ (2017) and even lower for women in the same age group (53,3\% in 2017) (Statistisches Bundesamt 2018). The integration in employment is also strongly segmented according to levels of qualification, for instance in $2017,71 \%$ of all workers aged 60 to 65 with the highest skill level were employed, whereas only $44 \%$ of all workers aged 60 to 65 with the lowest skill level achieved were employed (Statistisches Bundesamt 2018; DGB 2015; see Figure 9).

\subsubsection{Growing financial inequalities as effects of the paradigm shift}

Looking at the financial effects of the paradigm shift, the data confirm that the recent reversal of early retirement in Germany has been at the price of growing financial inequalities in old age pensions. The data show an increasing gap in retirement incomes and pension wealth between educational groups, and that spells 
of unemployment are increasingly dangerous to the pension income. This development is also mirrored among older workers in German representative survey data from 2012: almost 90\% of low-educated male older workers expect to have to work longer due to monetary reasons, while less than half of the highlyeducated do. A similar trend can be found among women (Rinklake \& Buchholz 2012; Heisig 2015; see also section 4.4).

\subsection{Unemployment among older workers decoupled from general trends}

\subsubsection{Increased unemployment among older workers}

Despite many years of good economic activity and the increase in employment rates of older workers, the number of unemployed people aged 60 to 65 more than doubled between 2009 and 2018, from about 90,000 to almost 220,000. The share of older people among the long-term unemployed (defined as unemployed for more than one year) was over $40 \%$ in September 2018, "and the probability of remaining unemployed is particularly high after the age of 50" (Stiemke 2020, p. $100 \mathrm{ff}$.) Above all, long periods of unemployment in the last third of working life devalue the career to date and "reduce their entitlements in the statutory old-age insurance scheme" (Stiemke 2020, p. $100 \mathrm{ff}$.). This conclusion is corroborated by the fact that in the EU, relative unemployment among older workers is since 2009/10 not higher than it is in Germany (see Figure 10).

As measured by absolute numbers, unemployment of older workers has decreased markedly in the last decade (BA 2019; see Figure 11). However, measured as a proportion of all unemployed people in Germany, unemployment of older workers, particularly the long-term unemployed, is still pronounced and seems to be decoupled from the general increase in labour force participation. This decoupling is particularly evident for the 60-65 age group. The probability of remaining unemployed is particularly high after the age of 60 , and the share of long-term unemployed among 60+ had risen to over 40\% by 2018 (Kaboth \& Brussig 2020a), to $48 \%$ among the $55^{-65}$ year olds, and by 12 percentage points higher than all age groups of unemployed (BMAS 2018a).

In reality, unemployment among older workers is probably even greater, because the older unemployed are often not included in the official unemployment statistics, because only those who are available to the employment agencies are explicitly counted. Furthermore, persons participating in employment promotion measures (see section 5.7) are not officially recorded as unemployed. Most cases of hidden unemployment (in 2018, this number was estimated to be 167,000, BA 2019; Kaboth \& Brussig 2020a) are due to a special regulation for older people in SGB II. Many older people without a job are not counted as unemployed and as a consequence are effectively excluded from employment promotion. It is expected 
that inequality and social exclusion of unemployed ageing workers will continue to increase (Brussig 2018).

Figure 10: Unemployment rates among the age group 55-64 in Germany compared to the EU (2002-2013)

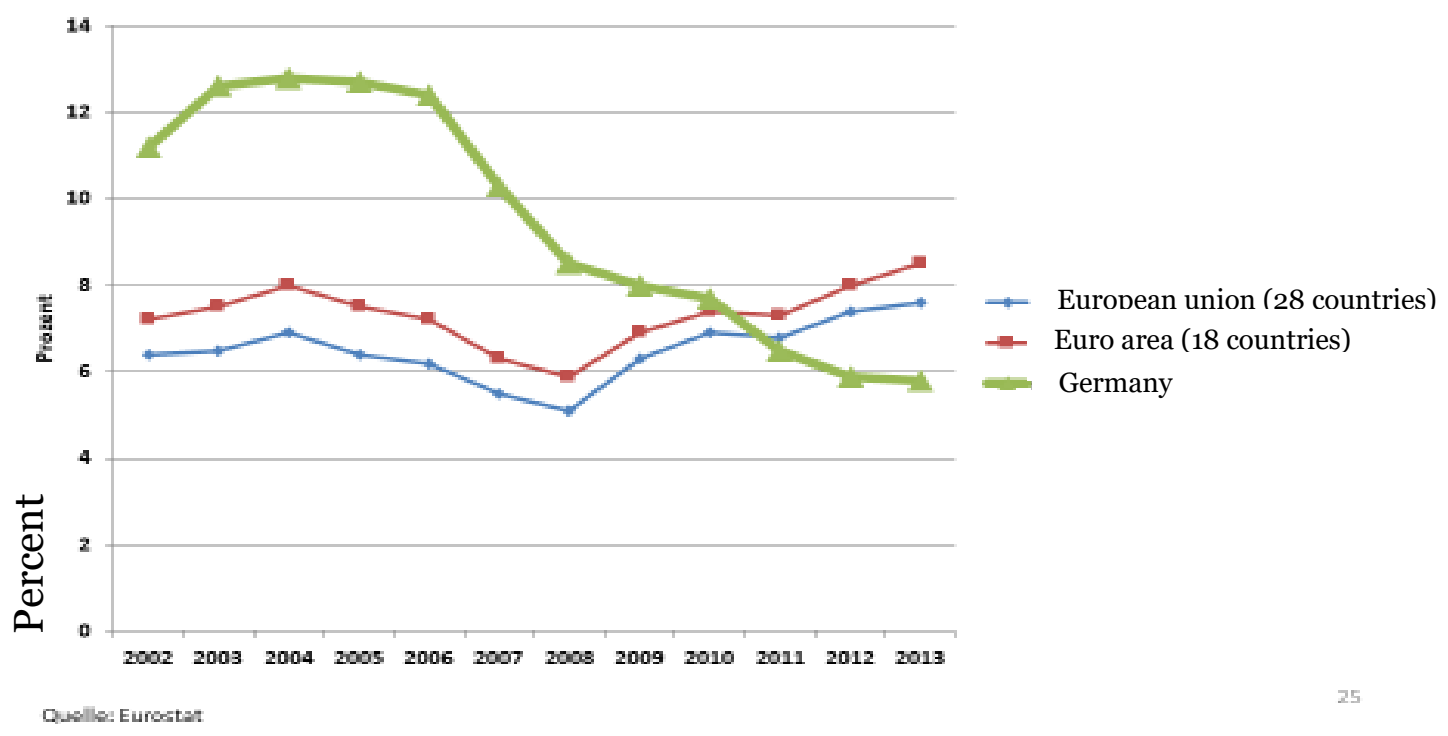

\subsubsection{Older unemployed: low risk of entry, but high risk of remaining}

Unemployment among older people in Germany is structured into growing and solidifying long-term unemployment. Long-term unemployment of older workers reflects a discrepancy that has long been known in unemployment research: there is a low risk of entry into unemployment, but a subsequent high risk of remaining unemployed once the job has been lost. In other words, the risk of becoming unemployed is comparatively low, not least because of both the strong protection against dismissal under collective agreements (see section 5.13) as well as the special company-specific qualifications of many older employees which can be understood as "de facto protection against dismissal" (Naegele 1992). On the other hand, the risk of remaining unemployed and not finding a new job is particularly high among older workers and rises even more when one approaches the official retirement age. This typical structures of unemployment among older workers also reflects decisive dimensions of social inequality.

\subsection{Who are Germany's 'silver workers'?}

\subsection{1 'Silver work' has always existed}

'Silver work', work after official retirement ages, has had a long legal tradition in Germany and started well before the EWL paradigm shift, but this type of work was thought to have less importance, at least in the beginning. In Germany, individual 
employment contracts usually end when the official retirement age is reached. Continued employment must be negotiated with the employer in each case and, if applicable, requires the approval of the works council. Even though work beyond the official retirement age was subsidized with financially attractive pension supplements for up to a maximum of two years (for two years of work subject to social insurance contributions for an additional two years, a maximum of $14.4 \%$ pension supplements over the entire pension period), these incentives led to very few people willing to take advantage of the offer (numbering at most a few thousand per year).

The reason for this low rate of use was primarily the unwillingness of companies (and also of their works councils) to keep older employees in employment subject to social insurance contributions for longer periods. Today, the majority of silver workers work outside regular employment relationships subject to social insurance contributions are in one of two main groups: (1) those working as self-employed on a contractual basis ('contract management') or (2) those working in precarious employment (geringfügige Beschäftigung) at a maximum of 450 Euro/month (Naegele 2017a).

\subsubsection{Increase since the change of paradigm - voluntary or forced?}

In recent years, the number of silver workers has continually increased; however, the reasons for working beyond official retirement age in Germany, compared to older workers in other EU countries, are less about financial reasons. Across the EU, silver workers are estimated to be more numerous, but in these cases, income from work after retirement provides more than half of the income - in other words, silver work is being used to help to avoid poverty (Naegele \& Bauknecht 2017). In Germany, for the vast majority of silver work, intrinsic motives seem to be the prime driving force. However, the numbers of older workers are also dependent on employer's preparedness. In Germany, the most significant criterion for employers to offer 'silver jobs' is the concrete utility value of the workers applying for these jobs (Naegele 2017a, b; Deller \& Naegele 2021).

\subsubsection{Social inequalities in the distribution of 'silver work'}

When analysing the structures of silver work, it can be shown that those with high socio-economic status stay in the labour market because these workers have a high level of identification with their occupations and often even with their former companies, while for those with lower socio-economic status, financial reasons are the more important factor (Hochfellner \& Burkert 2013; Naegele 2013a, 2017a, b; Hokema \& Scherger 2016; Hess 2017; Deller \& Naegele 2021). These conclusions are supported by the finding that highly-skilled older workers are assumed to be able to synchronize their expected to their preferred retirement age, while lowerskilled older workers expect to have to work much longer than they would like to (Hess \& Landmann 2015; Hess 2018; for more details see section 5.3.2). 
The results of the General Age Studies from 2013 and 2017 show that the number of silver workers has increased in Germany. In 2016 and 2013, 15\% and 11\% (respectively) of 65 to under 85-year-olds did silver work 'regularly', among them, mostly younger older workers from $65-69$ (29\% in 2016, 20\% in 2013), and more men (19\% in $2016,15 \%$ in 2013) than women (11\% in $2016,8 \%$ in 2013). A vast number of silver workers worked as freelancers and/or self-employed (including many former employees who were now employed on the basis of 'contract management') (38\% in both 2013 and 2017). Only 9\% worked full-time in 2016, but $42 \%$ worked part-time with an average of almost 14 hours/week. ${ }^{12}$

Examining the reasons for working show that a clear majority work for intrinsic motives ('work makes joy', 'I am still needed', 'social contacts'), especially among the upper professional status groups and/or more highly qualified people. Economic reasons are (still) subordinate (like 'poverty reduction', 'I need more money'), but as expected, these latter-named reasons are dominant in the group of working pensioners who are disadvantaged in terms of income and education. Doubtlessly, they are not (yet) the most important representatives of silver work, but they are probably a major one that will have increasing importance in future.

However, doing silver work requires an offer of a silver job, i.e. the employer must be willing to hire a silver-job seeker. In the field of silver work, there appears to be a new dimension of social inequality in that older workers, especially those who are better qualified (and therefore with generally better financial provisions through the statutory old-age-income-systems, company benefits, etc.) use silver work to create a new, attractive jobs. On the other hand, those who are 'really' (i.e. financially) dependent on silver work have less access to silver jobs. Experts suspect that against the background of the reported pension cuts (both in the course of 'pension at 67' as well as the closure or complication of alternative early retirement options, see also section 5.3.2), despite the clearly socially desirable distribution effects of silver work, the number of those dependent on silver work for economic reasons will increase, even though these workers will have fewer and fewer chances to find appropriate jobs (Naegele 2017a). 


\subsection{The participation of older women in the labour market in Germany}

\subsubsection{The West German 'breadwinner' model}

For many years, at least until the late 1980s, the (West) German economy and labour market policies were characterised by the credo of the male breadwinner. ${ }^{13} \mathrm{~A}$ man, or more precisely a husband, worked outside the house ('breadwinner'), while a woman, or more precisely a wife, was responsible for household, childcare, and elderly care. This arrangement is reflected in many specifics of the (West) German welfare state. "The option of equally splitting income between spouses before taxation (the 'Ehegattensplitting') and the low coverage of primary child care facilities provide incentives for married women and mothers to temporarily interrupt their working careers" (Hess 2016: 160). Esping-Andersen (2007) showed that in West Germany, earnings within couples were negatively correlated, meaning that wives of well-paid husbands worked very little, as was incentivised by the system. Conservative welfare states also provided earnings-related (or statuspreserving) pensions for widows (Holzmann 2006; Bäcker, Naegele \& Bispinck 2020 , vol. II), so that women could rely on their husband's welfare entitlements even if he died.

\subsubsection{The increase in the female employment rate}

However, there has been a long-lasting trend of increasing female employment rate, including older female workers. One reason for this development is the slowly but steadily growing importance of the service sector (from 60\% in 1990 to $74 \%$ in 2016; Destatis 2017a), and in this sector, the share of female employees is distinctively higher (very often on part-time basis). In general, younger women entering relevant age brackets substitute older women leaving this age brackets. These skills of younger cohorts and attitudes enabled and encouraged paid work on a higher level as well as for longer periods. The disadvantages of women in formal education have declined, and are sometimes even reversed in younger cohorts. Partly related to these trends, the number of women who can or must rely on their husbands' incomes has also declined, since the net marriage rate (marriages minus divorces) per 1000 inhabitants declined from 4.1-4.2 between 1980 and 1983 to

\footnotetext{
${ }^{13}$ Here one must keep in mind some particulars about German reunification. Until 1990, the two German states each had their own gender ideologies. In the former GDR, the male breadwinner model was much less dominant and female employment rates were significantly higher than in West Germany. Furthermore, women in West Germany used to (and still do) stay longer periods in parttime work after the birth of the first child compared to their East German counterparts. Although there has been some 'catching up' of the West regarding the gender values, the differences between East and West persist to this day.
} 
2.6-2.9 between 2010 and 2013 (Destatis 2017b). Although these statistics neglect different age profiles, they clearly shows changing circumstances. In addition, fewer women are getting married and having children, which results in fewer labour market drop-outs due to childbirth. Furthermore, due to the introduction of legal entitlements to public childcare facilities, this sector has been expanded strongly, enabling mothers to re-enter paid work after childbirth sooner. This re-entry to labour has been even more encouraged by the introduction of the national parental allowance in 2007 (Huebener, Müller, Spieß \& Wrolich 2016). ${ }^{14}$

Another factor for rising female employment in the wake of changing demands within sectors, with a constant decline of physical demands due to mechanisation and automatization of work. On the one hand this resulted in a constant increase of jobs in the service sector on the other hand, this was associated with particularly striking increases in female employment; but not unexpectedly also with aboveaverage numbers in part-time employment and, more recently, many in precarious employment (see section 4.5.4). Particularly the health and care sectors profited remarkably from an increase of female employment with even more higher rates of female part-time work (Merkel, Holman, Ruokolainen \& Hess 2020). Further, younger female cohorts with higher employment rates substitute for older female cohorts with lower employment rates.

\subsubsection{Gainful employment increasingly in conflict with private care obligations}

Older women younger than legal retirement age is the group most strongly affected by private obligations of elderly care. Against the background of increasing longevity, the number of elderly dependents requiring an increasing amount of care is expected to rise further, leading to an increase of private care efforts per dependent person. Partly because nursing homes are considered undesirable, and partly because dependents generally prefer to remain in their accustomed surroundings, care at home is an important issue and can be expected to remain so. This trend imputes a heavy care burdens on female (potential) older workers, and this burden will probably continue to rise, even if it can also be expected that private care will be increasingly equally distributed between men and women.

It is not known exactly how many employees in Germany have care obligations towards people close to them, but estimates range from 6\% to 10\% (Reichert 2016,

${ }_{14}$ Parental allowance compensates for missing income when parents who share gainful employment and family work care for their child after birth. It secures the economic existence of families and helps fathers and mothers to better reconcile family and career and should enable parents to take time for their child (Bäcker, Naegele \& Bispinck 2020; vol. II). 
2020, 2021). With 45 million people currently in employment, that translated to as many as 4.5 million people with care obligations, and most of these are probably women- The Institute of Economic and Social Research of the Hans Böckler Foundation concluded, on the basis of the representative DGB index 'Good Work' from 2017, that every tenth employee cares for dependents. These (estimated) percentages can vary considerably between sectors and companies (e.g. depending on the proportion of employees in the age groups relevant to care; Reichert 2021).

In recent years, several new measures have been introduced for the reconciliation of paid work and private care, yet so far these have probably had very weak effects (Schäufele \& Hendlmeier 2015; Reichert 2016, 2020, 2021; see also section 5.11). The strong emphasis of private female home elder-care might increase gender inequality in Germany. The dual breadwinner model, which today is widespread in Germany, has not necessarily led to a reduction in the burden on women in the family division of labour. On the contrary, the increase in the obligation to provide long-term-care at home to elderly family members has led to the fact that older women in particular (those between 55 and 65) are now more burdened than before (particularly those in the so-called 'sandwich generation') (Reichert 2016, 2020, 2021). On the other hand, many workers have now been relieved of child-rearing duties because the children have moved out. More and more women in this age group have no children at all.

\subsubsection{Atypical and/or precarious employment among (not only older) female workers}

A particular problem (not only for elderly) women in Germany is the high degree of both atypical (precarious) employment and part-time work, both typical for the lowpay sector, particularly in the wake of the Hartz reforms (see sections 2.3 and 5.7). In both parts of Germany in general, both young and older female workers are heavily represented in the low-pay sector (Romeu-Gordo \& Sarter 2020; see Figure 11). In Germany, earnings within couples are still negatively correlated, meaning that wives of well-paid husbands work little (Esping-Andersen 2007), and so many women engaged in part-time work have no direct problem of financial insecurity, since there is a second earner in the household. Yet in cases without a second income, earnings are low as are accrued pension entitlements. Given divergent employment rates and figures between men and women in 'normal' pay sectors, it is not surprising that a remarkable gender pension gap exists that used to be distinctively bigger in Western than in Eastern Germany. More than 30 years after the reunion, this pension gap is still one of the highest in Europe (Romeu-Gordo \& Sarter 2020), particularly in women aged 50+ with precarious employment (only partially socially secured) (Bäcker, Naegele \& Bispinck 2020 vol. I):

- Of the approximately 15 million part-time employees in Germany (2018), women predominate. The part-time rate of women increases with the birth of 
children and then remains at a comparatively high level until they retire. Women's employment after age 55 is predominantly part-time work.

- $\quad$ Among the almost 8 million marginally employed (mini-jobs, low-pay sector) (2018), two thirds are women and about 40\% are also housewives (i.e. with responsibilities for a family). The majority work part-time. The large group of women with only marginal employment are mostly wives whose income from work is more likely to be additional household income, and their social security is essentially derived from their husband's employment through their husbands' pensions or survivors' benefits. The mini-job system makes a decisive contribution to promoting and establishing this gender-hierarchical employment model. Since 2013, mini-jobs are automatically subject to statutory old age income security insurance, and in 2015, a statutory minimum wage was introduced (Romeu-Gordo \& Sarter 2020).

- It is not known how many of the approximately 3 million fixed-term employees (befristet Beschäftigte) and 1 million (2018) temporary workers (Leiharbeit) are women, especially those in the older age groups.

Figure 11: Dependent employees in full-time employment and in atypical employment forms 200O-2018, in millions

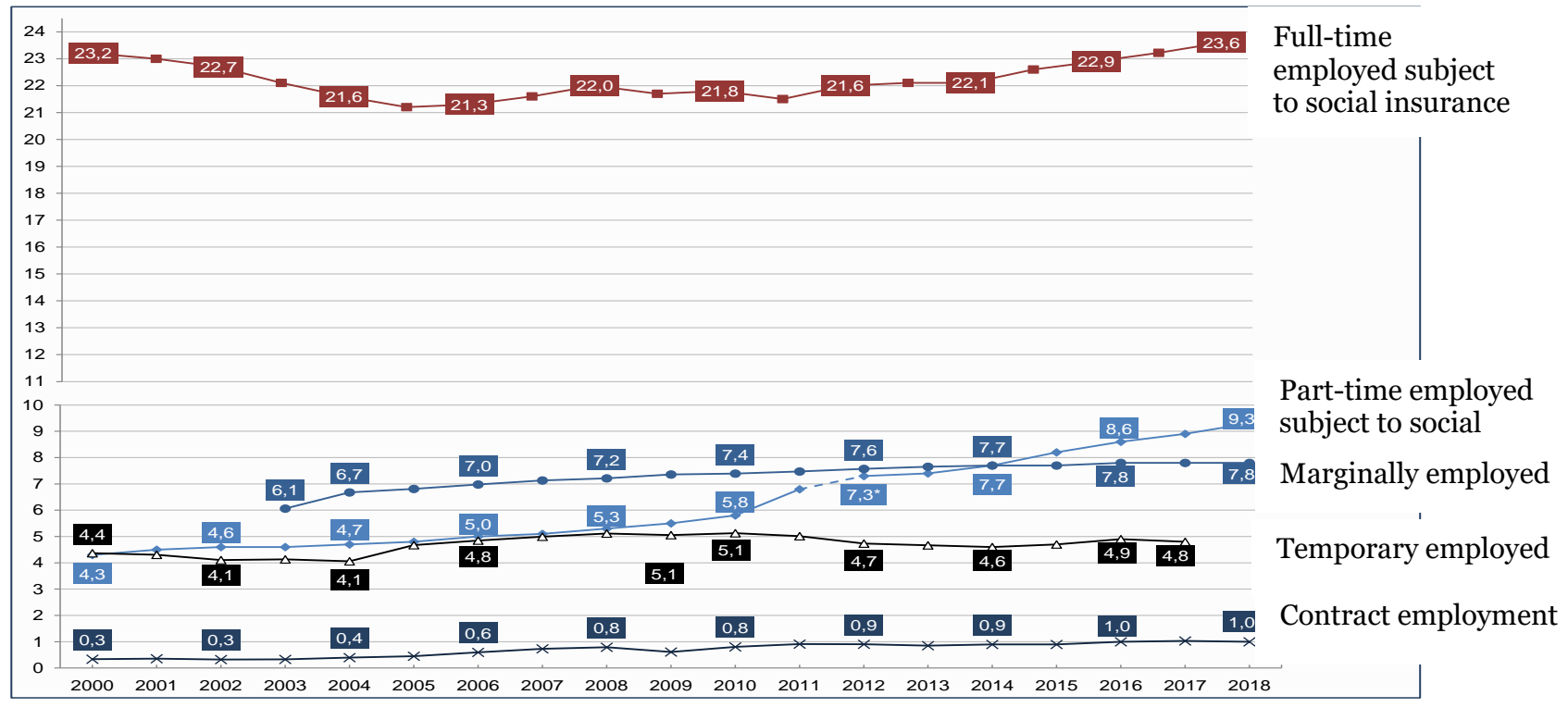

From 2012, new BA survey procedure, figures are only partially comparable with those of previous years. 1) Marginally employed as main and secondary staff, 2) with less than 40 hours per week, 3) including employees in apprenticeships. Source: Federal Employment Agency (last accessed 2019), employment statistics; Federal Statistical Office (last accessed 2019), microzensus. 


\section{$5 \quad$ Profile of EWL policies and inequalities therein}

\subsection{Overview}

The policies that are taking place or have taken place in Germany to extend working life can be roughly divided into two general levels of concern.

The first level (actions and policy) includes: ${ }^{15}$

- retirement age policies and related financial incentives,

- $\quad$ reducing and/or complicating entitlements for disability pensions,

- $\quad$ redesigning the transition processes (gliding retirement versus fixed retirement ages),

- $\quad$ promotion of 'silver work' and self-employment,

- $\quad$ active labour market policies including prevention of unemployment and reintegration into employment,

- health promotion, prevention, health protection and rehabilitation,

- qualification measures and lifelong learning (LLL),

- $\quad$ improving working conditions,

- career change processes,

- promoting the reconciliation of work and care,

- $\quad$ sensitization, education and awareness raising.

The second level (responsibilities and actors) can make distinctions among

- $\quad$ state/legal approaches,

- social partners,

- corporate measures,

- older workers themselves.

In practice, it is difficult to discern a clear separation of measures; rather, they take place additively or sometimes in parallel, and there is often overlaps between measures and actors; the same is true for both mixtures of measures and actors as well as for integrated forms of implementation. Many, if not most of the measures mentioned in this section have a promotional nature to aid the quest to reach EWL, but are not explicitly related to the political shift of paradigm.

15 This list mirrors the structure of this section. 
Historically, it was the state that first tried to reverse the trend in the hitherto dominant 'devocation of old age' ("Entberuflichung des Alters") through implementing policies and measures aimed at EWL (Frerichs \& Taylor 2009; BMFSFJ 2010; Dietz \& Walwei 2011; Naegele 2013b; Brussig 2018; see also section 2.1). Through its various measures, the paradigm shift was and is primarily focussing on pension reforms on the one side and labour market policies on the other side. Pension reforms, at least in the beginning, were mainly trying to incentivise companies to recruit older unemployed. However, state measures to promote EWL were not limited to only to those two policy areas. Sensitization and awareness building, age-related health promotion and prevention, protection against dismissals, further training, and other governmental and non-governmental measures mentioned in this section existed even before the politically-initiated paradigm shift. However, they have gained in importance in its wake, albeit not always with an explicit 'EWL-order', but at least with an indirect and/or additional effects.

Many initiatives, for which the social partners are mainly responsible, also have a longer tradition as collective agreement regulations in favour of older employees. However, collective agreements that regulated these areas and were explicitly aimed at shaping demographic change in work world (and cushioning its problematic consequences) are new. These agreements were not introduced until after the turn of the millennium, reaching their peak between 2010 and 2015, but did not spread further in subsequent years. Operational measures, now known as 'corporate age management', have also gained momentum in the wake of the paradigm shift, but have recently began to stagnate and show no sign of spreading further.

\subsection{Fields and areas of action and emerging social inequalities in the wake of EWL policies}

\subsubsection{Key threats from social inequalities}

"It should come as no surprise that the opportunities and risks of the transition into retirement are socially unequally distributed. This applies to gainful employment in old age, the average exit age from the labour market and the average retirement age, as well as to a direct transition from gainful employment to an old-age pension without intermediate unemployment. High workloads, unemployment in the late phase of working life and incapacity to work or prematurely reduced working capacity due to illness are the most important mechanisms that cause social inequalities in the transition to old age. Although they can overlap and reinforce each other, each of these mechanisms has a distinct effect on the course of the later working life" (Brussig 2018: 15).

Social inequalities in access to services, programmes, measures, and so forth that were intended to promote EWL have to be taken into account. In Germany, social inequalities so far have mainly been studied with respect to the financial 
implications ${ }^{16}$, though there are exceptions of individual analyses of access to and use of services and programmes. These are only available for selected measures. However, whenever measures are targeted at EWL, social selection effects can be expected to exist, especially according to age, qualification level, state of health, and current and previous employment. This connection will be examined below as far as the data for Germany permit, above all in terms of the possibilities of access to company age/ageing management as well as to collectively agreed support measures, to measures of health promotion, health protection and rehabilitation, and to measures of active labour market policy and LLL.

A third dimension of relevance for the emergence of social inequality in later working life phases is former unemployment, in particular former long-term unemployment. In Germany, the latter is typically linked with being an (mostly unqualified) older worker as well as working in part-time or in other unprotected ('precarious') employment forms. In Germany, the latter category often applies (older) female workers due to the male breadwinner model (see previous section), which is still very widespread in this generation (see also section 4.5). Each of these dimensions clearly reduces the chances of continuous integration into normal employment. The consequences of this lack of integration are both short-term and long-term with regard to financial provisions after retirement. In general, those who are disadvantaged in these dimensions are primarily those who were already affected by employment risks in earlier phases of their working life, including a high proportion of women.

The recently finished EXTEND project confirms these predictions: "The measures introduced in most EU Member States to extend working life (such as 'pension at 67 ' in Germany or the EU-wide closure of early retirement options) are not only generating new social inequalities but also exacerbating or even increasing the cumulative effect of social inequalities that have existed throughout previous working lives" (Naegele \& Hess 2020: 30).

\subsubsection{Health-threatening workloads, a key driver for social inequalities in realising EWL}

The effects of high workloads and their exposure duration on the particular risk of illness of older workers (Naegele 1992) and especially on the risk of reduced earning capacity (Bäcker 2012) have been well investigated and sufficiently confirmed for a long time (see section 5.9). High workloads are also associated with early access to normal old-age pensions (if there is scope for decision, as in Germany, but decisions might come with certain deductions) (Brussig 2018; 2021). This influence has increased in recent years and has been proven for the EXTEND project at the

${ }^{16} \mathrm{~A}$ broader perspective was taken up just recently by Naegele \& Hess (2020) (eds.). 
European level, and is especially pertinent for female employees (Brussig 2014). According to the EXTEND findings, the preventive reduction of workloads with high potential for early retirement is also considered an important additional prerequisite for achieving the EWL targets (de Breij \& Deeg 2020), which has been explicitly proven for professional care workers (Merkel, Holman, Ruokolainen \& Hess 2020).

\subsubsection{Unemployment with accelerated effect on forced early retirement}

To (mis)use the instruments of the Unemployment Insurance scheme to promote early retirement has been known for a long time as both a 'proven' instrument of state policies of promoting early retirement as well as of early retirement practices in companies. This has already been the case in the 1980 on and 1990s, when "to go into unemployment" was practiced as mutual agreement between workers and employers in order to achieve a socially secure path to early retirement after a certain period of being officially unemployed. After the reunion this instrument again was used particularly often in the former GDR to adjust the labour market to the economic transition processes (Naegele 1992; see section 2.1). However, it would be unjustified to assume that using this instrumentalisation of the Unemployment Insurance scheme was merely an 'abuse' of regulations, if one takes into account that in many cases high workloads, health reasons, and/or even 'really' threatening unemployment were the real drivers into early retirement.

\subsubsection{Illness and health-related premature loss of earning capacity}

The connection between illness and health-related premature loss of earning capacity and retirement has also been repeatedly researched and confirmed (Bäcker et al. 2009; Trischler 2014; de Brey \& Deeg 2020). Analyses show that illness has had an even stronger influence on retirement in recent years (Brussig, Knuth \& Mümken 2016). Currently, the issue of mental diseases (of older workers) has been identified as an increasingly relevant driver of both sickness days as well as of (early) disability pensions and vocational and/or medical rehabilitation, with increasing numbers of affected among women (see Figure 12; see also section 4.4). 
Figure 12: Pensions because of reduced earning capacity, entries by selected diagnosis groups, 1995-2010 (in \% of all pension entrants)

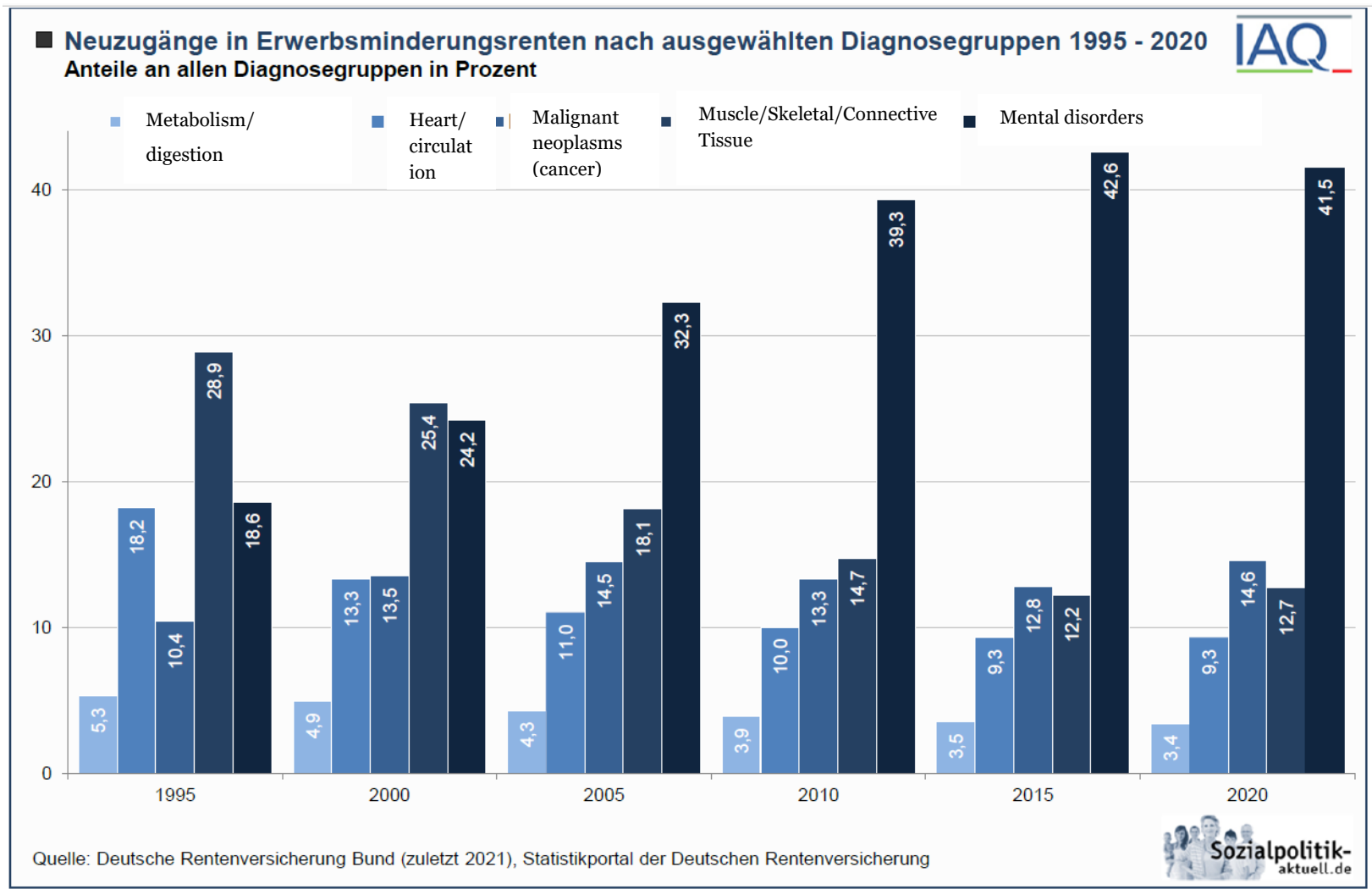

\subsection{The core of EWL policies - state retirement age policies and financial incentives that close or complicate early retirement pathways}

\subsubsection{Overview}

\section{Introduction of pension reduction for early retirement in 1992}

The first pension reform (Rentenreform) was designed in 1989 and implemented in 1992. Existing early retirement options for women, the unemployed, and people with severe health problems who were previously allowed to retire at 60 , were either closed or the eligibility criteria were tightened and the subsidised transition periods between labour force exit and retirement were shortened. Further, actuarial pension reductions by $0.3 \%$ for every month a pensioner retired before the official retirement age were introduced, aimed at making early retirement financially less attractive (Rürup 2002; Radl 2014; Bäcker, Naegele \& Bispinck 2020, vol. II). These policies led to later employment exit (Lüthen 2014), especially in the case of men. A 
few years, earlier the differences between men and women in the official retirement ages (M 65, W 60) had already been eliminated ${ }^{17}$ (see section 4.4).

\section{Raising the legal retirement age ("Rente mit 67") in 2007}

The closure of early retirement came to an end for the time being with the 'Act to Adjust the General Retirement Age to Demographic Developments'

(Altersgrenzenanpassungsgesetz) (2007), which, starting in 2012, would gradually raise the standard retirement age from 65 to 67 ("Rente mit 67"). These actions were decided in November 2005 by the new grand coalition of the political parties CDU, CSU and SPD. Accordingly, it was decided to gradually raise the official retirement age to 67 by 2029 (first by one month per year, later by two months per year), and that the new retirement age would apply to women.

The process began in 2012 with those born in 1947 (Figure 13). For those born later, the regular retirement age has since then increased by one month from year to year. For those born after 1958, the retirement age rises by two months per cohort, so that those born in 1964 and later will only be able to receive the regular retirement pension after age 67 . It is possible to draw a pension early under certain conditions, but also to accept actuarial deductions for doing so. These policies also applied to severely disabled persons as well as for long-term insured (see Early retirement pensions, Figure 14).

\footnotetext{
${ }^{17}$ In February 1987, the Federal Constitutional Court (1 BvR 455/82) ruled that different age limits for pensions for women and men were unconstitutional and incompatible with Article 3(2) of the Basic Law. In the Social Code applicable from 1 January 1992, the regulation applicable to women was then again amended. Insured women are entitled to an old-age pension if they have reached the age of 60 , have more than ten years of compulsory contribution periods after reaching the age of 40 , and have fulfilled the waiting period of 15 years.
} 
Figure 13: Pension at 67 in Germany

\begin{tabular}{|c|cc|}
\hline \multicolumn{2}{|c|}{ Raising of the official retirement age in Germany } \\
\hline Year of birth & $\begin{array}{c}\text { Standard retirement age } \\
\text { from year }\end{array}$ & $\begin{array}{c}\text { Reaching the new standard } \\
\text { retirement age }\end{array}$ \\
\hline until 1946 & 65 & 02.2012 until 01.2013 \\
until 1947 & $65+1$ Month & 03.2013 until 02.2014 \\
until 1948 & $65+2$ Months & 04.2014 until 03.2015 \\
until 1949 & $65+3$ Months & 05.2015 until 04.2016 \\
until 1950 & $65+4$ Months & 06.2016 until 05.2017 \\
until 1951 & $65+5$ Months & 07.2017 until 06.2018 \\
until 1952 & $65+6$ Months & 08.2018 until 07.2019 \\
until 1953 & $65+7$ Months & 09.2019 until 08.2020 \\
until 1954 & $65+8$ Months & 10.2020 until 09.2021 \\
until 1955 & $65+9$ Months & 11.2021 until 10.2022 \\
until 1956 & $65+10$ Months & 12.2022 until 11.2023 \\
until 1957 & $65+11$ Months & 01.2024 until 12.2024 \\
until 1958 & 66 & 03.2025 until 02.2026 \\
until 1959 & $66+2$ Months & 05.2026 until 04.2027 \\
until 1960 & $66+4$ Months & 07.2027 until 06.2028 \\
until 1961 & $66+6$ Months & 09.2028 until 08.2029 \\
until 1962 & $66+8$ Months & 11.2029 until 10.2030 \\
until 1963 & $66+10$ Months & 01.2031 until 12.2031 \\
until 1964 & 67 & \\
\hline
\end{tabular}

Source: Bäcker, Naegele \& Bispinck 2020, vol. II: 1010.

This act was (and is still today) quite fiercely opposed by trade unions, who saw (and still see) the danger that a large group of workers in physical demanding jobs will not be able to stay employed until age 67 and will have to face severe pension cuts (DGB 2015). When this law was enacted, it was agreed that every four years (starting in 2010), a report would have to be delivered by the Federal Government on the labour market situation of older workers, and that this report would states whether the raising of the retirement age is feasible under the current labour market conditions. Not surprisingly, these reports gave no hints that it is not feasible (2018). Furthermore, considerations of placing the 'new policy for the elderly' (Naegele \& Schmähl 2007) in the context of age discrimination have played 
no role at all, partly because this concept has no tradition in Germany and is not well known among the actors involved.

\section{'Pension at 63' ('Pension for long-term insured'), 2012/2014 - a step backwards?}

Although applied for the first time in 2012, the 'pension at 67' was reformed again in 2014 when Rente mit 63 (Rente für langjährig Versicherte) was introduced, which in essence means a return to the previously valid regulations to provide an option for early retirement for certain groups of employees with particularly long insurance careers. However, these workers had to accept pension deductions with each month before the official retirement age of 67. Only those (comparably few) older workers who have completed a waiting period of 45 years are still allowed to retire at 65 without any deductions. However, when the legal retirement age is gradually raised to 67 , they will then also have to pay deductions for the period between 65 to 67 , up to a maximum of $7.2 \%$.

This contradiction in the original key philosophy of the paradigm shift in the political debate was often understood as a 'bow to the trade unions', having once again been able to exert influence on the pension policy around the 'pension at 67' for a long time. At the same time, it was also regarded as an election gift to voters from the classic working-class milieu. Since 2014, the (mainly older) workers who had contributed to the pension insurance for 35 years have been allowed to draw a pension at 63 years, however, they are punished by severe pension deductions over the complete payment period. The vast majority of those entitled to benefits have used this route, which has led to a further increase in skill shortage in many companies (see section 2.2). However, many experts saw this reform as only a minor correction to the previous major pension reforms (Blank 2020), which, as many critics repeatedly stressed, aimed at a complete shift of paradigm in the hitherto prevailing pension policy: that is, towards consolidation of finances and contribution rate stability instead of securing living standards and avoiding poverty (Naegele \& Schmähl 2007). In both the academic and political debates, the reintroduction of the pension at 63 through the back door and thus the softening of the pension at 67 was (and is still today) strongly criticized, particularly by neoliberal economists and conservative social politicians.

Figure 14 provides an overview of the current age limits and the conditions for their utilisation, including the respective pension reductions. 
Figure 14: Early retirement pensions (Status 2020)

\begin{tabular}{|l|}
\hline \multicolumn{1}{|c|}{ Most relevant early retirement pensions } \\
\hline Old-age pension for long-term insured persons aged 63 and over \\
The prerequisite is that a waiting period of 35 years ('long-term insured') has \\
been fulfilled. This pension is subject to a deduction of o.3\% per month, \\
measured against the relevant standard age limit. If the standard age limit \\
(in 2018) is 65 years and seven months, this corresponds to a pension \\
reduction of 9.3\% if the pension begins at 63 years of age. At the end of 2029, \\
when the standard retirement age of 67 years is reached, the reduction \\
amount will have increased to $14.4 \%$. \\
Old-age pension for certain long-term insured persons aged 65 and \\
over \\
Anyone who has completed a waiting period of 45 years can retire at 65 \\
without any deductions. Compulsory contributions from periods of \\
employment, nursing care, and periods of bringing up a child up to the age of \\
10 are credited against the waiting period of 45 years. However, periods \\
spent receiving unemployment and unemployment benefits II (Hartz IV 18 ) \\
do not count against the 45 years. \\
Old-age pension for severely disabled persons \\
Since 2012, starting with people born in 1952, the retirement age for severely \\
disabled persons for the earliest possible claim to this pension will be raised \\
gradually from 60 to 62 years. At the same time, the age limit for receiving \\
this pension without deductions will be raised in stages from 63 to 65 years. \\
This means that a maximum deduction of $10.8 \%$ will remain for the earliest \\
possible claim.
\end{tabular}

Source: Bäcker, Naegele \& Bispinck 2020, vol. II.

In addition to receiving a pension, it is possible to work and earn an unlimited income (see section 5.5). If, however, the old-age pension is drawn prematurely, that is, before the standard retirement age is reached, strict additional income limits apply (earnings may not exceed 450 Euros per month).

\section{Abolishment of old-age pensions after unemployment, 2006-2011}

Before this reform, unemployed people older than 60 could enter this scheme (59er Regelung). In most cases these people were 'made unemployed' by mutual 
agreement in order to enter the age meeting the official eligibility requirements. Afterwards, it was possible to receive the early old-age-pension after unemployment. The reference retirement age to enter this scheme was raised to 63 in 2006 and again to 65/67 in 2012 (Bäcker, Naegele \& Bispinck 2020, vol. II), resulting in a more or less complete stop of this scheme in practice. It was/is still used by individual companies but must be financed only by them.

\subsubsection{Social inequalities in achieving the objectives of 'pension at 67'}

\section{Widespread doubts about reaching 'pension at 67'}

Social inequalities are particularly pronounced in achieving the goal of 'pension at 67 '. If one looks at the objective possibilities for EWL via 'pension at 67' and asks about the primary user groups, it is mainly members of the middle and upper social class groups, who can also (from a purely statistical point of view) expect to continue to benefit for a longer period of time from measures which have been cofinanced by non-users or only low users (Naegele, Leve \& Sporket 2009; Naegele 2015; Brussig 2018). The situation is made even more remarkable from a sociopolitical point of view, because in Germany, both morbidity and mortality are unequally distributed and clearly disfavour the lower social groups, in other words, lower class older workers are still characterized by an earlier and more serious morbidity risk, a shorter healthy remaining life expectancy, and a significantly earlier mortality risk (Mladovsky et al. 2009, Lampert et al. 2016; Grigoriev, Scholz \& Shkolnikov 2019).

As will be discussed later in section 5.3.2, in direct connection with the introduction of 'pension at 67', there were already many indications that about half of the older workers affected by this regulation were not expected to retire and achieve 'pension at 67', at least not under the contemporary working conditions (Naegele, Leve \& Sporket 2009; Kistler \& Trischler 2014; Naegele 2015; Hofäcker, Hess \& König 2018; Naegele \& Hess (eds.) 2020).

Figure 15 shows that manual workers in particular are in favour of maintaining the existing age limits and that workloads and health reasons are particularly relevant here. In contrast, particularly qualified workers (technicians, administrators, managers) would like to continue with an early exit so as 'to have more time for private interests'.

Figure 17 differentiates the various sectors. It can be seen that particularly the sectors of social services, health, catering and construction are seen as negatively affected by 'pension at 67', arguing 'it would not be possible to hold out in these sectors until the new retirement age was reached'.

In 2009, Heien et al. (2009) published a study about how women (45+) regarded 'pension at 67 ', with the result that $60 \%$ agreed that 'yes, [the plan is] feasible' while $40 \%$ thought 'no, not feasible'. The sceptics were primarily blue-collar workers. Among the anticipated reasons for not expecting to reach the new retirement ages included health reasons (43\%), working conditions (27\%), individual, family 
obligations (16\%), skill problems (13\%). Asked 'What is needed to reach pension at 67 ?', the answers included reduction of workloads (54\%), better reconciliation of work with private/family obligations (46\%), greater recognition of work performance through the company, superiors, and management (37\%), skill updating (36\%), adjusting working time schedules (35\%), and job and task redesign (27\%).

Figure 15: Do workers think they will stay in their jobs until age 65/67? (2013)

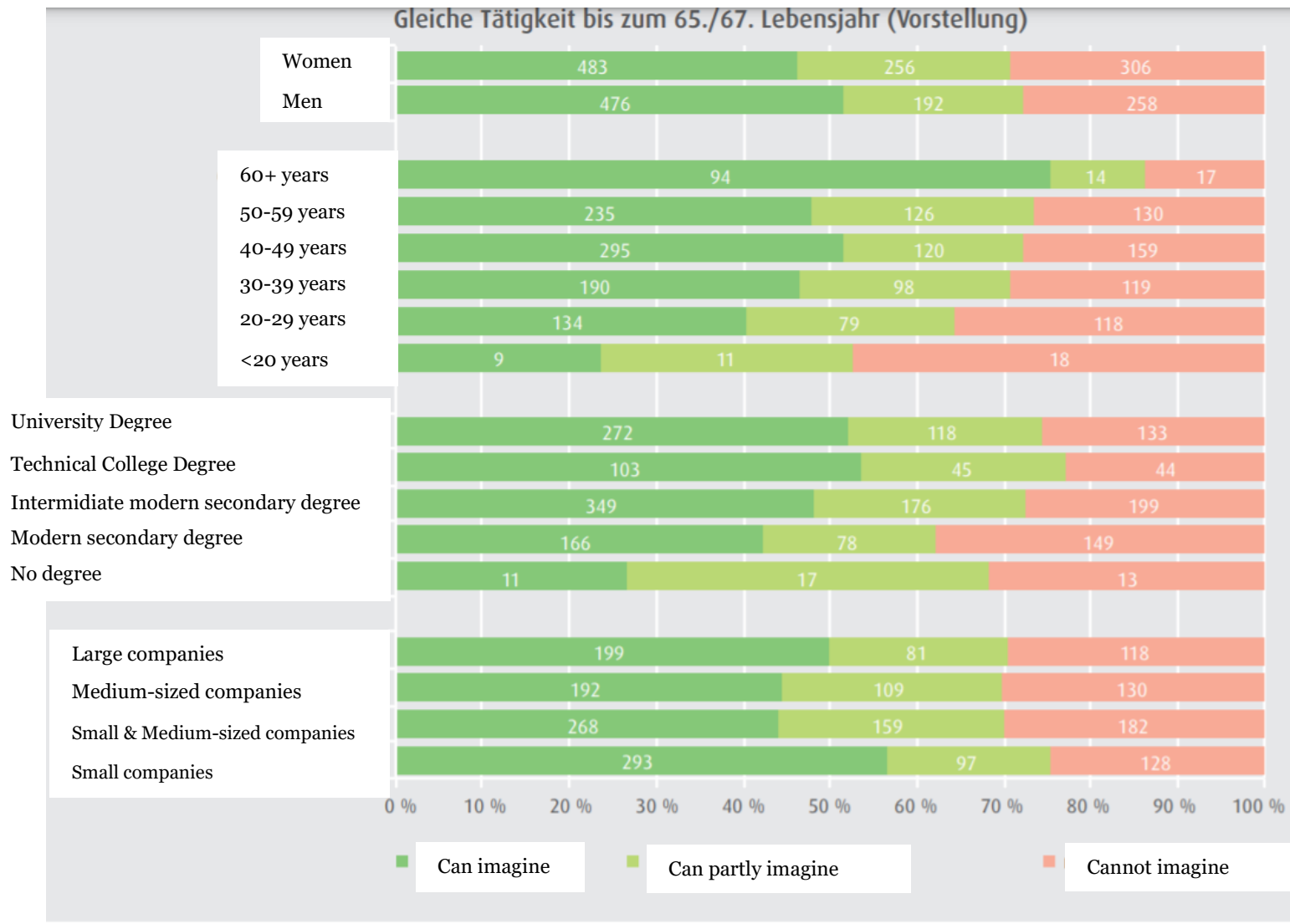

Source: Iga Barometer, $4^{\text {th }}$ wave 2013. The question was: Can you imagine working in your current job until the age of 65 or 67 ? 
Figure 16: Desire to maintain an earlier exit age by occupational category and motives (workers 45+, 2013)

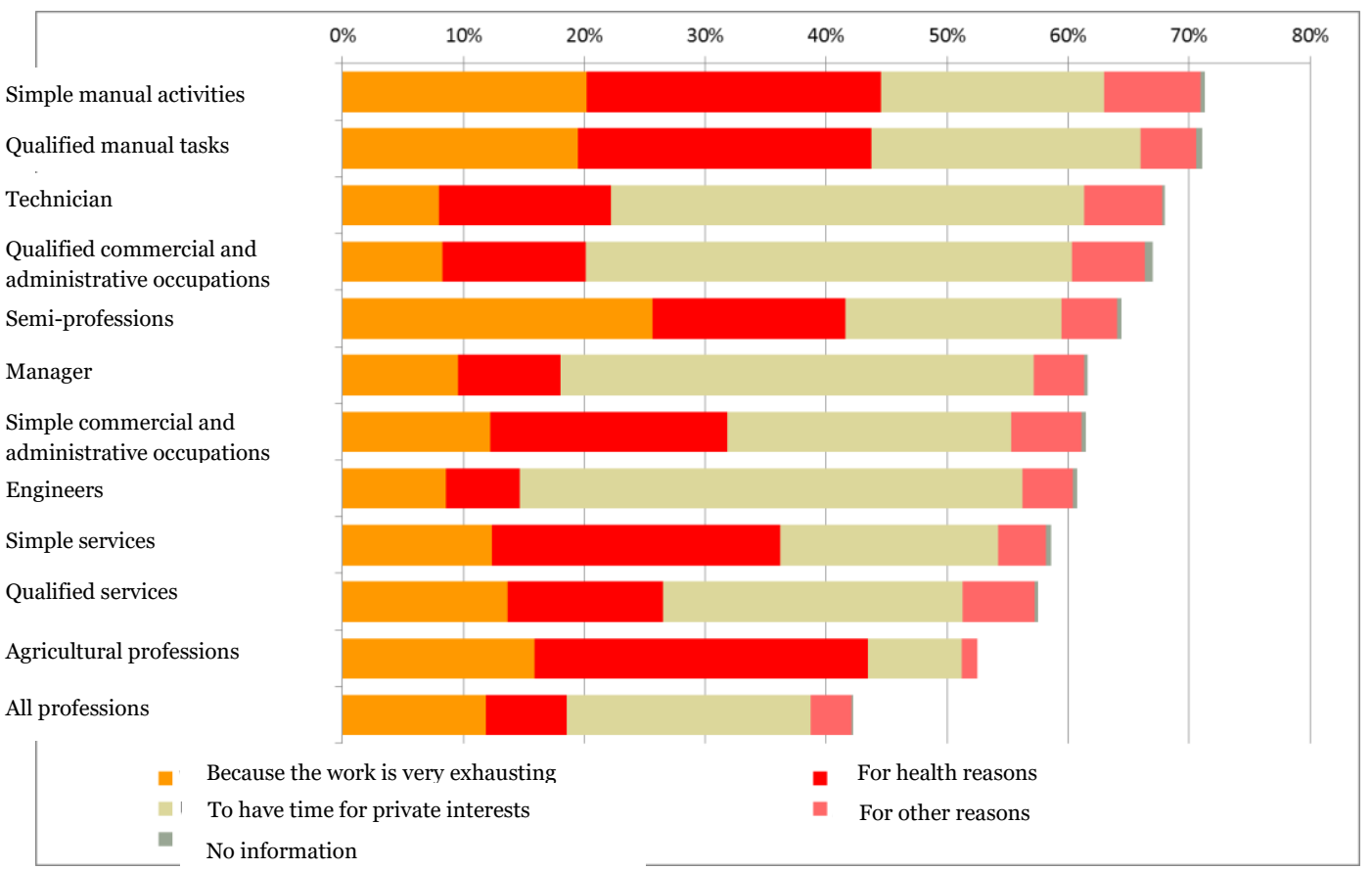

Source: Bundesinstitut für Berufsbildung (BiBB) 2013. 
Figure 17: Percentage of workers in selected sectors who do not believe they will be able to continue working in their current conditions until the new retirement age

$$
\text { (in \%) (2012) }
$$

Anteil der Beschäftigten aus ausgewählten Branchen, die unter den jetzigen Anforderungen davon ausgehen, nicht bis zur Rente durchzuhalten (in Prozent)

Social services

Hospitality

Construction

Healthcare

Transport and storage

Education and training

Metal production and processing

Financial services and insurance

Machinery and transport

equipment

Trade

Supply and disposal

Chemicals

Scientific, technical and other services

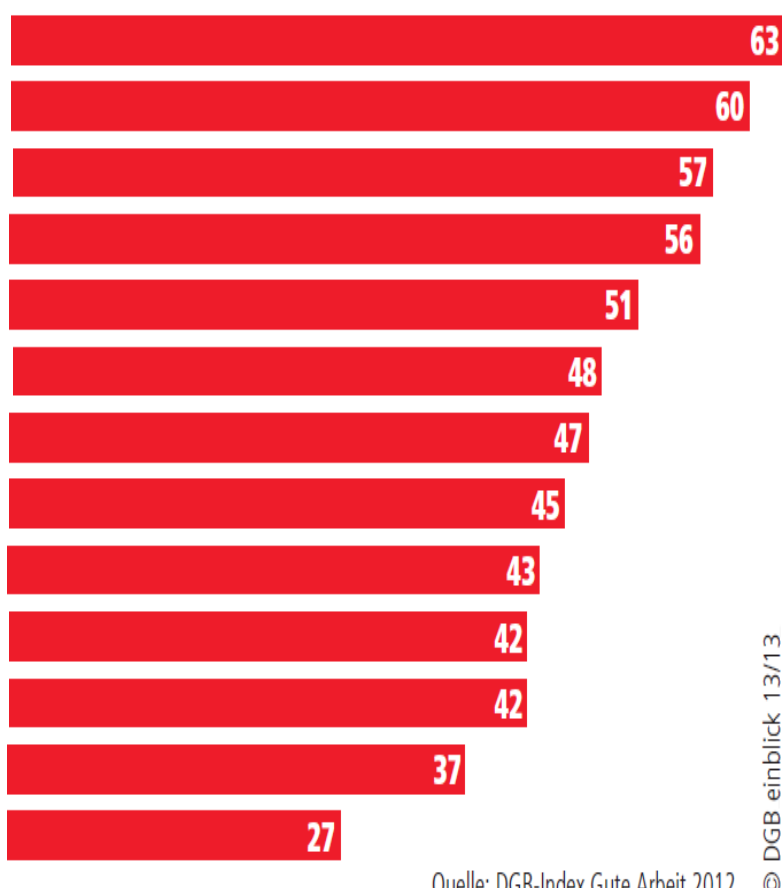

Quelle: DGB-Index Gute Arbeit 2012

Source: Deutscher Gewerkschaftsbund (DGB) (2012): DGB-Index Gute Arbeit 2012.

\section{The reality of premature and postponed retirement ages}

In 2017 (the latest available figures), only about 40\% of new pensioner were above the (newly-raised) standard age limit (65+). Another 40\% exited at age 63, mostly using 'pension at 63 for long-term insured'; see the previous section, 5.3.1). Up until 2009 for men and 2013 for women, the statistics on pension access showed a crash of the standard retirement age (65 years). Since then, however, use of the standard retirement age has stagnated, which can be explained by the continued existence of early retirement options, including the 'pension at 63 for long-term insured' which was introduced in 2012 (see the previous section, 5.3.1). It is expected that the increased retirement age will continue to stagnate in the future, as the earliest possible retirement age will continue to be 63 (pension at 63), confirming the assumption that the change to pension at 63 for long-term insured older workers is gradually threatening to 'remove the basis', which is also due to the fact that more and more older workers are reaching the required insurance years (35 years). So far, 
pension at 63 has mostly been used by men, whereas the proportion of women entitled to use it is still less than $10 \%$.

In addition to the possibilities of drawing a reduced earning capacity pension and disability pensions (each linked with deductions as will be addressed more in this section), early retirement was also available in connection with the use of oldage pensions for women, which between 2004 and 2013 had influenced women's career exit behaviours, namely taking the early retirement pension due to unemployment and after part-time work for older workers, which had previously been used exclusively by men. In all these pension types, the 'punishment' with pension deductions have now expired and no longer determine the current pension access.

\section{Pension deductions}

In 2018, half of the pensioners had their pension (insured person's pension) reduced by deductions, which in concrete terms means that they did not or could not fulfil the requirements of increased retirement ages (for whatever reasons). Reconsidering the existing data, one can easily assume that this group is mainly the socially weak, the less qualified older workers, and those with severe health problems. How many of them belong to the group of immigrant workers cannot be evaluated exactly because there is simply no official data. The few available findings point to significantly earlier retirement dates and consequently to shorter work courses for the majority of immigrants (Söhn 2018). The following quote from Dirk Hofäcker (2015: 1529) is representative of many other authors. "Especially in countries with little employment support, those with unstable work careers, employment interruptions and few financial resources are at a high risk of being crowded out from late career employment and thus from the possibility of ensuring a decent standard of living." This idea has repeatedly been stated also in other studies and by other scholars, and is at least partially empirically based on the increasing number of older workers who think they will not be able to work until the age of 67 under the present working conditions (and many often do not in fact work until 67) (Naegele, Leve \& Sporket 2009; Kistler \& Trischler 2014; Naegele 2015; Hofäcker, Hess \& König 2018).

The number of new pensioners with deductions is particularly high in the new Federal states, namely about three quarters of all new pensioners. The amount of the deductions ranges between $10 \%$ and $15 \%$ of the unreduced pension. With the new standard retirement age of 67 , the deductions (3.6\% per year brought forward) add up to $14.4 \%$ for the pension most frequently drawn in 2018 for those long-term insured (35 years) when retiring at 63 . Until now, only the (currently very small) group of those older workers who have reached the precondition of a 'very long insurance period' of 45 years of compulsory contributions can transfer to a pension, but then after 65 these will be fully free of deductions (see section 5.3.2). However, when the legal retirement age is gradually raised to 67 , they will then also have to 
pay deductions for the period between 65 to 67 , up to a maximum of $7.2 \%$. But it can be assumed that these long insured (with a few exceptions, mostly men) have already acquired high pension entitlements from the old-age income security systems, i.e. presumably they can better cope with the comparatively small reductions due to pension losses. Furthermore, it can be observed that in the (most important) old-age pension for long-term insured persons since 2009, the average months of deduction have increased to about 27 months in 2017 (from 10 months between 2004 and 2017; Kaboth \& Brussig 2018).

Starting at age 50, insured persons may pay additional contributions to compensate for the deductions or limit their amount. However, in case of doubt, those employees who are most burdened by health problems and who want to or have to retire prematurely from working life can least afford the deductions or the purchase of deductions. In addition, further pension losses are caused by the fact that the number of years of insurance that can be taken into account is reduced if a pension is taken early, and therefore the pension is also lower. In the case of early pensions without deductions, on the other hand, it must be questioned whether the fulfilment of long waiting periods alone is a suitable yardstick for the health and occupational performance of employees.

Recent research in the context of the 2nd Age Transition Report (Altersübergangs Report) shows a widespread interest among insured persons in early retirement. The authors conclude that "[t]hose who have the opportunity to take early retirement also make use of it. Overall, individual resources, operational conditions and opportunities or restrictions on the labour market appear to be the decisive factors in determining whether gainful employment up to retirement age is possible" (Kaboth \& Brussig 2018: 12).

When it comes to solving the problems of those employees who cannot keep up with the policy of constantly raising the standard age limit, flexible age transitions come into view, which take into account the fact that the living, working, and health conditions of employees differ interpersonally. This observation argues for a greater variability in the early retirement ages, and the concept of a flexible retirement, which has been discussed for many years, must be revisited.

\subsection{Reducing and/or complicating disability pensions (2001, 2012)}

Early retirement via disability schemes - another often-used pathway into early retirement - was made increasingly difficult. In 2001, the distinction between disability (inability to work) and occupational disability (inability to work in the last job) was abolished. Especially for those born after 1960, status security vanished because employment in a different job (almost always with lower pay and lower status) was now considered appropriate (Bäcker 2012). In 2012, the official retirement age for a disability pension without deductions was gradually raised 
from 63 to $65 / 67$ years of age. Since then, deductions have also been introduced for early disability pensions (Bäcker, Naegele \& Bispinck 2020, vol. II); however, to compensate for these deductions, the objectives of vocational rehabilitation have been improved (see section 5.9).

\subsection{Redesigning the transition process into retirement}

\subsubsection{Introduction of gradual retirement in 1996 and its abolishment in 2009}

In 1996, the Federal Government started to subsidise an old-age part-time programme with the aim of delaying retirement. Employees who were at least 55 years old and had been working for three out of the last five years could use the scheme to reduce their working hours to $50 \%$ of a full-time equivalent. The resulting income from wages was decreased by only $20 \%$, financed via subsidies from the Federal Employment Agency and often complemented by additional money from the companies.

However, in the German scheme, workers could choose between real part-time work (half of the normal working time for six years) and the 'bloc model' (full-time for three years and then zero hours per week for three years). However, in practice, the scheme was increasingly misused more like an early retirement than as a 'real' gradual retirement scheme (Bäcker \& Naegele 2017). The scheme was abolished in 2009/10, when at that time more than $90 \%$ of the eligible older workers were using it as a 'bloc model into early retirement' (Brussig, Knuth \& Wojtkowski 2009). In 2014 Deller \& Pundt (2014: 170) stated that "Germany today still does not have a formal culture of bridging from full-time employment to full retirement."

\subsection{2 'Improving' the unsuccessful partial pension scheme introduced 1992}

Even earlier, namely in 1992, the Federal Government introduced a new public partial-pension scheme allowing workers who had reached the earliest possible legal retirement age to choose between paid work and pension payments in ratios of 1/3:2/3, one half:one half and 2/3:1/3. However, this law did not have any measurable success in terms of take-up rates due to resistance on the part of employers as well as older employees.

\subsubsection{Flexible pension act (Flexirentengesetz) (2017)}

A reform to make this program more attractive took place in 2017, when the Flexirentengesetz ('flexible pension act') was introduced (Bäcker \& Naegele 2017). Since that time, the public partial pension scheme has become more flexible in terms of ratios and additional earnings. The previous step-by-step regulation has 
been replaced by a sliding calculation method. ${ }^{19}$ So far, the take-up rates are rather disappointing, which this time is mainly due to the over-complexity of the regulations; however, it more general terms, the low rates of usage also reflect the repeatedly confirmed reluctance of older male employees in particular to work parttime shortly before retirement (which contrasts with the pattern often observed for women, see the previous section, 4.5) - men often experienced part-time work as 'discriminatory'. These patterns again mirror the previous failure of the idea of 'gliding retirement' (Bäcker \& Naegele 1992).

Social inequalities in access and use are also widespread for the undeniably positive dimensions that have been empirically confirmed for the use of the 'flexible pension act'. Here, social selection is confirmed: the participants are recruited predominantly from the middle and upper status groups in companies, who are in any case more likely to be able to afford to voluntarily work either less or longer, and who are additionally favoured by the support measures. If the companies have to agree to continued work (which is always the case with most measures that are not regulated by law but are based on the employer's will), the selection is made according to the company's needs. The positive reactions of companies with a high level of qualification and performance have been confirmed in keeping with the 'Matthew Effect' (see section 5.10.5 for further discussion of this effect). However, if measures are explicitly aimed at disadvantaged groups of employees, such as the ' 50 plus initiative' (see section 5.7), then nationwide successes are more likely.

\subsection{Promoting self-employment}

A program promoting self-employment has been aimed at (older) unemployed. Interested workers planning to start their own business are supported by a broad repertoire of tools, containing among other things financial assistance and consulting services ('Bridging allowance', after 1986), and also including founding allowances ('start-up subsidies' or Gründungszuschuss), special loans for long-term unemployed, as well as subsidies/loans for additional equipment expenses. Furthermore, since 2006, the construction of voluntary unemployment insurance (the self-employed do not normally have unemployment insurance) can give

\footnotetext{
${ }^{19}$ Before reaching the standard retirement age, up to 6300 Euros per year can be earned without reduction of the retirement pension. Any earnings in excess of this amount will be credited at $40 \%$ of the monthly pension. Only when the sum of the reduced pension and the additional earnings is higher than the previous income (best income of the last 15 calendar years) are the additional earnings above this amount credited $100 \%$ to the remaining partial pension, and the old-age pension is completely cancelled. The pension part that is claimed is reduced by deductions. However, this does not apply to the old-age pension without deductions for those who have been insured for a particularly long time. The additional income is fully subject to the insurance obligation in the GRV (Gesetzliche Rentenversicherung = Statutory old age income security system).
} 
especially those founders who were employed some security: if the business fails, they can fall back on (high) earnings-related unemployment benefits instead of means-tested (household level) benefits. In addition, self-employed silver workers are not treated differently from the non-self-employed. Overall, though, the take-up rates are very small and there has been no systematic evaluation. Since 2017, selfemployed persons have also been entitled to a re-entry allowance under certain conditions.

\subsection{Active labour market policies}

\subsubsection{Active and passive labour market policies}

In Germany, labour market policy generally includes all measures that are supposed to influence supply and demand on the labour market. A distinction is made between active and passive labour market policies. Active labour market policy has the goal of reintegrating the unemployed (e.g. from the problem groups of longterm unemployed and older workers) into the labour market. Passive labour market policy focuses in particular on alleviating the economic consequences of unemployment through wage replacement benefits such as unemployment benefit (insurance benefit), unemployment benefit $\mathrm{II}^{20}$, or short-time work benefit (also insurance benefit).

In the past, active labour market policy was mainly aimed at tackling overall unemployment. State employment programs, job creation measures, and qualification programs or measures to promote job mobility (addressed further in this section) was intended to help unemployed people to be reintegrated into the labour market. Many of them were older workers, however, in this section only those aimed explicitly at older workers/unemployed will be addressed. It needs to be remembered that among the unemployed, and particularly among the long-term unemployed (longer than 12 months), older workers $(55+)$ are strongly overrepresented (see section 4.3).

\footnotetext{
20 Unemployment benefit II (Alg II or ALG II for short, colloquially known as Hartz IV; decided to be abolished in April 2022) was a welfare benefit aimed at basic security benefit for those eligible for benefits in accordance with the Second Book of the German Social Code (SGB II). It was intended to enable those entitled to benefits to lead a life in keeping with human dignity. However, it could be reduced by a maximum of $30 \%$ through permissible sanctions. The subsistence minimum was not paid unconditionally (see also section 5.7.6).
} 


\subsubsection{From combating or alleviating unemployment to 'support and demand'}

According to the current view, labour market policy is no longer only aimed at combating or alleviating unemployment. For example, by promoting economic growth and improving competitiveness in international markets and reducing governmental regulation in the labour market, the aim is to improve the conditions for job creation by companies. In addition, there is an increasing focus on the personal responsibility of those affected by unemployment to seek work, and this focus is encouraged (or enforced) by reducing wage replacement benefits or unemployment benefit II according to the principle of 'promoting and demanding'. The Federal Employment Agency Responsible is responsible for active and passive labour market policies, and in many communities works together with the local authorities in so-called 'job centres'. In addition, employers' associations and unions can be seen as bearers of labour market policy (Frerich 2009; Duden 2016; Bäcker, Naegele \& Bispinck 2020, vol. I, II).

\subsubsection{Employment protection against dismissals}

In Germany there is no special age-related legal employment protection. However, many collective agreements provide seniority-protection, mostly based on a combination of both job tenure and chronological age (Bispinck 2016; Anlauft \& Feldes 2021; Guggemoos \& Conrads 2021). There is only weak empirical evidence about possible ambiguities ('boomerang effects') of collective agreements, indicating that these might hinder both the chances of recruiting older jobseekers (there are fears that they could not be dismissed at a later date) as well as those of younger workers wanting to enter companies (because the existing jobs are occupied by older workers covered by collective agreements) (Naegele \& Bauknecht 2017).

\subsubsection{Age-dependent wage subsidies to better integrate the older long- term unemployed}

In Germany, in some sectors, older workers' incomes are higher not because they are older, but because they have a longer tenure (and are therefore drawing de facto seniority wages). Hence, older unemployed workers have higher wages before unemployment than younger unemployed. As a result, their wage expectation towards new jobs are comparatively high, which can be a barrier to re-employment and negatively affect the hiring of older unemployed (Keese, Hirsch \& Bednarzik 2006; Bovenberg 2008; Frerichs 2009; Frerichs \& Taylor 2009). To alleviate this problem, the recruitment of workers over 50 can be subsidised for up to 36 months, paid as 'integration subsidies' (Eingliederungszuschüsse) according to §§ $88 \mathrm{ff}$. SGB III (see further in this section). The research institutes ZEW, IAB and IAW (2005) assessed the effects of integration subsidies for persons with short unemployment. These subsidies were found to increase the probability of re-employment, but the effect was not very high but also not negligible. 
Since 2017, an entry benefit (Einstiegsgeld) has been granted to jobseekers who have been unemployed for longer periods. It is a state benefit that can be paid as a supplement benefit to the integration subsidies when taking up self-employment or other employment subject to social insurance contributions. Unemployed persons are thus offered entry benefit as a financial incentive to overcome their need for assistance, in particular through certain forms of private business start-ups. The declared aim of the subsidy is not only to reduce the unemployed person's need for assistance, but to eliminate it permanently (Bäcker, Naegele \& Bispinck 2020, vol. I).

The wage protection scheme (Entgeltsicherung) (Frerichs 2009) for older workers provides incentives for the unemployed as well for those threatened with unemployment who have reached the age of 50 to take up work. If taking a new job entails financial losses compared to the remuneration from the previous job, the new remuneration can be supplemented for a certain period of time by benefits from the local Employment Agency. The period of entitlement is two years.

\subsubsection{Training subsidies}

In addition to paying subsidies to wages, the training of older workers and establishing the idea of lifelong learning has been on the policy agenda since $1990 \mathrm{O}$ (Frerichs 2009; Frerichs \& Taylor 2009; Hess 2017; see also section 2.2). A wellknown example is the initiative Weiterbildung gering qualifizierter und beschäftigter älterer Arbeitnehmer im Unternehmen (WeGebAU) (Further training of low-skilled and-employed older employees in the company), which since 2019 has been regulated in the Qualifizierungschancengesetz (Qualification Opportunity Act) (see further in this section). These initiatives are training stratagems of the Federal Employment Agency, which has existed since 2006 and which pays subsidies to promote vocational qualification for low-skilled and older employees $\left(45^{+}\right)$in companies (Duell \& Vogler-Ludwig 2012). An evaluation in 2009 showed that a total of 102,000 older workers used this program (Lott \& Spitznagel 2010). Its effectiveness is however under discussion, as Singer \& Toomet (2013) found that participating in training financed by WeGebAU did not improve the job stability of older workers.

Although essential for the employability of older workers, education and life-long learning still do not play a major role for German labour market policymakers and there is considerable room for further improvement of the employability of older workers. Especially in smaller companies and the trades, older workers rarely participate in any kind of training measures (Goebel \& Zwick 2010). Furthermore, when looking at the participation rate of older employees in training measures, initial education is found to be a decisive factor: almost $70 \%$ of older workers with tertiary education participated in some kind of further training, whereas the rate for workers without a formal education was less than 10\% (Schmidt 2009). 


\subsubsection{Unemployment reforms following the Hartz commission (2004-} 2018)

In 2002, a commission called 'Modern Services in the Labour Market' (also called the Hartz Commission, named after Peter Hartz, former human resource manager and chairman of the board of Volkswagen AG) was established by the Federal Government with the explicit aim to reform the unemployment scheme (see also section 2.3). Following its recommendations, earnings-related unemployment benefits were reduced, but the payment duration still partly depends on age and previous employment duration. In most cases, after 12 months of unemployment, earnings-related unemployment benefits are substituted by low means-tested benefits.

Previously, long-term earnings-related unemployment benefits had been used to bridge the time between work and retirement (Dlugosz, Stephan \& Wilke 2009). The main argument was that lower and shorter benefits reduced unemployed people's reservation wages (in other words, they would be more willing to accept low-paid jobs - reluctance to accept low-paid jobs is known to be an important barrier to re-employment, Dietz \& Walwei 2011). Furthermore, decreased generosity would reduce incentives to use unemployment as an early retirement scheme (Duell \& Vogler-Ludwig 2012), which would mean expecting the unemployed to be more active in job searches and to be more prepared for job acceptance (Brussig 2016). The underlying idea can be seen in the well-known concept of 'support and demand' (Fördern und Fordern) (Frerichs 2009; Frerichs \& Taylor 2009; Brussig 2016).

In addition to other reforms, the Hartz Commission recommended termination of the unemployment assistance (Arbeitslosenhilfe), which was a welfare benefit and has been calculated in accordance with the equivalence principle as a form of wage-replacement but at a somewhat lower level than the previous unemployment benefit (Blank 2020). Instead, a new basic income support for job seekers (Arbeitslosengeld II) was introduced which was strictly means-tested and where increased conditionality criteria were attached ${ }^{21}$. These changes were considered radical divergence from the traditional German wage-related welfare system according the equivalence principle (Blank 2020). In the wake of these reforms, long-lasting unemployment benefits for older workers (up to 32 months), which had been established in 1987 to ease the negative effects of unemployment for older workers, were cut to a maximum of 18 months for workers over 55 . In 2008, this

${ }^{21}$ According to the decisions of the new federal government ("traffic light coalition"), this benefit is to be abolished and transferred to a general citizen's income (Koalititionsvertrag 2021). Critics, however, do not see this as a fundamental improvement in performance and speak of "old wine in new wineskins". 
measure was partly revised so that eligible older workers were allowed to receive up to 24 months of unemployment benefit. In the wake of the Hartz Reforms, the principle of 'support and demand' has been tightened by profiling measures for the unemployed in general and specific support for older unemployed people (Brussig 2016). These changes have resulted in increasing cases of not meeting the necessary criteria to be re-integrated easily, and in its wake, rising cases of poverty among older unemployed, particularly in the territories of former Eastern Germany (see section 5.3.2).

\subsubsection{The Federal Initiative '50plus' (2005-2015)}

In addition to the Hartz reforms, several active labour market approaches have been particularly aimed at older workers: for example, there were various types of wagesubsidies to decrease their labour costs in case of recruitment, various measures to increase employability (e.g. training subsidies; see further in this section), and efforts to improve the hiring process. The measures have been combined into a bundle and marketed within a national programme under the label of 'Perspectives 5oplus - Employment pacts for older workers' and these include 78 regional employment pacts with local job centres. The pacts included further vocational training, job application training, internships, and wage subsidies. Individual counselling and coaching were considered crucial parts of the program. The program activated around a third of the older long-term unemployed and placed about a seventh of them back in the regular labour market. Some of these received wage subsidies and only a minority of those leaving unemployment also exited public financial support, partly due to the high share of part-time workers among the re-employed. The high share of part-time workers resulted from the fact that part-time work was more stable, since participants in the programme had often reduced capabilities.

Results for the project are so far considered to be positive (Duell \& VoglerLudwig 2012), since a high share of older long-term unemployed people were activated. Yet the share of those older than 60 was low and the mean age was 54, so the programme activated the 'young old', which is a group that is easier to bring back into work than the 'normal old'. For methodological reasons, a clear evaluation is difficult, but results rather point into a positive direction (Knuth et al. 2012). 


\subsubsection{Mixing of existing legal instruments and priorities in employment promotion for older worker, the current instrument of the Federal Employment Agency ${ }^{22}$}

The measures listed below are part of the general pool of instructions of the Federal Agency of Labour for the Integration of the Unemployed. These measures are also applied to older, mainly long-term unemployed people. However, older people have been underrepresented among benefit recipients for years. The age structure of participants in labour market policy measures has changed due to the fact that older workers are more affected by unemployment, and the share of people aged 60 to 64 who are unemployed has increased considerably. However, older people (55 to 64 years) continue to receive significantly less support than younger people. The focus of support for older people differs significantly from that for younger people. Among older people, promoting continuing vocational training has increased in importance, but only in the legal sphere of SGB III (unemployment insurance). The proportion of older people who have taken up employment after completing a measure is almost always smaller than that of younger people, and in some cases considerably smaller. Often an explicit EWL reference is only indirectly recognisable and given in practice.

- The instrument of activation and vocational integration (Förderung der Anbahnung oder Aufnahme einer versicherungspflichtigen Beschäftigung, $\S \S 44 \mathrm{ff}$. SGB III) aims to strengthen and support the employability, orientation, and initiative of jobseekers. This includes, among other things, measures with an employer (e.g. internships or in-company training measures) which are used to determine the suitability of the unemployed person for a job and to provide them with vocational orientation. At the same time, employers' reservations about the unemployed person are to be reduced by testing the unemployed person concerned. Another measure that belongs to this instrument is the placement budget. This individual form of support involves the assumption of costs to support the taking up of employment subject to social insurance contributions. Typical costs that are taken over are, for example, application and relocation costs.

- The instrument of taking up gainful employment (Eingliederungszuschuss, §§ $88 \mathrm{ff}$. SGB III) includes measures aimed at promoting a concrete start to gainful employment (see above). The measures are mainly aimed at jobseekers whose placement is difficult due to personal factors and who are expected to underperform at least when entering employment, e.g. due to 
long periods of unemployment. To compensate for this underperformance, employers can be granted wage subsidies if they hire unemployed persons. These subsidies are limited in time because it is expected that the underperformance will only exist initially and will cease after a training period. The duration of the subsidy is to be assessed on a case-by-case basis. It can be up to 36 months for older persons who have reached the age of 50 . The instrument is not only for placement in dependent employment, but also promotes self-employment (e.g. through the start-up grant, see the previous section, 5.6).

- $\quad$ The instrument of continuing vocational education and training (CET) (Förderung der beruflichen Weiterbildung, $\S \S 81 \mathrm{ff}$. SGB III) is used to support both unemployed and employed persons in order to permanently increase (re-)employment opportunities or to prevent unemployment. The prerequisite is that there is a need for further training (e.g. for occupational integration), a counselling interview has taken place prior to participation, and the measure and the provider of the measure are approved. Qualificationrelated CET is offered as well as CET for the acquisition of basic skills (e.g. reading, writing or computer skills). Depending on the educational objective or qualification content, further prerequisites regulated in SGB III must be fulfilled.

- $\quad$ Employment-creating measures are only provided for in SGB II (Arbeitsbeschaffungsmaßnahmen, §§ 16 in SGB II) and, in contrast to the instruments explained so far, are aimed at employment beyond the general labour market. These employment relationships are also referred to as publicly funded employment relationships or as employment on the 'second labour market'. Depending on the exact form of the funding conditions, these relationships serve both to introduce people to employment in the general labour market and to promote the social participation of people who are permanently unemployed, and they can also be used to improve the public infrastructure. These include, in particular, work opportunities ('1-Euro-Job') and the promotion of employment relationships. The latter is a wage subsidy limited to 24 months for employers who employ jobseekers subject to social insurance contributions. The difference to the integration subsidies in SGB III is that, on the one hand, no underachievement is required, but rather there must be some obstacle to placement. On the other hand, only the long-term unemployed (unemployed for at least 12 months) who have at least two other placement obstacles in addition to the duration of unemployment are supported. 


\subsection{EWL-aimed learning and training - Germany on the way to an institutionalised vocational life-long-learning (LLL)}

\subsubsection{Vocational LLL in the service of EWL}

The concept of (vocational) life-long-learning (LLL) was already mentioned and discussed in Europe in the 1970s and afterwards made more prominent in the 'European year of Lifelong Learning' in 1996. The Memorandum of the Lisbon Europe Council in 2000 declared that

... lifelong learning must accompany a successful transition to a knowledgebased economy and society [and] must become the guiding principle for provision and participation across the full continuum of learning contexts. The coming decade must see the implementation of this vision. ${ }^{23}$

In the current discussion in Germany about the paradigm shift towards the promotion of EWL, the idea of LLL plays an important role, but not a prominent position, which is reflected in the comparatively low funding figures. To put it briefly, more is reported and talked about regarding the possibilities of LLL than it is used as an additional instrument to promote the readiness for EWL and to invest in its practical implementation. It was true for many years and is still true today that in Germany, vocational education and training is 'front-loaded', i.e. it is geared to the early parts of the acquisition phase (Bosch 2010).

Vocational LLL includes formal, non-formal, and informal education (definitions to follow). Training intended for professional education in institutions (universities and so forth) is categorised as formal education. These are courses within the general education system that end with a certified degree. Non-formal vocational training is provided by the enterprises (in-company continuing training) or is carried out individually (individual job-related continuing training). Informal learning implies learning through experiences gathered in certain stages of the individual (working) life course. Previous results have shown that, for older people and therefore also older workers, learning works best when it has been adapted to their special needs, e.g. learning should be application-oriented and needs to correspond to the utility value. These adaptations are particularly needed for vocational training aimed at older workers (Bäcker, Naegele \& Bispinck 2020, vol. I). Research investigating German workers has shown that older workers dislike formal activities (Naegele \& Bauknecht 2017).

\footnotetext{
${ }^{23}$ Commission of the European Communities (2000): Commission Staff Working Paper, A Memorandum on Lifelong Learning, p.3. Available at arhiv.acs.si/dokumenti/Memorandum_on_Lifelong_Learning.pdf.
} 


\subsubsection{Facts about continuing vocational learning}

In-company training is by far the largest segment of adult learning in Germany, accounting for around $70 \%$ of all continuing training activities. In recent years, incompany training activities have increased because of the pressure of impending shortages of skilled workers. There are also individual job-related continuing training programs organised and financed privately and offered by a wide variety of providers and organisations. Distance learning courses have gained in importance, and universities and technical colleges have also entered the adult learning market recently. Despite these trends, for many years, Germany has had no systematic (institutionalized) legal regulations about or promotions of further education for adults.

Lifelong learning in Germany was (and is still) closely linked to one's current job and tends to concentrate on professional skills, although it is generally thought that further vocational education and training should be flexible and adapted to the needs of the overall labour market and not only to a particular company's needs. Data from studies in Germany also show that in company-initiated further training, the 'Matthew principle' often dominates: those already highly qualified are overrepresented (see section 5.10.5), and the principle especially applies to older workers with special qualifications who are deemed to be of outstanding significance for a company's objectives. In Germany, employers are not required by law to provide training, although collective and/or company agreements in certain sectors might require training (Naegele \& Bauknecht 2017).

\subsubsection{Recent participation and funding figures}

The trend of workers participating in continuing vocational training measures has been clearly declining for years. Since 2005, the number of employees who have received assistance for training has been well below 200,000, and in 2018 the figure was around 149,000. Only $35 \%$ of those who receive assistance are in the legal category covered by Book III of the Social Code (SGB III), which covers two thirds of all unemployed persons.

To a large degree, the decline in participation mirrors a decline in funding (see Figure 16). However, declining participation is not the result of a reduced need for qualifications, but rather a consequence of the reorientation of the funding and business policy of the Federal Employment Agency. The promotion of continuing vocational education and training has become less and less important compared to direct placement. In particular, longer-term qualifications (graduation-related measures) have been reduced. The focus now is on the goal of direct applicability of qualifications and rapid placement in employment. Short-term successes, tied to strict funding criteria, determine the allocation of funding. 
Figure 18: Persons sponsored in continuing vocational training 1994-2018, in thousands

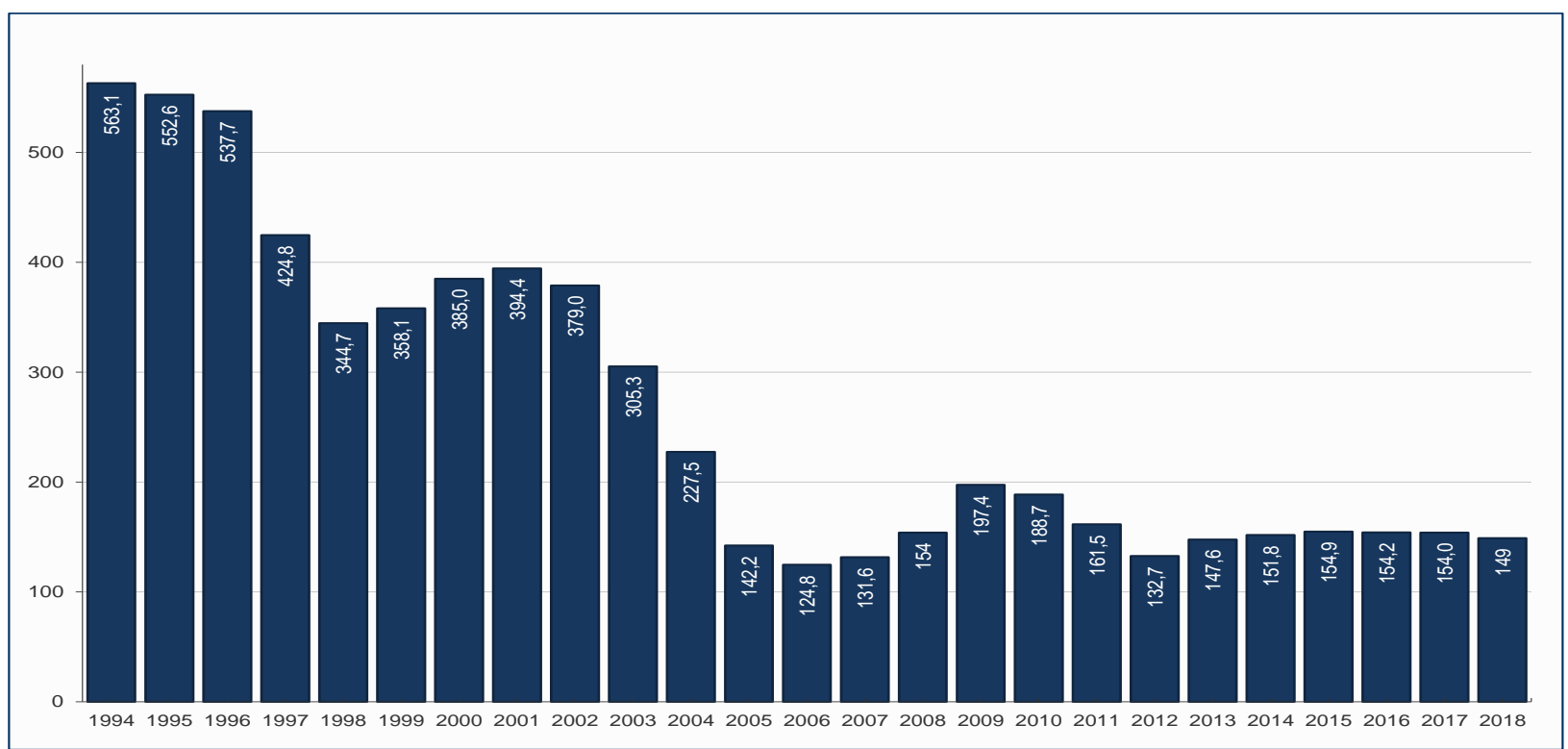

Source: Bundesagentur für Arbeit (last 2019), Arbeitsmarktberichte und Arbeitsmarkt in Zeitreihen.

Available data indicate that there are large discrepancies in the supply and take-up of continuing vocational training in terms of sectors, company size, and employee groups. Employees in micro, small, and medium-sized enterprises, employees in precarious employment, and low-skilled workers are especially disadvantaged. However, a reversal of this restrictive orientation has been discernible since about 2015. Several amendments to Social Code Book III (see section 5.7), most recently the Qualification Opportunities Act (Qualifizierungschancengesetz, see further in this section) have expanded not only the objectives of subsidised continuing training, but also the circle of those explicitly entitled to receive it.

\subsubsection{Protection of qualifications in Germany's social law}

In a number of labour and social law regulations, the German welfare state guarantees protection of occupational status and thus also of qualification in certain cases where there are social risks. However, this protection is quite limited, has been reduced, and is usually only related to income. With regard to the protection of vocational skills, the following regulations are of particular importance:

- In case of unemployment, one of the objectives of employment promotion according to Social Code Book III (SGB III) is to counteract substandard employment, which corresponds to a certain status protection. Unemployed persons who are entitled to unemployment benefits may refuse 'unreasonable' employment. 'Reasonable'-ness means that graduated regulations apply with 
regard to the amount of remuneration: In the first three months of unemployment, a 20\% reduction in gross salary is considered reasonable, and in the following three months a 30\% reduction. From the seventh month onwards, all employment is reasonable if the net income does not fall below the level of unemployment benefit.

- In contrast, for unemployed persons within the legal scope of the SGB II, any employment relationship is reasonable, provided it is not against the law and good morals, irrespective of previous income or qualifications. Nor is the objective of avoiding subordinate employment found here.

\subsubsection{Supported further education according to Social Code Book III and II (SGB III and II)}

In Germany, the continuing vocational training of employees is first and foremost the task and obligation of enterprises and the appropriate social partners, which must ensure (for their own interest) that their personnel are able to meet the changing demands of work in terms of qualifications. However, continuing vocational training can be financed by public funds if there is a particular political interest in doing so and/or if certain groups of persons have not been reached by the company measures. Public financing is particularly relevant for unemployed persons and for low-skilled or insufficiently qualified employees who have no access to continuing vocational training in enterprises and who cannot afford to finance continuing training themselves.

The promotion of vocational education and training in accordance with Book III of the Social Code (also valid in the basic provision for job seekers/SGBII) is intended to close this gap, and represents the core area of preventive and active labour market policy (see section 5.7). The support consists in coverage of the costs of further training and the payment of unemployment benefits during participation. This program is not a legal entitlement, but an optional benefit, the granting of which is at the discretion of the authorities. However, in 2018, this program has been changed by the 'Qualification Opportunity Act', which in principle favours many of the group not covered hitherto (see further in this section). The regulations on further training support in accordance with SGB III also apply to the basic provision for job seekers. Employees can be supported if further training is necessary to integrate them into the labour market when they become unemployed, or to avert the threat of unemployment.

\subsubsection{Promotion of further training during employment}

Both the unemployed as well as employed workers can, under certain circumstances, also benefit from a subsidy if its legal requirements are met. This subsidy applies in particular to those who lack usable vocational qualification, or whose previous jobs are no longer needed. Workers who have completed their vocational training but have been employed for at least four years in semi-skilled or 
unskilled work and are no longer able to carry out the activity they have learned ('occupational alienation') can also be subsidized to earn a vocational qualification. In addition, under certain conditions, employees who have left school without a certificate are entitled to have the costs of continuing education and training for obtaining a lower secondary school certificate paid for. It is required that the employer also pays the remuneration for periods of time during which no work is done because of the further training. Finally, workers who have not yet received vocational training may receive support for the acquisition of basic skills (in particular in reading, writing, mathematics and information and communication technologies) if this is necessary for successful participation in a final vocational training measure. Unemployment benefits are paid throughout the period of the measure, even if the entitlement would expire during this period. Anyone who is entitled to unemployment benefit II and takes part in a continuing vocational training measure pursuant to Social Code Book III will continue to receive unemployment benefit II. 2018, and the Qualification Opportunities Act (Qualifizierungschancengesetz) has further strengthened this option.

\subsubsection{The National Continuing Education Strategy (2018)}

In the meantime, the framework conditions for effective LLL have further improved. Since 2018, it is possible for the first time to speak of increasing public responsibility for LLL. The new Federal endeavours are part of the initiative 'Qualification Offensive - Knowledge and Security for Change' which resulted in implementing the 'Qualification Opportunity Act' also in 2018

(Qualifizierungschancengesetz) (see next subsection). In their explanatory memorandum, the Federal Government explicitly refers to "immense challenges", such as "an ageing society with fewer available workers. The digital transformation in particular is bringing about a rapid technological change that is fundamentally altering the world of work. We will not run out of work in the future. However, digitisation and automation will change job profiles and activities. ... According to current studies, one in four employees in Germany could be affected by automation in the coming years and have to reorientate themselves professionally. Profound changes are also to be expected for employees in occupations that will remain. The OECD assumes that more than 35 per cent of all occupations will be fundamentally transformed by 2030. Good work under the auspices of digitalisation therefore requires systematic development of the skills of all employees. The majority of people who will be employed in 2030 are already in work today. Therefore, the right course must be set now in order to actively accompany and support those in employment in their processes of change and adaptation. Therefore, the central answer to the digitally driven structural change is the qualification of employees.... By joining forces, we will succeed in securing prosperity and competitiveness in the future. Together, we must ensure that all workers have the opportunity to acquire the right skills and qualifications to be able to move safely in the labour market. In 
the interest of securing skilled labour, it is also important to renew qualifications through further training” (BMAS 2018b: 1).

\subsubsection{The Qualification Opportunities Act (2018)}

To implement the National Continuing Education Strategy (CET), the Qualification Opportunities Act (Weiterbildungschancengesetz) came into force in 2018. Central to this act is the right to further training guidance and financial support for these measures. Employees, regardless of qualification, age, and company size, will have access to if there is a need for CET, which mainly pertains to digital structural change or structural needs in some other way. Support is also aimed at those who are seeking further training in a bottleneck occupation. Skilled workers, low-skilled workers, and unskilled workers are to be encouraged to acquire additional qualifications or to catch up on their qualifications. For companies, the law is also a good opportunity to develop and retain their own skilled staff in the course of digitalisation, which is especially important in view of the shortage of skilled workers in technical professions in particular.

The assumption of training course costs and the payment of wage subsidies are in principle subject to co-financing by the employer. The employers' shares of the costs depends on the size of the company: larger companies must participate more than small or medium-sized enterprises. It is assumed that the skills, knowledge and abilities imparted go beyond exclusively job-related short-term adaptation training, that the vocational qualification was generally acquired at least four years ago, and that the measure is carried out outside the company or by an approved institution in the company to which they belong. At present, there has been no systematic evaluation of the effects of this Act.

\subsubsection{Latest news from Germany`s adult education policy (12/2021)}

The "traffic light coalition" that has been in power since December 2021 is now also bringing movement into the statutory continuing education landscape. The coalition agreement of November 2021 literally states (Koalitionsvertrag 2020: 67f.); "In times of digital and demographic change, a targeted National strategy is an essential prerequisite for achieving our economic and societal societal goals. We are improving opportunities for professional reorientation, training and continuing education - also on a part-time basis. We are coordinating the instruments of education policy and active labour market policy are coordinated.

In order to support personally motivated lifelong learning, we are expanding the upgrading Federal Training Assistance Act (Bundesausbildungsförderungsgesetz; BAföG) open up the maintenance allowance for part-time training, promote training at the same level as the at the same level of the German Qualifications Framework and also for a second fully qualified education.

We are significantly increasing the funding rates and allowances and closing the funding gaps to BAföG. The aim is to ensure that upgrading courses and 
examinations are free of charge at reasonable prices. With the BAföG life chances program (Lebenschancenförderungs-BAfö $G$ ), we are creating a new instrument for self-determined beyond vocational and degree-related qualifications for everyone. To this end, we are creating a simple way to save for education in a free account. People with low incomes receive annual subsidies for this.

With an education (part) time scheme based on the Austrian model, we offer employees financial support for labour market-related employees financial support for labour market-related training. This enables them, for example, to catch up on a vocational vocational qualification or a new career orientation. The prerequisite is an agreement between employer and employee.

For people who are unemployed and receiving basic benefits, we are expanding the independent promotion of basic skills. skills and make it clear that job placement does not take precedence over vocational training and continuing education. vocational training and continuing education that strengthens employment opportunities. In the case of vocational further training SGB II and III beneficiaries will receive an additional monthly training allowance of 150 , thus creating an effective incentive for further training. After further training, people should be entitled to at least three months' unemployment benefit."

\subsection{Health promotion, prevention, protection and rehabilitation}

Germany's health policy around the issue of work and retirement has traditionally been dominated by the objectives of, first, prevention of ill health and second, rehabilitation before retirement. However, little attention has been paid to the realisation of these objectives for a long time. Meanwhile, in the long phase of early retirement and releasing old age from the world of work (see section 2.2), the order of objectives can even be said to be reversed: Early exit from work through related premature reduction/loss of health-related earning capacity and leaving labour market via disability pathways have been widely used options for early retirement. However, the change of paradigm led to a remarkable 'rediscovery' of this classic primacy, but also at the cost of social inequalities.

\subsubsection{Premature reduction/loss of health-related earning capacity (Minderung der Erwerbsfähigkeit)}

Since the reform of reduced earning capacity pensions which came into force in 2001 (see section 5.4), approval of reduced earning capacity has been based on health capacity. Since then, the distinction between disability and occupational disability no longer applies. The standard that applies today is whether and to what extent the earning capacity is still available and thus could generate an income through paid work. 
Premature reduction of the earning capacity was and still is a key driver for health-related involuntary (forced) early exit from working life of those under age 6o. Numerous factors of social inequality accumulate because people from the lower social strata or workers with low educational and vocational qualifications in occupations, jobs and sectors that are also particularly burdened by heavy physical and psychical work-loads are disproportionately affected (Bäcker, Naegele, Bispinck 2020, vol. I). Professional care-workers in the LTC (long-term care) sector are considered to be particularly affected (Christofczik 2020; Merkel, Holman, Ruokolainen, Hess 2020; Reichert 2021). There has also been evidence for years of an increase in reduced earning capacity due to mental illness, especially among older working women. Although there has been a downward trend in reduced earning capacity pensions since 1996 , when it was around $25 \%$, to $2006 / 2007$, when it was around $17 \%$ (measured in terms of the share of all new pensions in the statutory old-age income security system), this proportion rose slightly and was around 18\% in 2018 (see Figure 19). In other words, just under one in five employees loses their full earning capacity prematurely for health reasons and must therefore apply for a pension.

Figure 19: Old-age and reduced earning capacity pensions (1996-2018)

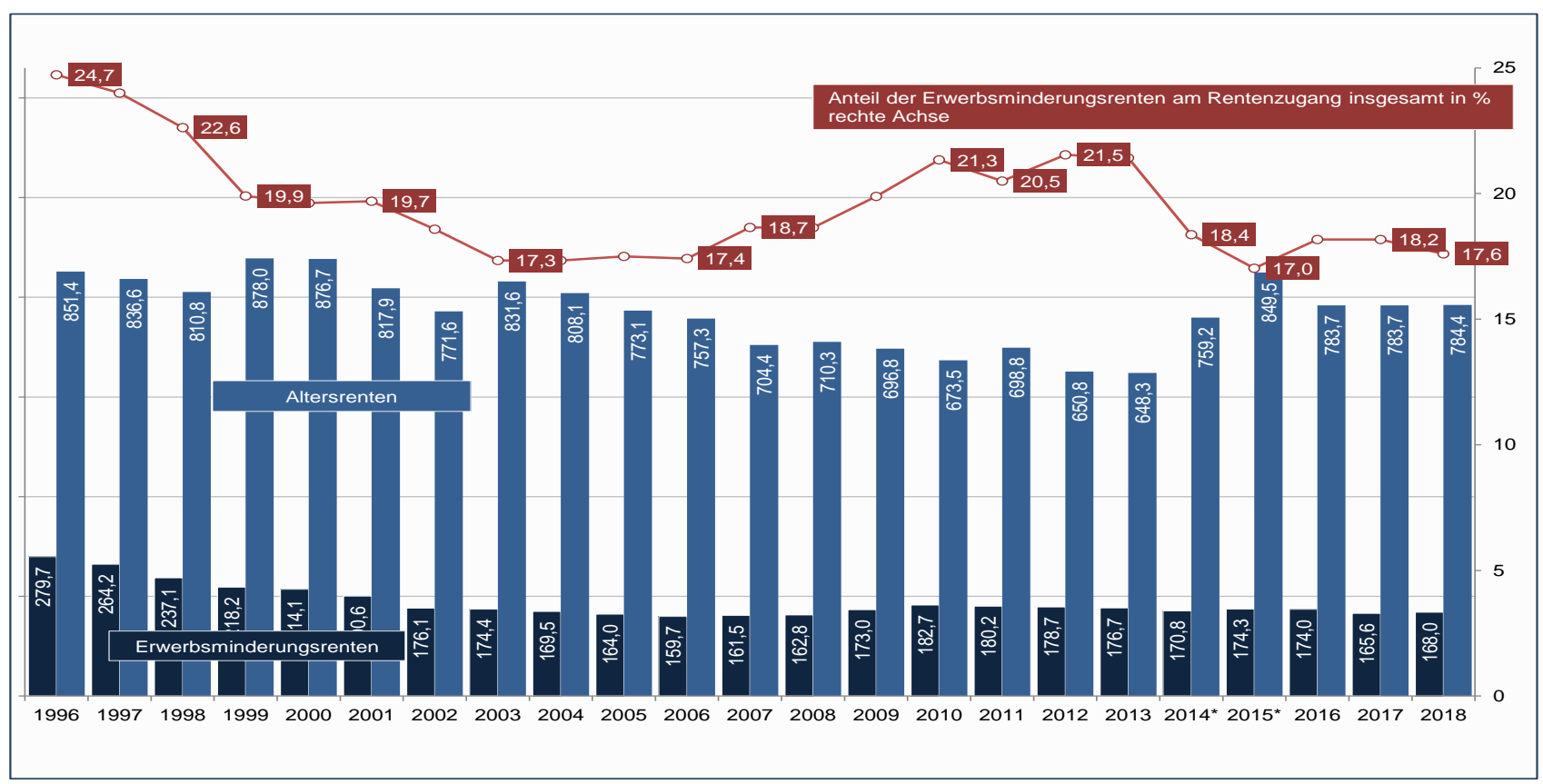

Red line: Share of disability pensions in total pension receipts in \% Right axis.

Blue crossbar: old-age pensions

Dark blue/black crossbar: Disability pensions

Source: Deutsche Rentenversicherung Bund (last 2019): Rentenversicherung in Zahlen. 


\subsubsection{Terms and objectives of health promotion, prevention, protection and rehabilitation}

Health promotion, illness prevention and vocational rehabilitation can be seen as important policy concepts when it comes to avoiding premature reduction in earning capacity, and these measures play key roles in realising EWL. The term 'health promotion' is usually understood above all as the non-specific measures for maintaining health, and is a matter of disease prevention in the broader sense. Workplace health promotion is one of the legally regulated tasks of health funds in Germany. In contrast, preventive health policy can be seen as a special strategy of action within a comprehensive public health concept. These policies aim at preventing or delaying the onset of (mainly chronic) diseases through various measures, and are based on the recognition that individual diseases, to varying degrees, can be caused by factors in work, life, and the environment. The core area of preventive health policy therefore also includes the containment of work-related health risks. Finally, rehabilitation is devoted to the consequences of illnesses. Rehabilitation is intended to restore one to the state of health before an illness, or at least to prevent aggravation or secondary diseases, and to bring about professional and social reintegration, at least as far as is possible (Bäcker, Naegele, Bispinck 2020 , vol. I). The most important target group for health promotion and prevention in the world of work is employees in generally unfavourable living conditions. Special efforts will be required to reduce health-related social inequalities in this setting (Pott 2017).

\subsubsection{Prevention Act, a new law to strengthen health promotion and prevention (2015)}

In part because of demographic change, a law to strengthen health promotion and prevention ('Prevention Act') was passed in 2015. This Act improves the basis for cooperation between social insurance institutions, the Länder and local authorities in the fields of prevention and health promotion for all age groups and in many areas of life, among them older workers in companies. After all, prevention and health promotion should be effective where people live, learn, and work, whether in workplaces, in day-care centres, in schools or in nursing homes. By explicitly referring to people's living environments ('lifeworld-related prevention', lebensweltbezogene Prävention) and the real risks that exist there, behavioural prevention, which previously dominated prevention activities (and thus with a high risks of excluding lower social classes), has been expanded to include the important dimension of relational prevention. A national prevention strategy is on its way to being developed within the framework of a national prevention conference, the aim of which is not only to increase people's health competence but also to work towards living environments that are beneficial for health. The basis for prevention in the 
workplace setting should be a workplace-risk assessment (Bäcker, Bispinck \& Naegele 2020, vol. I).

Workplace-related prevention includes concepts such as healthy workplace design (work tasks, work organisation, working environment), health-friendly working time regulations, addressing the effects of addiction, stress, or violence at work, burdens typical for the sector (e.g. in long-term care), special burdens due to increasing digitisation of work, and so forth. Unemployed workers are also considered an important target group for health-promoting measures and prevention. There are particular implementation difficulties for adequately reaching employees in small and medium-sized enterprises. Social inequalities are thus generated less by socio-demographic personal characteristics (although these also play a role), and more by differences in company size.

\subsubsection{Common German Strategy for Occupational Safety, or GDA (Gemeinsame Deutsche Arbeitsschutzstrategie)}

GDA was implemented in 2009 and it aimed to promote occupational health and safety by means of preventive occupational health care and is a long-term platform of the Federal Government, the federal states, and accident insurance institutions anchored in the Occupational Health and Safety Act and the Social Code VII. The aim of this alliance is to continually modernise Germany's occupational safety system in light of changes in the work world and to create incentives for companies to further strengthen the safety and health of their employees. The aim is to achieve practical improvements for employees in occupational health and safety in consultation with the social partners. To this end, GDA's members agree on joint health and safety objectives, improved advisory concepts, and monitoring practice as well as comprehensible rules and regulations. These jointly developed health and safety objectives are implemented in nationwide work programmes. GDA's work programmes are aimed in particular at companies - in other words, they support entrepreneurs, managers, employees, and occupational health and safety experts in the concrete design of occupational health and safety.

\subsubsection{Mental health diseases, a new health-risk factor}

A few years ago, the issue of mental diseases (of older workers) was identified as an increasingly relevant driver of both sickness days as well as of (early) disability pensions and vocational/medical rehabilitation. Female workers were particularly often affected. In 2013 the German Parliament changed legislation to encourage employers to strengthen their endeavours to prevent work-related mental strain. GDA (Gemeinsame Deutsche Arbeitsschutzstrategie or Common German Strategy for Occupational Safety, see previous section) developed guidelines that help employers detect and eliminate the various risk factors (GDA 2016). 


\subsubsection{Vocational rehabilitation}

Vocational rehabilitation is a summary term for certain social benefits for rehabilitation. The pertinent law (SGB I) also refers to vocational rehabilitation as benefits for participation in working life. Vocational rehabilitation serves to regain the ability to work and to secure an earned income in the general labour market. The vast majority of recipients are older workers over 50, but (most of them) under 60.

In contrast to its predecessor regulations in the former law on employment and occupational disability, the new law on reduced earning capacity (in force since 2001) no longer asks about the qualification of the person with reduced earning capacity, but only about how many hours (3 or 6) he or she can still work per day. However, when assessing reduced earning capacity, the state of health should not be taken as an abstract starting point, but it must also be examined (within the framework of the concrete approach, konkrete Betrachtungsweise) whether the insured person is actually able to convert his or her residual capacity into gainful employment in an existing job. A reduced earning capacity pension can be granted even if significant earning capacity is still available, but no suitable job can be found. In the past, this loophole was often used to circumvent the increased requirements of the law.

In the past decades, underlying health problems that have resulted in individuals receiving disability pensions have changed substantially, from musculoskeletal diseases (which was the leading disease in the past) to mental health problems (which dominate today). Since 2014, the provisions of rehabilitation services aim primarily to maintain or restore the capacity to work: "Following the general principle 'rehabilitation before pension', this program's primary aim is to try to avoid early exit from the labour market due to health problems by providing medical care and vocational integration measures. If rehabilitation is not possible, individuals who cannot work due to health issues can opt for a disability pathway" (Romeu-Gordo \& Sarter 2020: 276). The possible benefits include in particular:

- focusing on prevention and rehabilitation,

- voluntary health check-ups from the age of 45 onwards,

- $\quad$ assistance in maintaining or obtaining a job, including activation and occupational integration services, e.g. retraining, further education, and vocational training,

- individual in-company training in the context of supported employment,

- formation subsidy according to $§ 93$ SGB III,

- $\quad$ other aids to promote participation in working life in order to enable and maintain appropriate and suitable employment or self-employment for disabled persons, such as motor vehicle assistance, the costs of any necessary work assistance, or the costs of technical work aids for designing workplaces suitable for disabled persons, 
- $\quad$ various subsidies to employers for the training allowances and wages paid.

\subsubsection{Company-based operational integration management (BEM)}

BEM aims at overcoming a health-related incapacity to work in the run-up to early retirement within the framework of the early age limits for severely disabled persons, among them many older workers, preventing renewed incapacity to work and preserving the jobs of those affected. BEM is aimed primarily at employees in small and medium-sized enterprises.

According to $\S 167(2)$ of SGB IX, every employer is obliged to have a BEM if an employee has been unfit for work for more than six weeks straight or for a total of six weeks during the past twelve months. In order to determine the group of persons concerned, monthly evaluations of the employees' sickness rates are collected by the responsible personnel department. In the case of repeated incapacity to work, the condition for initiating the BEM procedure can be fulfilled after a total of more than 30 days of absence (sick days) or 42 calendar days within the past twelve months. The employees concerned are invited in writing to join the program. This invitation means that the procedure is subject to the employee's free will. Should the employee reject the offer, the procedure would be concluded at this point. The employer would then have the opportunity to examine whether further measures outside the BEM (e.g. of a labour law nature) should be taken.

From the perspective of social inequality, it should be noted that the practical implementation of this legal requirement for BEM is not universal and there is still a need to catch up, especially in small and medium-sized enterprises. Around threequarters of works councils state that a BEM is offered. In companies with fewer than 50 employees, the figure is around $73 \%$, and in companies with 500 or more employees, it is as high as $91 \%$. These figures are surprising considering that BEM was aimed at smaller enterprises.

\subsubsection{Personal health promotion through practicing health competence}

Against the background of increasingly positive cohort and level effects in future cohorts of older workers, the topic of individual health promotion has gained in importance. Individual health promotion is one's personal responsibility for maintaining and improving health as the most important dimension of an individual's ability to work and be employed. Here, particular social inequalities become apparent, since the abilities to perceive, assess, and take personal precautions in the case of work-related health risks are by nature socially unequally distributed (Pott 2017). Empirical studies from Germany focused on working women $(50+)$ look at individuals' assessments of their chances to realise a longer working life; these have shown a very high allocation of personal responsibility and willingness to promote own health status as one of the prime preconditions for a longer working life. The most frequently mentioned measures practiced on one's 
own to retain an ability to work include doing sports, eating healthy food, having a healthy lifestyle, and "staying mentally fit" (Heien et al. 2018).

\subsection{Corporate HR (CHR) strategies and corporate management of age and ageing}

\subsubsection{CHR as a tool to promote EWL}

As already briefly mentioned (see section 2.2), more and more employers are implementing various human resource measures (age and ageing management) aimed at sustaining the ability of their older employees to work and be employed, thereby keeping them in their own companies. 'Stay' and 'retain' interests have become of increasing importance at least in some sectors, but are clearly focussed on company and workplace-needed skills and qualifications. However, there are clear social inequalities among the distribution of these interests and the corresponding usage figures (see section 5.10.5). Nevertheless, corporate management of age and ageing is in line with a general assessment according to which "the decision for or against gainful employment for older workers is made in the companies and is primarily to be influenced there" (Naegele 1992: 280f.). The 6th Federal Report on Ageing (see section 5.12) and the MOPACT WP 3 project (Naegele \& Bauknecht 2017,2019 ) update and justify this statement with regard to EWL as follows:

Organizations play an outstanding role in promoting EWL. Age- and ageingmanagement needs to be developed and implemented. ... The concepts of workability/employability are the best points of departure, with a need to differentiate between both small and large employers as well as between industries. When introducing EWL-aimed personnel policies companies' actions are highly dependent on HR leaders' attitudes. There is an urgent need for both active involvement of works councils and 'end users' as well as a 'demographic-sensitive' culture among first-line managers. Collective agreements are seen as helpful in facilitating and promoting age-/ageing management. Due to the fact that particularly in 'front-runner' countries attitudes and values of older/ageing workers in terms of quality of work, quality of life and work-life-balance are of outstanding influence for the individual readiness for EWL respective approaches have to be aware of these attitudes. (Naegele \& Bauknecht 2019: 129f.)

With respect to macro-economic dimensions, the 6th Federal Report stated that continued concentration on gainful employment is still the appropriate strategic orientation for the world of work. The demographic aging of the workforce should first and foremost be taken into account when designing corporate personnel policies, because the demand of companies for labour is the determining factor for the employment prospects of job seekers of all ages. This demand is strongly influenced by the structure of the human capital in the (increasingly ageing) supply of job seekers. Against this backdrop, it is still significant to ask whether the specific 
human capital potential of ageing and older workers meets the new requirements that have emerged as a result of structural changes in industry, or whether this potential needs to be adjusted accordingly. The report emphasized above all the following aspects of structural changes in employment with consequences for the employment situation of older and ageing workers and relevant personnel policy requirements in industry and public administration:

- transition from an industrial society to a knowledge and information society,

- further growth in the services sector,

- globalisation of the markets,

- increasing competitive pressure,

- accelerated corporate innovation dynamics,

- $\quad$ high cost pressure,

- new management concepts (e.g. outsourcing, lean production),

- $\quad$ increasing technology orientation, i.e. the trend towards digitization and incorporating information technology in production and services.

\subsubsection{Corporate management's tool box for age and ageing}

Corporate management of age and ageing is seen as a tool for securing and maintaining the ability of an ageing workforce to work and be employed.

Management should, if possible, be supported by collective bargaining. Good practice examples for such corporate age-/ageing-management can be found in the following main fields of action (Naegele \& Sporket 2010; Naegele \& Hess 2020):

- retaining and promoting health,

- $\quad$ promoting actively working longer/working after retirement,

- $\quad$ adjusting working time and having flexible work time schedules,

- monitoring of health and skills related risks,

- $\quad$ special measures for overloaded workers (e.g., shift workers),

- mixed-age teams,

- career development and planning,

- work-life-balance policies,

- life-course oriented personnel policies,

- reconciliation of paid work and care,

- overcoming unemployment/active integration measures,

- age-neutral recruitment strategies,

- $\quad$ gliding retirement schemes,

- preparation for retirement,

- fostering self-employment,

- awareness campaigns, 
- $\quad$ knowledge transfer, skill promotion, and LLL.

\subsubsection{Distributional deficits}

Research in Germany has confirmed that there is a high discrepancy between the need for corporate age-management (at least as measured in terms of the empirically proven demand from older employees) on the one hand, and the corresponding distribution of measures on the other (see

Figure 20) and recently this discrepancy has only increased (Bellmann, Dummert \& Leber 2018), revealing evidence for social inequality in access and usage (see section 5.10.5). At the same time, empirically it can be confirmed that with the spread of age management and the like, both job satisfaction and individuallyassessed productivity (in terms of being able to reach the new retirement age of 67) increase (Eitner \& Naegele 2012). Recent studies in the EXTEND project also confirm corporate productivity to be increased by age management and similar measures, and there can be little doubt that corporate investments in age management and comparable measures pay off in the long term (Rigo \& Heß 2020). Despite the selective distribution of 'good practice' and selective access and usage data (see further in this section), stagnation in introducing these measures has recently been observed. The significantly increased attention paid by policy makers, economists, employer's associations and others to demographic change in the world of labour obviously does not automatically induce relevant corporate action (Bellman, Dummert \& Leber 2018).

\subsubsection{The new credo of a life-cycle oriented personnel policy}

One of the key messages of the 6th Federal Report on Ageing (see section 5.12) addressing explicitly companies was the need to change company personnel policies away from the individual-related acute crisis intervention (often associated with discriminating change in jobs/tasks or early retirement) in favour of life-courseoriented personnel policies (Flüter-Hoffmann 2010). These conclusions were later updated and enriched with results from both the MOPACT-WP3 (Naegele \& Bauknecht 2017, 2019) and the EXTEND project (Hess \& Naegele 2020), and the following objectives and justifications were requested:

- $\quad$ safeguarding continuity and social security throughout the entire occupational lifecycle,

- $\quad$ supporting workers in individual and corporate flexibility and continuity, particularly through taking more consideration of the work life balance,

- facilitation and support of occupational and/or familiar status transitions,

- no longer focusing on the older worker, but instead the ageing worker in a life-course perspective.

- $\quad$ "The promotion of older workers continuing in employment should no longer be effected exclusively by targeted measures for older workers - that is, no 
explicit 'policy concerning older workers' - but instead through a totally different view of employment biographies",

- $\quad$ "Necessary is a total different view of employment biographies and not a view exclusively on older workers/chronological ages" (BMFSFJ 2010: 122).,

- "What is needed is a personnel policy not at all (or no longer) oriented on (partly internal corporate) age images, one which no longer practices categorizing and stereotyping based on the calendar, but is lifecycle oriented instead ('lifecycle oriented personnel policy')" (BMFSFJ 2010: 123).

"A lifecycle-oriented personnel policy means a human resources management system that is strategically adapted to the needs of employees in the course of their work cycles and lifecycles and covers all stages of life from choice of occupation to retirement. ... It is true that such a lifecycle-oriented human resources management system cannot altogether dispense with - at least approximate - fixed retirement ages. Such systems make it easier to avoid rigid and consequently counterproductive categorisation according to [...] chronological age, which can also hardly be justified by scientific facts, and instead adapt human resources policy measures more closely to the individual occupational cycles and lifecycles of the employees, which, by the way, have recently become much more variable" (BMFSFJ 2010: 123).The following tool box is advocated and justified (Flüter-Hoffmann 2010; BMFSFJ 2010):

- training and encouragement of young talents,

- permanent career development,

- promotion of mobility,

- $\quad$ promotion and protection of skills,

- lifelong learning,

- measures to reorganize working time over the life course,

- $\quad$ promotion of reconciling work and family (including eldercare),

- knowledge transfer and creating a knowledge culture,

- preventive health promotion and protection,

- creating a new culture and new images of age within the corporation,

- taking into account more seriously the concept of work-life balance particularly at a later stage in the working life course,

- $\quad$ mixing age and ageing management measures with lifecycle approaches based on the concepts of ability to work and be employed,

- helping to reorganise working-time over the life-course to establish flexibility in working time schedules (including work and retirement),

- helping to reconcile work and eldercare,

- $\quad$ promoting the concept of age diversity and intergenerational relations, 
- $\quad$ promoting internal mobility (e.g. second careers, learning on the job, work organisation,

- $\quad$ promoting older workers' individual flexibility through introducing different working time schedules

- $\quad$ using the experience of the ageing/older workforce as 'experts in their own matters',

- $\quad$ promoting an age-friendly corporate culture (e.g. fighting against age discrimination, improving management styles and the behaviour of colleagues and line managers).

Although they were started with great enthusiasm, the idea of life-course oriented personnel policies seems to have stagnated recently and comparatively few good practices are reported. As examples, see "good practices" in Flüter-Hoffmann (2010) and a recent overview edited by Frerichs (ed.) (2016), in both of which remarkably good corporate and branch-related examples are compiled. Unfortunately, it is not clear whether there are qualifying internal corporate retirement ages and how these can be overcome.

\subsubsection{Who benefits from corporate and/or social partner activities promoting age management?}

\section{Dominance of the Matthew Principle}

It is not surprising that even in the distribution and use of support measures at company level, social inequalities are widespread with regard to both access and usage. This inequality can also be observed for measures initiated by collective bargaining, e.g. as implemented in demographic collective agreements (see section 5.13). Obviously more and more older workers are benefiting from corporate services, but clear gaps persist. Following the Matthew Principle of 'those who have, receive', particularly valued, usually highly-skilled workers (with high incomes and good working conditions) are those who benefit most (Hofäcker \& Unt 2013). These workers are more likely to have the special skills, qualifications, and knowledge that the companies need, and, hence, employers try to delay their retirement ('retain/stay factors').

In this way, social inequalities in the retirement process are further strengthened. Taking into account that in Germany age management experiences are overrepresented both in larger companies (and generally increase with the company size) and those captured by collective and/or company agreements (Eitner \& Naegele 2013; see

Figure 20), it is not surprising that older workers in small and medium-sized enterprises or in companies with no collective agreement and/or only with week tariff commitment are disadvantaged. This trend is all the more problematic as recent data from the IAB Establishment Panel of 2015 showed that only $15 \%$ of all German companies offered special measures for older employees at all (compared 
to $18 \%$ in 2011, BMAS 2018a), giving the IAB experts cause for complaining about the "constancy of age-based measures despite increasing employment of older workers” (Bellmann, Dummert \& Leber 2018: 20).

Figure 20: Measures to preserve workability/employability of older workers from business' and employee's perspective

\begin{tabular}{|c|c|c|}
\hline \multicolumn{3}{|c|}{$\begin{array}{l}\text { Measures to preserve workability/employability of older workers from business } \\
\text { and employee's perspective (G2015) }\end{array}$} \\
\hline & $\begin{array}{l}\text {...is practiced in ... \% of } \\
\text { the company }\end{array}$ & $\begin{array}{l}\text {...is desired by ... \% of } \\
\text { the older workers }\end{array}$ \\
\hline $\begin{array}{l}\text { Special training } \\
\text { programs for older EE }\end{array}$ & 13,5 & 69,6 \\
\hline Age diverse teams & 69,5 & 70,0 \\
\hline $\begin{array}{l}\text { Involvement in } \\
\text { continuing education }\end{array}$ & 58,3 & 81,5 \\
\hline In-house job-rotation & 34,1 & 34,9 \\
\hline $\begin{array}{l}\text { Assignment as coach, } \\
\text { trainer, consultant }\end{array}$ & 37,2 & 65,9 \\
\hline Part-time models & 57 & 61,4 \\
\hline $\begin{array}{l}\text { Selective assignment of } \\
\text { older employees in } \\
\text { development projects } \\
\text { and improvements }\end{array}$ & 20,6 & 73,9 \\
\hline $\begin{array}{l}\text { Reduction of labour } \\
\text { requirements }\end{array}$ & 22,6 & 64,2 \\
\hline $\begin{array}{l}\text { Ergonomic design of the } \\
\text { work environment }\end{array}$ & 37,7 & 84,2 \\
\hline Offers of healthcare & 40,5 & 79,1 \\
\hline $\begin{array}{l}\text { Lifetime working } \\
\text { accounts }\end{array}$ & 17,0 & 73,5 \\
\hline
\end{tabular}

Source: Eitner \& Naegele, 2013.

Particular social inequalities result from the existing access regulations, which automatically exclude those who are not covered by collective protection and/or any age management. Here the Matthew Principle applies in a special way. Since 
protective provisions usually tend to exist in both large companies as well as in strongly unionised sectors, a 'double (dis)advantage' becomes visible, as it can be expected that companies and sectors with these qualities (i.e., large and covered by other agreements) already have more favourable working conditions, pay non-tariff benefits more frequently, etc. As mentioned earlier, the principle of collective bargaining autonomy leaves it up to the negotiating parties to regulate company matters (see section 3.2). Only rarely are collective agreements in question extended to whole sectors and companies covered by explicit general binding declarations by the responsible Federal Ministry of Labour (Bäcker, Naegele \& Bispinck 2020, vol. I). A similar argument can be made with regard to company-organised age management.

\subsection{Provisions for workers with private care obligations (mainly older women)}

Reconciling work and care (see section 4.4) is also a concern in the EWL promotion debate, as many see an untapped labour market potential for women (Reichert 2021). Although the German Long-term Care Insurance (LTCI) supports working carers with social security entitlements (seen by many experts as insufficient, Reichert 2016, 2020, 2021), there is evidence that the financial compensation only partially fills the gaps. Employees in companies with more than 15 workers are legally entitled through the Pflegezeitgesetz (Caregiving leave act) to stay away from paid work partly or for up to a total of six months and repay loans in instalments, but this service is rarely used. In companies with 25 employees or more, employees in the same situation are entitled to reduce working time for at least 15 hours per week for up to 24 months, but also here the benefit has hardly been used due to administrative and financial barriers. In 2017, there were estimated to be 72,000 users (Bäcker, Naegele \& Bispinck 2020, vol. II; Reichert 2021).

A decisive reason that these benefits are not used much is that there is no income compensation analogous to parental allowance for care of sick children. Although it is possible to take out an interest-free loan (a 'nursing care loan'), the obligation to repay the loan after care is over tends to be a deterrent. Since 2015, fewer than 1,000 eligible private carers have taken advantage of this program (initially, just under 10,000 applications has been expected). Limiting the legal entitlement to persons in companies with more than 15 or 25 employees is tantamount to eliminating a large proportion of women, because around $17 \%$ of all female employees in Germany work in companies with fewer than 15 employees and 44\% in companies with fewer than 20 employees. Other studies confirm that other company initiatives (like work time flexibility) are offered primarily in cases of more highly qualified, 'important' top performers, whereas the 'less important' either reduce hours or change into early retirement (Christofczik 2020; Reichert 2016, 2020). 


\subsection{General strategies aiming at sensitization, education, and raising awareness}

Here, only a selection of publicly organised and financed initiatives will be mentioned - those initiated by social partners, employer's associations, chambers of trade and commerce, local authorities and/or organisations for seniors and so on on different occasions fall outside the scope of this paper. The approaches discussed here mostly have been initiated at the Federal level and aim at disseminating information to and building awareness of various actors and institutions. The general aim has been to better inform, influence and sensitize the public discussion and stakeholders, companies, and so on about the consequences and challenges of demographic change in the labour world. A highly significance report is the Bundestag Inquiry Commission on Demographic Change (Bundestags Enquete Kommission zum Demografischen Wandel) (2002) and two relevant Federal Reports on Ageing (Bundesaltenberichte) (2006 and 2012). Both initiatives originally intended to generally shape the challenges of demographic change, and the world of work and the idea of EWL have always played a prominent role here. In accordance with these reports, INQUA and DDN (see section 5.12.4) explicitly address demographic change in the labour world and put a strong focus on corporate responsibilities. Special attention is given to the Federal AntiDiscrimination Legislation and its focus on age.

\subsubsection{Anti-discrimination legislation}

In contrast to the Anglo-Saxon countries, the culture of age discrimination in gainful employment is significantly less pronounced in Germany, not least because of the numerous protections and support provisions (some of which are regulated by collective agreements, see section 5.13). For this reason, it is feared that even introducing the Anglo-Saxon terminology would exacerbate existing negative associations and images of age. In 2006, the General Anti-Discrimination Act/Equal Treatment Act) (Allgemeines Gleichbehandlungsgesetz, AGG), following EU requirements (2000/78/EG, November 2000), was implemented (Frerich 2009). To this day, there has been no research on its impact concerning older workers (Ebener \& Hasselhorn 2015), and no systematic evaluation of its effects is available. Some interested parties refer to its declamatory character, which, however, is unlikely to bring much practical help in concrete individual cases.

$\S 1$ of the Equal Treatment Act states that the goal of this law is to prevent discrimination (Benachteiligung) for several reasons, age among them. §2 defines the areas of application and among the areas defined in §2 (1), there are lots of work-related topics such as selection of applicants, hiring, access to employment, access to promotion in employment, redundancies, payment, etc. §3 defines direct and indirect discrimination. 
Direct discrimination refers to cases in which the person has received worse treatment due to one of the factors in $\S 1$ (e.g. age) in comparison to another person in a 'comparable situation' (i.e. someone similar in other respects). Indirect discrimination refers to cases in which "ostensibly neutral rules, criteria or proceedings can because of one of the $\S 1$ reasons (e.g. age) put people at a disadvantage, unless these rules, criteria or proceedings are justified by a legal goal and the means of reaching this goal are appropriate and necessary." $\$ 8$ regulates "legally different treatment due to occupational requirements" [author's own translation] and allows discrimination on one of the grounds of $\S 1$ "if this ground is a relevant and crucial occupational requirement because of the kind of job to be done or the circumstances under which the job is done, as long as the goal is legal and the requirement is appropriate" [author's own translation].

\subsubsection{Parliamentary Inquiry Commission on Demographic Change (1989-} 2002)

Parliamentary inquiry commissions are set up in Germany whenever fundamental issues of crucial importance to major societal developments as a whole are to be dealt with. Usually, these commissions represent issues that transcend political party interests and even individual political fields of action. In these commissions, politicians (mostly members of Parliament) and academics work together and advise each other on an equal footing with regard to rights, duties, and even voting rights. With respect to EWL, the most significant commission was the Bundestag's 'Inquiry Commission on the Challenges of Demographic Change for the Individual and Society', which worked over three (!) legislative periods between 1992 and 2002. The topics with regard to EWL were 'work and economy', 'lifelong learning', 'old-age income security' and 'retirement ages'.

In its final report in 2002, the Commission advocated the promotion of employment for older workers and the expansion of lifelong learning, including continuing vocational training in enterprises and with a special focus on older workers in small and medium-sized companies. The report explicitly makes a plea for 'enabling longer gainful employment' (Deutscher Bundestag 2002: 188f.) and for gradually adjusting retirement ages to increasing life expectancy, with the life time gained being adjusted equally between the two areas of work and leisure. However, the report did not address the potential risk of creating social inequalities through discriminating against older workers with lower life expectancies, which are mainly members of the lower social classes (de Tavernier 2020). In retrospect, Kruse, Kuhlmey \& Naegele (2017: 420ff.) attest to the recommendations "in large parts and in essence, far more innovative potential than that which can be expected, for example, from the Federal Government's 'demographic strategy [see section 3.3] as a whole." However, although the report is often addressed in scientific literature, in reality the report has had very little influence on political decisions and actions on the Federal level (Kruse, Kuhlmey \& Naegele 2017). 


\subsubsection{The Federal Government's Reports on Ageing in Germany}

In contrast, the Federal Government's Reports on Ageing, which have been published regularly per legislative period since 1993 and are written by an interdisciplinary expert commission of politicians and academicians, are considered to be central documents for debates and developments in policy regarding senior citizens in Germany. These reports include scientifically sound information on processes of ageing and on the development of the living conditions of older people, providing politicians with suggestions and thus influencing the public debate on the position of older people in society. In particular, the 5th and 6th Reports on Ageing have placed the issues ageing of the working population and EWL at the centre of attention. The $5^{\text {th }}$ Report dealt with the potential of older people in general (with a special focus on their economic potential) and how to better use these people as one answer to new demographic challenges (BMFSFJ 2006). The 6th Report (BMFSFJ 2012) dealt with images of old age. Both reports also devoted extensive attention to the need for lifelong learning.

In the $5^{\text {th }}$ Report, the Commission explicitly advocated a paradigm shift in the organisation of working life and called for 'integrated efforts in various fields and policy levels' (health, education, family and labour market policy). Furthermore, the Report criticised in particular the under-utilised potential of older workers and advocated improvements. The proposals were directed, among other things, at 'creating a demographically sensitive corporate culture' and developing 'guidelines for good practice', sustainable 'incentive structures for health protection, health promotion and prevention', the 'conclusion of demographically appropriate collective agreements', 'genuine part-time work for older workers', the simplification of existing labour market policy instruments, as well as allowing 'greater flexibility in the transition to the post-employment phase'. The 6th Report concretised the demands made in the $5^{\text {th }}$ report and addressed in particular the main actors in the world of work, including (above all) the companies and the social partners. The 6th Report also appealed to individual responsibility for health promotion, however in doing so it did not reflect the various chances among different social groups of older people properly (Enste 2018). The Federal Government was called upon to provide a reliable and consistent framework. The plea for a life-course oriented company personnel policy (see further in this section) can be seen as one of the most important messages of the 6th Report postemployment phase' (BMFSFJ 2006: all categories from pages 554-558).

\subsubsection{INQUA and DDN - National attempts to better equip companies to handle demographic change}

The national initiative New Quality of Work (Neue Qualität der Arbeit, INQUA) (www.inqua.de) was launched in 2002 and can be regarded as Germany's contribution to the concurrent EU-wide activities for more and better jobs. INQUA can also be regarded as a first attempt to foster co-ordination among the central 
players in the field of EWL activities, but with a strong focus on the company level. With its memorandum Demographic Change and Employment - A Call for New Corporate Strategies (INQUA 2004a) and the campaign '30, 40, 50 plus - healthy work into old age' (INQUA 2004b), INQUA intends to encourage business to develop more constructive and realistic pictures of the skills and abilities of older people and, at the same time, to foster corporate health policies that aim to safeguard the work ability of younger members of the workforce in the long-term (Frerich 2009).

INQUA is a joint initiative of the Federal Government (Federal Ministry of Labour) (BMAS) and the 16 State governments, the social partners, social insurance institutions and businesses, and is aimed specifically at active participation of social partners. With this initiative, the INQUA partners intend to improve working conditions for better the health and employability of workers, to address the need for jobs that are as stress-free as possible, and to prompt a broad societal debate on the future of work. INQUA provides services to help companies recognise and resolve problems posed by demographic change, such providing as a tool-box for HRM development (www.demowerkzeuge.de), a data-base of good practice (www.inqa.de), and supporting a company network to further develop expertise in this field. INQUA's objective is a modern "culture of work" and a modern HR policy, and, more generally, better quality of work in the spheres of health and motivation. Support is concentrated on four main areas of action or issues:

- $\quad$ personnel management: leadership and communication,

- equal opportunities and diversity: families and jobs, demographics, inclusion, advancement of women,

- health: physical and mental health, organisational and individual resilience,

- $\quad$ knowledge/competence: staff development, LLL, knowledge transfer,

For each of these four issues, there is an 'issue emissary', and these include for example a former chief human resources officer of a big telecommunications company, a scientist, a health expert and a high-profile HR representative of a software company.

\subsubsection{The demography network (DDN)}

The Demography Network (DDN, Das Demografie Netzwerk e.V.) was founded in 2006 through an initiative of the Federal Ministry of Labour and Social Affairs (BMAS) and INQUA. Around 400 companies and other institutions like associations, consultancy firms, and scientific organisations (with more than two million employees in total) are part of the network. DDN's mission is to 'make the demographic change the Chefsache' (that is, an issue of high priority). DDN has ten golden rules, among them a non-discriminatory HR policy, a staff with a balanced age structure, holistic health promotion and knowledge transfer between generations. Rules include e.g. working times adjusted to life phases or flexible retirement. DDN's backbone consists of 11 working groups that can exchange 
existing knowledge and develop new tools and practices. Examples of working groups are those focussed on 'health', 'leadership', 'strategic staff planning' and 'occupational pension schemes and time savings accounts'. Clearly, the 11 working groups cover all topics relevant for encouraging longer working lives at the company level. Since DDN members believe that discourse creates new ideas, the network is explicitly open to new companies. Doubtlessly, DDN has the potential to enable e.g. HR leaders to prepare for demographic change and to adjust working conditions and become connected with others in similar situations.

With regard to the issues surrounding the demographic challenges in the world of work, the following recommendations were adopted, although it remains to be seen how they will be implemented in practice. In this context, the Federal Demography Report (BMI 2012: 123) states: "A mix of measures is required: a longterm personnel policy, company health promotion, a better work-life balance and lifelong qualification and further training. The basis for the success of all measures is a corporate culture that focuses on the participation of and communication with all employees." Among others, the following objectives and measures, some of which have already been introduced, are named, which relate to securing the overall demand for labour and which also essentially target older workers:

- utilisation of unused reserves (e.g. conversion of part-time to full-time jobs)

- activation of job seekers/activating labour market policy,

- increasing the participation of women in the labour market,

- increasing the labour force participation of older people,

- increasing the labour market participation of people with recent immigrant backgrounds,

- $\quad$ promotion of age- and ageing-appropriate working conditions (e.g. in the framework of the INQUA work, see above),

- $\quad$ expansion of workplace health promotion and prevention (e.g. through measures of workplace integration management; BEM),

- $\quad$ promoting the participation of people with disabilities in employment,

- continuing vocational training and lifelong learning.

\subsubsection{BMAS/INQUA's new initiative 'Working 4.0'}

Just recently, the Federal Ministry of Labour and Social Affairs (BMAS) launched a dialogue process entitled 'Working 4.o', which was partly a technical dialogue about the future of the labour society. The aim was not only to work in the new production worlds of Industry 4.o, but also to address and help shape the social conditions and rules of the future labour society on the basis of the guiding principle of 'good work'. In fact, the dialogue process, summarised in the White Paper on Work 4.0, revealed new perspectives and design opportunities, but it also found areas of tension in the working world of the future. The dialogue process made it clear that companies are less and less able to continue the development of their business activities in a linear 
fashion. Digitalisation, changing markets or production conditions, and rapidly changing supply and business interdependencies mean that companies have to adapt to changes iteratively or experimentally. One result of the dialogue process was that the BMAS launched 'company learning and experimentation spaces for work innovations' as part of the New Quality of Work initiative. The homepage for the platform (experimentierraeume.de) shows companies that have started experimenting on the path to the working world of tomorrow. Numerous funded experimental spaces are also in development (as of this writing in Autumn 2020).

\subsection{Collective agreements to regulate demographic change in companies}

To support companies in shaping the demographically-induced ageing and shrinking of the workforces, trade-unions and employer's associations started to negotiate collective agreements (INQUA 2014; Stiemke, Hess \& Naegele 2020; Anlauft \& Feldes 2021) that focus on demographic issues and the promotion of employability of older workers. Currently, 13 of these agreements are in force (INQUA 2014), but they are often criticised (especially by experts close to the trade unions), mainly because of these lack any power of enforcement. One of the demands is for a review of the implementation practice with regard to the concrete effects on the employees themselves (Anlauft \& Feldes 2021).

For example, the following collective agreements on demographic issues can be mentioned (Katenkamp et al. 2012; Tullius et al. 2012, INQUA 2014; Guggemoos \& Conrads 2021):

- $\quad$ collective agreement for the Steel Industry (covering approximately 85,000 employees),

- collective agreement for the automotive company Volkswagen (covering approximately 370,000 employees) and

- collective agreement for the Chemical Industry (covering approximately 550,000 employees).

The collective agreements state the aim to strengthen in-company age-integrative approaches. The following areas of action are addressed and partly made obligatory (ibid):

- $\quad$ analysis of the age and qualification structure of the staff to identify needs for improving working conditions,

- $\quad$ adjustment of working time according to the needs of older workers (e. g. for older shift workers) and development of working time accounts,

- the development of further vocational training (partly explicitly aimed at disadvantaged groups) and

- $\quad$ support for health promotion and in-company health management. 
The collective agreements differ partly in the scope of the addressed measures and were agreed upon at different times. Furthermore, in many cases it seems that Federal and sectoral employers' associations concern about reducing the incidence of early exit is not shared by representatives of the companies, and large companies in particular. Early retirement still plays a strategic role in their personnel policy options in order to better adjust to structural changes in the economy. This option is especially important for many companies and businesses with current or alreadyforeseeable requirements for reductions in personnel (e.g. banking, insurance and telecommunication business, as well as industrial sectors). These companies demand the option of both maintaining early exit options and reducing or shifting respective costs. Another popular argument in companies for promoting early exit concerns older workers with severe health problems or reduced vocational capacities.

But even before the demographic collective agreements, there were collective bargaining policy efforts by the trade unions that were intended to protect older workers. According to the German tradition (and law) for regulating immediate workplace related issues between social partners (Tarifautonomie) (see section 3.2) there are many more collective agreements, e.g. regulating wage-security (in the case of age-related job change, e.g. away from taskwork and/or shift work jobs), working time schedules (e.g. for older shift-workers) including special leave entitlements and (long-term) working time-accounts, and even agreements regulating the participation of older workers in skills adjustment like in the Iron and Steel Industry in Baden-Württemberg (a German region) (BMFSFJ 2006; Bispinck 2016; Guggemoos \& Conrads 2021).

\subsection{Selected conclusions}

This paper has presented overwhelming evidence that the age-related connections between workload, unemployment, illness, etc., are not new (Naegele 1992). What is new is that for those who (still) have to retire early after the new labour market and pension law conditions, changes, and incentive structures, this connection is still virulent as factor of promoting involuntary early retirement. The changes introduced in the course of the paradigm shift in social security around retirement risk leaving people "who cannot change their working life in the lurch to a greater extent than before" (Brussig 2018: 17; 2021).

As a consequence, long-term concepts promoting the organisational employability of an ageing workforce (focusing e.g. on health promotion and protection to avoid health-related effects of heavy workloads) are more needed than ever. Both a national preventive health policy and a national education policy favouring further adult education in an institutionalized form are required, because these could be helpful for incentivising appropriate policies, collective agreements, and and company-based initiatives and measures. There also needs to be a change in paradigm from a reactive 'older worker's policy' mindset to a mindset 
encouraging preventative policies of employment promotion and protection that are age-neutral and pursued throughout an employee's working life (Walker 2020). (Certain age-specific solutions will still have to exist in the future, for example, solutions for older long-term unemployed or older workers suffering from chronic illnesses and/or early disabilities.)

Fighting social inequalities in reaching EWL will also require targeting certain disadvantaged groups of older workers, particularly the unemployed and those with low skills, low income, and health problems, who have decidedly lower chances and opportunities to reach EWL (Naegele \& Hess (eds.) 2020; Brussig 2021). Integrative measures with training, social support, physical rehabilitation programmes, and job-placement consulting by case managers can be seen as one way to effectively place such people and prevent social exclusion (Brussig, Knutz \& Mümken 2016; Walker 2020). Otherwise, it remains doubtful whether all older workers have a realistic chance to stay in employment until the new statutory retirement age of 67 . Increasing numbers of older workers could be facing unemployment for a prolonged period before retiring, and if working conditions are not adjusted adequately, more and more workers could have to accept a reduced-earning pension. Under both circumstances, income levels for retirees will be significantly lower than they have been in the past (see various authors in Naegele \& Hess (eds.) 2020).

\section{A new holistic perspective - news from the EXTEND-project ${ }^{24}$}

The EXTEND project (Naegele \& Hess (eds.) 2020) provides a much more comprehensive view and analysis of modern retirement decisions, based on reanalyses of the increasing labour market participation of older workers in Germany, Denmark and the UK. The core thesis of EXTEND is that an isolated consideration of one possible factor alone offers little explanatory power for retirement decisions; rather, this decision is influenced by a large number of factors that are embedded in overarching processes of change in important societal sub-sectors (e.g. the labour market, companies, families), each of which have direct and indirect influences on retirement (Wang, Olson, \& Schultz 2013; Fisher, Chaffee, \& Sonnega 2016; Hess, Naegele \& Bauknecht 2020). According to this reasoning, changes in the labour market participation of (not only older) workers are generally associated with (1) macro-level structural changes (overall economic situation, demand), (2) a change

24 The following paragraph is in large part from Jensen 2020: 63-68. 
in the relevant discourses ('welfare, work or leisure society'; 'active ageing'), (3) structural changes in institutions (welfare state, labour market, family) and (4) changes in individual dimensions of employability and subjective dispositions. EXTEND's analyses have shown that the overall conditions for EWL have both improved and increased. EXTEND proves, for the countries under study, that only the interactions of these megatrends can explain the complex reality of the increase in employment of older workers that has recently taken place (and is ongoing).

At the macro-level, changes in the employment of older workers have been significantly influenced by the transition from a welfare to a working society. A characteristic feature of a welfare society was that the population was divided into a working population (mostly men working at their 'best' age) and a non-working population (e.g. early retirees, housewives, etc.). In a working society, on the other hand, paid employment is seen as a normative requirement for all, and it is expected that older people, mothers, the long-term unemployed, people with disabilities, and so forth should all try to work, at least within the scope of their capacities.

In the meantime (not least under the influence of demographic change), discourses have changed. In the welfare society, for example, the fair redistribution of income and work is still emphasized. Against this background, retirement is seen as a guarantee for new jobs, especially in underemployed segments of the labour market (in Germany and other places, this view is often embedded in a barelyquestioned ideal of 'generational solidarity' and justified, among other things, by ideas of a necessary withdrawal of old age from active society, according the thesis of disengagement). In the working society and under the influence of demographic change, this view of old age is then put to the test and old age re-conceptualized; today, this change usually goes in the direction of 'active', with 'productive' age(s). Older people should work longer, partly because they are needed. As a result, older workers have become an important economic resource ('grey gold'). Early retirements are discredited as too expensive and even as unhealthful (BMFSFJ 2006; 2010).

The previous type of welfare state was also transformed into an 'enabling state'. In the welfare state, low employment levels of older workers were still associated with the emancipation from paid work and decommodification (decoupling social security from the labour market), which allowed individuals to "still maintain a socially acceptable standard of living regardless of their [lack of] market participation" (Esping-Andersen 1990: 37). Today, in addition to more pressure on the unemployed to actively participate in reintegration into employment, the enabling state also includes restrictions on the (partial) privatisation of state old-age provisions and the (new) normative demand to be jointly responsible for one's own social security (including old-age provisions among other things) by working longer and saving for retirement.

Labour markets and companies have also changed in favour of the integration of older people by transitioning from closed to open (Weber 1978). In a closed labour 
market, certain persons (e.g. women, older people) were either completely excluded from employment, limited in their possibilities, or tied to certain conditions (Germany had an at-the-time negatively connotated 'double earner campaign'). ${ }^{25}$ With regard to older people, the prevalence of age stereotypes at companies and among colleagues and trade unions had an additional excluding effect. Older people became a "manoeuvring mass in terms of labour market policy" (BMFSFJ 2010). In contrast, open labour markets deny access to almost no one who wants to work and is able to do so. Open markets are favoured by regions and sectors experiencing labour shortages (e.g. typical of the service sector) and should favour an increase in age management. However, all too often this new 'opening' increasingly only affects precarious employment relationships (part-time, fixed-term, temporary work, selfemployment).

Family structures have also changed in favour of gender- and age-specific labour market participation. The male (patriarchal) main breadwinner model, which had positioned women to be housewives in informal work, has largely disappeared, replaced by the dual breadwinner model, which implies more equality and democracy in the family. It also implies that women can now increasingly pursue formal, paid employment and that couples coordinate retirement together. Women in particular have benefited from improved conditions in working life after work has been interrupted for family reasons. Not only do women return to work earlier now, but they also stay in the labour force much longer, thereby increasing employment rates, especially in the older age groups (although increasingly often at the cost of part-time work, see section 4.4).

Last but not least, there have also been changes in attitudes on the part of individuals that are conducive to gainful employment. Firstly, there is an increase in positive work orientations among older workers (as there has been in the population as a whole). Secondly, the health and education level of older workers has improved (due to cohort effects). While many older workers in industrial societies are in poor health and have poor education, both of those conditions has improved significantly in modern working society and correspond to important, general cohort effects with beneficial effects on employability in old age and thus on the EWL target (see section 2.3).

Against this background, EXTEND recommends that governments should approach the policy objective of EWL on at several levels of governance and with equal attention to all employment groups. The first important prerequisites for doing so are a stable economy and a stable demand (also) for (older) workers. The second most important prerequisite is that companies are motivated to invest (even

25 The dual-earner campaign played a role in the late 1960s and early 1970s during periods of high unemployment among men and was launched to exert moral pressure on women who were also working ("dual-earners") to free up the jobs they occupied for unemployed men. 
more) in the employability of older workers, i.e. to design and adapt working conditions and environments accordingly, e.g. through age management measures, health prevention, LLL, and work-life balance measures. A third prerequisite would be for both individual and collective dispositions (e.g. work orientation, motivation to EWL) to change through comprehensive discourse and new indirect forms of control (e.g. influencing corporate culture, changing negative age stereotypes). Crucially, more attention must be paid to the special needs and wishes of women relevant to EWL (different 'compatibility requirements', special interest in a balanced work-life-balance). In many countries they are still an unused labour market resource. In order to secure voluntary (further) work 'in dignity' for newcomers to employment or women re-entering the labour market (e.g. older female job-seekers after a previous unemployment), precarious forms of employment should be avoided or eliminated.

Policies and companies must not target only older workers with a high level of employability. Although behaving as though the 'Matthew Principle' ('he that has plenty of goods shall have more') must always hold true makes measures easier to implement, this idea must not be a primary starting point for EWL-relevant support measures because of the 'Fairness Challenge' (Naegele \& Hess (eds.) 2020). What is required are comprehensive, broad-based approaches that also cover individuals with fewer and less favourable employment and EWL prospects. Here, the need to catch up and make provisions is clearly greatest, and comparatively more time and money must be invested, if only to avoid higher subsequent costs (e.g. by combating social exclusion and poverty in old age). Focusing on these typical 'problem groups' is an innovative strategy appropriate to the diverse challenges of demographic and social change. 


\section{$7 \quad$ References}

Ankril, R., Hietikko, M., Mattila, K., Nieminen, J., Rissanen, P. \& Spangar, T. (2002): The National Programme on Ageing Workers: Evaluation. Reports of the Ministry of Social Affairs and Health 2002:2. Helsinki.

Anlauft, W. \& Feldes, W. (2021): Demografietarifverträge - Genese, Wirkungen und Perspektiven eines Gestaltungskonzeptes. In: Richter, G. (Hrsg.): a.a.O.: 253-281.

BA (Bundesanstalt für Arbeit) (2019): Ältere am Arbeitsmarkt. Nürnberg. Baethge, M., Severing, E. \& Weiß, R. (2013): Handlungsstrategien für die berufliche Weiterbildung. Bielefeld: Bertelsmann.

Bäcker, G. (2012): Erwerbsminderungsrenten: Strukturen, Trends und aktuelle Probleme. Altersübergangs-Report, 2012-03. Universität Duisburg: IAQ.

Bäcker, G. \& Naegele, G. (1992): 'Heiß geliebt - aber dennoch verschmäht'. Der gleitende Ruhestand in Theorie und Praxis. Zeitschrift für Sozialreform, 9: 504509 .

Bäcker, G., Brussig, M., Jansen, A., Knuth, M. \& Nordhause-Janz, J.H. (2009): Ältere Arbeitnehmer. Erwerbstätigkeit und soziale Sicherheit im Alter. Wiesbaden: VS Verlag für Sozialwissenschaften.

Bäcker, G. \& Naegele, G. (2017): Gleitender Altersübergang statt starrer Altersgrenzen? Ein Blick zurück nach vorn. In: Schulten, T., Dribbusch, H., Bäcker, G. \& Klenner, Ch. (Hrsg.): Tarifpolitik als Gesellschaftspolitik. Herausforderungen im 21. Jahrhundert. Hamburg: VSA Verlag: 198-209.

Bäcker, G., Naegele, G. \& Bispinck, R. (2020): Sozialpolitik und soziale Lage. Grundlegend überarbeitete und erweiterte 6. Auflage. Bd. I, II. Wiesbaden: SpringerVS.

Bauknecht, J. \& Naegele, G. (2015): Delaying Retirement in Germany and Europe. In: Torp, C. (ed.): Challenges of Aging: Pensions, Retirement and Generational Justice: Palgrave Macmillan: 179-204.

Bellmann, L., Dummert, S. \& Leber, U. (2018): Konstanz altersgerechter Maßnahmen trotz steigender Beschäftigung Älterer. WSI-Mitteilungen 71 (1): 20 27.

Bertelsmann Stiftung (Hrsg.) (2006): Nationale Programme fördern: Ältere Arbeitnehmer. Finnische Erfolgsstrategie. Forum, 3: Gütersloh.

Bispinck, R. (2016). Arbeitszeit - Was bietet der tarifvertragliche Instrumentenkoffer? Elemente qualitativer Tarifpolitik, 82. Düsseldorf: WSITarifarchiv. 
Blank, F. (2020): The German welfare system. The calm after the storm. In: S. Blum, J. Kuhlmann, K. Schubert (eds.): The Routledge Handbook of European Welfare Systems. Abingdon: Taylor \& Francis: 110-128.

Bleses, P. \& Seeleib-Kaiser, M. (2004): The Dual Transformation of the German Welfare State: Palgrave Macmillan.

BMAS (2006) (Bundesministerium für Arbeit und Soziales) (Hrsg.): Initiative 5oplus. Eckpunkte zur Erhöhung der Beschäftigungsfähigkeit und der Beschäftigungschancen älterer Menschen in Deutschland. Berlin.

BMAS (2018a) (Bundesministerium für Arbeit und Soziales): Dritter Bericht der Bundesregierung gemä $\beta$ \$ 154 Absatz 4, Sechstes Sozialgesetzbuch, zur Anhebung der Regelaltersgrenze auf 67 Jahre, Berlin.

BMAS (2018b) (Bundesministerium für Arbeit und Sozialordnung): Qualifizierungsoffensive Wissen und Sicherheit für den Wandel. Berlin.

BMFSFJ (2006) Bundesministerium für Familie, Senioren, Frauen und Jugend: Fünfter Bericht zur Lage der älteren Generation in der Bundesrepublik Deutschland: Potenziale des Alters in Wirtschaft und Gesellschaft - Der Beitrag der älteren Menschen zum Zusmmenhalt der Generationen. BundestagsDrucksache, 16/2190. Berlin: Bundestagsdruckerei.

BMFSFJ (2010) Bundesministerium für Familie, Senioren, Frauen und Jugend: Sechster Bericht zur Lage der älteren Generation in der Bundesrepublik Deutschland - Altersbilder in der Gesellschaft und Stellungnahme der Bundesregierung. Bundestags-Drucksache, 17/3815. Berlin: Bundestagsdruckerei. BMI (Bundesministerium des Innern) (Hrsg.) (2012): Demografiebericht. Bericht der Bundesregierung zur demografischen Lage und künftigen Entwicklung des Landes. Berlin.

Bönke, T., Schröder, C. \& Schulte, K. (2009): Income and Inequality in the Long Run: The Case of German Elderly. German Economic Review, 11(4): 487-510.

Bosch, G. (2010): Lernen im Erwerbsverlauf - Von der klassischen Jugendorientierung zu lebenslangem Lernen. In: Naegele, G. (Hrsg.): a.a.O.: 352370 .

Bovenberg, A.L. (2008): The Life-course Perspective and Social Policies: An Overview of the Issues. Modernising Social Policy for the New Life Course. OECD Publishing: 23-73.

de Breij, S. \& Deeg, D.J.H. (2020): Gesundheit vor und nach der Rente. In: Naegele, G. \& Hess, M. (Hrsg.): a.a.O.: 139-146.

Brussig, M. (2010): Künftig mehr Zugänge in Altersrenten absehbar. Gegenwärtig kein Ausweichen in die Erwerbsminderungsrente zu beobachten. Altersübergangsreport 2010-02. Universität Duisburg: IAQ.

Brussig, M. (2012): Weiter steigendes Renteneintrittsalter, mehr Renteneintritte aus stabiler Beschäftigung, aber zunehmend geringe Altersrenten bei 
Langzeitarbeitslosen. Aktuelle Entwicklungen beim Rentenzugang.

Altersübergangsreport 2012-02. Universität Duisburg: IAQ.

Brussig, M. (2014): Arbeitsbelastungen im letzten Beruf und

Verrentungsentscheidungen. Beschleunigen hohe Belastungen den Übergang in den Ruhestand? Zeitschrift für Sozialreform, 60(1): 37-60.

Brussig, M. (2015): Alter beim Austritt aus sozialversicherungspflichtiger Beschäftigung ist gestiegen. IAQ: Altersübergangsreport 2015-1. Universität Duisburg: IAQ.

Brussig, M. (2018): Verlängerte Erwerbsbiografien: Triebkräfte, Grenzen, soziale Ungleichheiten. WSI-Mitteilungen, 71, 01: 12-19.

Brussig, M. (2021): 20 Jahre Altersübergangsforschung. Eine Skizze zur Bilanz der Entwicklungstrends und Forschungsperspektiven. In: Richter, G. (Hrsg.): a.a.O.: 105-128.

Brussig, M., Knuth, M. \& Wojtkowski S. (2009): Altersteilzeit: Zunehmend Beschäftigungsbrücke zum späteren Renteneintritt. Altersübergangs-Report 200902. Universität Duisburg: IAQ.

Brussig, M., Knuth, M. \& Mümken, S. (2016): Von der Frühverrentung bis zur Rente mit 67. Der Wandel des Altersübergangs von 1990 bis 2012. Bielefeld: transcript.

Busemeyer, M. (2006): Moving the unmovable: Policy strategies of pension reforms in Germany. German Policy studies, 3(3): 400-445.

CDU, CSU \& SPD (2005): Koalitionsvereinbarung für die 16. Legislaturperiode. Zusammen für Deutschland. Mit Mut und Humanität. Berlin.

Clemens, W. (2010): Lebensläufe im Wandel - Gesellschaftliche und sozialpolitische Perspektiven. In: Naegele, G. (ed.): a.a.O.: 865-109.

Christofczik, R. (2020): Rentenübergänge bei erwerbstätigen privaten Pflegepersonen - Wünsche und Erwartungen. In: Naegele, G. \& Hess, M. (Hrsg.). a.a.O.: $147-158$.

Deller, J. \& Naegele, L. (2021): Weiterarbeit im Rentenalter. Zurückliegende Entwicklungen, Stand des Wissens und offene Fragen. In: Richter, G. (Hrsg.): a.a.O.: 331-354.

Destatis (2017a): Arbeitsmarkt. https://www.destatis.de/DE/ZahlenFakten/Indikatoren/LangeReihen/ Arbeitsmarkt/lrerw013.html (accessed 2017/03/27).

Destatis (2017b): Bevölkerung. https://www.destatis.de/DE/ZahlenFakten/GesellschaftStaat/Bevoelkerung/ Ehescheidungen/Tabellen_/lrbevo6.html (accessed 2017/o3/27).

Deutscher Bundestag (2002): Referat für Öffentlichkeitsarbeit (Hrsg.): EnqueteKommission Demografischer Wandel. Herausforderungen unserer älter werdenden 
Gesellschaft an den Einzelnen und die Politik. Zur Sache, 3. Berlin:

Bundestagsdruckerei.

De Tavernier (2020): Indexing retirement age to life expectancy. In: Naegele, G. \& Hess, M. (Hrsg.): a.a.O.: 133-138.

Deutscher Bundestag (2018): Dritter Bericht der Bundesregierung zur Anhebung der Regelaltersgrenze auf 67 Jahre. Bundestagsdrucksache, 19/6239. Berlin. Bundestagsdruckerei.

Deutscher Gewerkschaftsbund (DGB) (2015): Zur Arbeitsmarktsituation Älterer: Erwerbstätigkeit Älterer steigt, aber ungelöste Probleme mit Arbeitslosigkeit und sozialer Polarisierung beim Altersübergang. Arbeitsmarkt aktuell, 10.

Dieck, M. \& Naegele, G. (1993): 'Neue Alte' und alte soziale Ungleichheiten vernachlässigte Dimensionen in der Diskussion des Altersstrukturwandels. In: Naegele, G. \& Tews, H.-P. (Hrsg.): Lebenslagen im Strukturwandel des Alters. Opladen: Westdeutscher Verlag: 43-60.

Dietz, M. \& Walwei, U. (2011): Germany - No Country for Old Workers? Journal of labour market research, 44: 363-376.

Dlugosz, S., Stephan, G. \& Wilke, R.A. (2009): Fixing the leak. Unemployment incidence before and after the 2006 reform of unemployment benefits in Germany. IAB discussion paper, 25. Nürnberg.

Duden (2016): Wirtschaft von A bis Z: Grundlagenwissen für Schule und Studium, Beruf und Alltag. 6. Auflage. Mannheim: Bibliographisches Institut 2016. Lizenzausgabe Bonn: Bundeszentrale für politische Bildung.

Duell, N. \& Vogler-Ludwig, K. (2012): Germany. European Employment Observatory. EEO Review: Employment policies to promote active ageing . van Dyck, S. \& Lessenich, S. (2009): Ambivalenzen der (De-)Aktivierung. Altwerden im flexiblen Kapitalismus. WSI-Mitteilungen, 62,10: 540-545.

Ebbinghaus, B. (2006): The reform of early retirement in Europe, Japan and the USA. Oxford: Oxford University Press.

Ebbinghaus, B. (ed.) (2011): The varieties of pension governance: Pension privatization in Europe. Oxford: Oxford University Press.

Ebener, M. \& Hasselhorn, H.M. (2015): National Policy Report: Germany. In: Hasselhorn, H.M. \& Apt, W. (eds.): Understanding employment participation of older workers: Creating a knowledge bases for future labour market challenges. Research Report. Federal Ministry of Labour and Social Affairs (BMAS) and Federal Institute for Occupational Safety and Health (BAuA). BMAS/BAuA. Berlin: 76-78.

Eitner, C. \& Naegele, G. (2013): Fremd- und Selbstbilder vom Altern in der Arbeitswelt. In: Jahrbuch Sozialer Protestantismus, 6: Alternde Gesellschaft Soziale Herausforderungen des längeren Lebens. Gütersloh: Gütersloher Verlagshaus: 167-189. 
Enste, P. (2018): Gesundheitliche Eigenverantwortung im Kontext der

Lebensspanne. Eine Mixed Methods Studie mit Fokus auf die Lebensspanne Alter. Wiesbaden: SpringerVS.

Esping-Andersen, G. (1990): The Three Worlds of Welfare Capitalism. Princeton University Press: Princeton.

Esping-Andersen, G. (2007): Sociological Explanations of Changing Income Distributions. American Behavioural Scientist, 50: 639-658.

Fisher, G.G., Chaffee, D.S. \& Sonnega, A. (2016): Retirement Timing: A Review and Recommendations for Future Research. Work, Ageing and Retirement, 2: 230-261. Flüter-Hoffmann, C. (2010): Der Weg aus der Demografie-Falle Lebenszyklusorientierte Personalpolitik. In: Naegele, G. (Hrsg.) (2010): a.a.O.: 411429 .

Frerichs, F. (2009): Demografischer Wandel und Arbeitsmarktpolitik für ältere Arbeitnehmer/innen. Das Vereinigte Königreich, Japan und Deutschland im Wohlfahrtsstaatsvergleich. Münster: Lit-Verlag.

Frerichs, F. (Hrsg.): Altern in der Erwerbsarbeit. Perspektiven der Laufbahngestaltung. Vechtaer Beiträge zur Gerontologie. Wiesbaden: SpringerVS. Frerichs, F. \& Naegele, G. (2008): Active ageing in employment - prospects and policy approaches. In: Taylor, P. (ed.): Ageing Labour Forces - Promises and Prospects. Cheltenham: $174-203$.

Frerichs, F. \& Taylor, P. (2009): Ageing and the Labour Market - A Comparison of Policy Approaches. In: Walker, A. \& Naegele, G. (eds.): Social Policy in Ageing Societies. Britain and Germany Compared. Palgrave Macmillan: 46-81.

Friedenstab, C., Schulz-Weidner, W. \& Väänänen, N. (2015): Tätigkeitsbezogene Frührentensysteme in Europa - die Bewertung besonderer beruflicher Belastzungen. Deutscher Rentenversicherung 3/2015: 183-199.

Gemeinsame Erklärung (2001): Gemeinsame Erklärung des Bündnisses für Arbeit, Ausbildung und Wettbewerbsfähigkeit zu den Ergebnissen des 7.

Spitzengespräches am 4. März 2001. Berlin.

GDA, Gemeinsame Deutsche Arbeitsschutzstrategie (2016): Empfehlungen zur Umsetzung der Gefährdungsbeurteilung psychischer Belastungen. Available under http://www.gda-portal.de/de/pdf/Psyche-UmsetzungGfB.pdf?_blob=publicationFile.

Generali Zukunftsfonds \& Institut für Demoskopie Allensbach (2012): Generali Altersstudie 2013. Wie ältere Menschen leben, denken und sich engagieren. Frankfurt/M.; Fischer Taschenbuch Verlag.

Goebel, C. \& Zwick, T. (2010): Which Personnel Measures are Effective in Increasing Productivity of Old Workers? ZEW Discussion Paper, 10-069. Grigoriev, P., Scholz, R. \& Shkolnikov, V. M. (2019): Socio-economic differences in mortality among 27 million economically active Germans: a cross-sectional 
analysis of the German Pension Fund data. Max Planck Institute für Demographic Research Rostock (ed.): BMJOpen 2019; 9:e028001.doi:10.1136/bmjopen-2018028001.

Guggemoos, P. \& Conrads, R. (2021): Zur Verankerung demografiebezogener Themen in Tarifverträgen und Betriebsvereinbarungen - Beobachtungen und Einschätzungen. In: Richter, G. (Hrsg.): a.a.O.: 217-253.

Hanel, B. \& Riphahn, R.T. (2012): The Timing of Retirement - New evidence from Swiss female workers. Labour Economics, 19: 718-728.

Heien, T., Kowalski, I., Leve, V., Naegele, G., Rockhoff, M. \& Sporket, M. (2008): 'Rente mit 67', Voraussetzungen für die Weiterarbeitsfähigkeit älterer Arbeitnehmerinnen. Dortmund: INQUA-Eigenverlag.

Heisig, J.P. (2015): Late-career Risks in Changing Welfare States: Comparing Germany and the United States Since the 1980s. Amsterdam University Press.

Hess, M., Bauknecht, J. \& Pink, S. (2018): Working Hours Flexibility and Timing of Retirement: Findings from Europe. Journal of Aging \& Social Policy [online first].

Hess, M. (2018): Expected and Preferred Retirement Age in Germany. Zeitschrift für Gerontologie und Geriatrie, 51(1): 98-104.

Hess, M. (2016). Germany: A Successful Reversal of Early Retirement? In: Hofäcker, D., Hess, M. \& König, S. (eds.): Delaying Retirement: Progress and Challenges of Active Ageing in Europe, the United States and Japan. Palgrave Macmillan: 147-169.

Hess, M. (2017): Determinants of Prospective Retirement Timing in Germany. Zeitschrift für Sozialen Fortschritt, 66(9): 593-610.

Hess, M. \& Landmann, J. (2015): Großer Bedarf an flexiblen Übergängen vom Arbeitsleben in die Rente. Impulse 06/2015. Bertelsmann Stiftung.

Hess, M., Naegele, G. \& Bauknecht, J. (2020). Renten- und Arbeitsmarktpolitiken und die Beschäftigungssituation älterer Arbeitnehmer*innen in Deutschland. In: Naegele, G. \& Hess, M. (Hrsg.). a.a.O: 69-98.

Hochfellner, D. \& Burkert, C. (2013): Employment in retirement: continuation of a working career or essential additional income? Zeitschrift für Gerontologie und Geriatrie, 46(3): 242-252.

Hofäcker, D. (2015): In line or at odds with active ageing policies? Exploring patterns of retirement preferences in Europe. Ageing and Society, 35(7): 1529

Hofäcker, D., Hess, M. \& Naumann, E. (2015): Changing Retirement Transitions in Times of Paradigmatic Political Change: Toward Growing Inequalities. In: Torp, C. (ed.): Challenges of Aging: Pensions, Retirement and Generational Justice.

Houndmills: Palgrave Macmillan: 205-226.

Hofäcker, D., Hess, M. \& König, S. (2018): Wandel von Ruhestandsübergängen im politischen Paradigmenwechsel Europas. Späterwerbsphase und Rentenübergang in 
Deutschland, Österreich, Schweden und Estland, in: Zeitschrift für Gerontologie und Geriatrie, 52, (Supplement 1): 540 - 551.

Hofäcker, D. \& Unt, M. (2013): Exploring the 'new worlds' of (late?) retirement in Europe. Journal of International and Comparative Social Policy, 29(2): 163-183.

Hokema, A. \& Scherger, S. (2016): Working pensioners in Germany and the UK: Quantitative and qualitative evidence on gender, marital status and the reasons for working. Journal of Population Ageing, 9(1): 91-111.

Holzmann, R. (2006): Toward a Coordinated Pension System in Europe: Rationale and Potential Structure. In: Holzmann, R. \& Palmer, E. (eds.): Pension Reform. Issues and Prospects for Non-Financial Defined Contribution (NDC) Schemes. Washington, D.C.: The World Bank: 225-265.

Huebener, M., Müller, K.U., Spieß, C.K. \& Wrolich, K. (2016): Zehn Jahre Elterngeld: Eine wichtige familienpolitische Maßnahme. DIW-Wochenbericht, 83 (49): 1159-1166.

Hüther, M. \& Naegele, G. (2012): Demografiepolitik: Warum und wozu? In: Hüther, M. \& Naegele, G. (Hrsg.): a.a.O.: 13-33.

Hüther, M. \& Naegele, G. (Hrsg.) (2013): Demografiepolitik. Wiesbaden: VS Verlag für Sozialwissenschaften.

INQA (ed.) (2004a): Demographic Change and Employment. A Call for New Corporate Strategies. Dortmund: Eigenverlag.

INQA (Hrsg.) (2004b): 30-40-50plus: Gesund arbeiten bis ins Alter. Mit Erfahrung die Zukunft meistern. Altern und Ältere in der Arbeitswelt. Dortmund: Eigenverlag. INQA (Hrsg.) (2014): Monitor - Tarifverträge zur Gestaltung der Qualität der Arbeit. Ein aktueller Überblick über Vereinbarungen zu alternsgerechten und demokratiefesten Arbeitsbedingungen. Berlin: Eigenverlag.

Jensen, P.H. (2020): Politiken zur Verlängerung der Lebensarbeitszeit (EWL) und Auswirkungen auf soziale Ungleichheiten. In: Naegele, G. \& Hess, M. (Hrsg.). a.a.O.: 63-68.

Kaboth, A. \& Brussig, M. (2019): Trotz steigender Altersgrenzen stagniert das durchschnittliche Rentenzugangsalter: Aktuelle Entwicklungen im Rentenzugang. Altersübergangsreport 2019-2. Universität Duisburg: IAQ.

Kaboth, A. \& Brussig, M. (2020a): Trotz Alterserwerbsbeteiligung auf Rekordniveau: mehr Ältere von Arbeitslosigkeit betroffen. Großer Anteil älterer Arbeitsloser bleibt nach wie vor verdeckt. Altersübergangs-Report 2020-01. Universität Duisburg: IAQ.

Kaboth, A. \& Brussig, M. (2020b): Arbeitsmarktpolitische Maßnahmen : Wie werden Ältere gefördert? Altersübergangsreport 2020-02. Universität Duisburg: IAQ. 
Katenkamp, O., Martens, H., Georg, A., Naegele, G. \& Sporket, M. (2012): Nicht zum alten Eisen! Die Praxis des Demographie-Tarifvertrages in der Eisen- und Stahlindustrie. Berlin.

Keese, M., Hirsch, D. \& Bednarzik, R. (2006): Live longer, work longer. Paris: OECD.

Kistler, E. \& Trischler, F. (2014): ‘Gute Erwerbsbiographien’ - Der Wandel der Arbeitswelt als Risikofaktor für die Alterssicherung. In: Kistler, E. \& Trischler, F. (Hrsg.): Reformen auf dem Arbeitsmarkt und in der Alterssicherung - Folgen für die Einkommenslage im Alter. Düsseldorf: 171 - 204.

Klös, H.-P. \& Naegele, G. (2013): Alter als 'Ressource' - Befunde und verteilungspolitische Implikationen. In: Hüther, M. \& Naegele, G. (Hrsg.). a.a.O.: 123-141.

Knuth, M., Niewerth, C., Stegmann, T., Zink, L., Boockmann, B., Brändle, T., Kirchmann, A., Kleimann, R. Klempt, C. \& Langkabel, H. (2012): Evaluation der Zweiten Phase des Bundesprogramms 'Perspektive 5oplus - Beschäftigungspakte für Ältere in den Regionen' (2008-2010). Abschlussbericht, Kurzfassung, 30 September.

Koalitionsvertrag (2021). Koalitionsvertrag 2021-2025 zwischen der SPD, Bündnis 90/DIE GRÜNEN und FDP: Mehr Fortschritt wagen. Bündnis für Freiheit, Gerechtigkeit und Nachhaltigkeit. Berlin.

(https://www.spd.de/koalitionsvertrag2021/).

Kohli, M. (1985). Institutionalisierung des Lebenslaufs. Historische Befunde und theoretische Argumente. Kölner Zeitschrift für Soziologie und Sozialpsychologie, 37: 1-29.

Kohli, M. (1987): Retirement and the moral economy: An historical interpretation of the German case. Journal of Ageing studies, 1: 125-144.

Kohli, M. (1990): Lebenslauf und Lebensalter als gesellschaftliche Konstruktion: Elemente zu einem interkulturellen Vergleich. In: Elwert, G. et al. (Hrsg.): Im Lauf der Zeit. Ethnographische Studien zur gesellschaftlichen Konstruktion von Lebensaltern. Breitenbach. Saarbrücken et al.: 11-32.

Kohli, M., Rein, M., Guillemard A.M. \& van Gunsterden, A. (eds). (1991): Time for Retirement. Comparative studies of early exit from the labour force. Cambridge: Cambridge University Press.

Kruse, A., Kuhlmey, A. \& Naegele, G. (2017): Gerontologische Politikberatung Möglichkeiten und Grenzen wissenschaftlicher Beratung. Zeitschrift für Gerontologie und Geriatrie, 5: 420-428.

Lampert, T., Hoebel, J., Kuntz, B., Fuchs, J., Scheidt-Nave, C. \& Nowossadeck, E. (2016): Gesundheitliche Ungleichheit im höheren Lebensalter. Robert-Koch Institut (Hrsg.): GBE kompakt, 1.

Lehr, U. (1988): Arbeit als Lebenssinn auch im Alter. In: Rosenmayr, L. \& Kolland, F. (Hrsg.): a.a.O.: 29-46. 
Lehr, U. \& Naegele, G. (2018): Ältere Arbeitnehmer - gestern gejagt, morgen gefragt? In: Welti, F. et al. (Hrsg.): Gesundheit, Alter, Pflege, Rehabilitation - Recht und Praxis im interdisziplinären Dialog. Freiburg: Nomos-Verlag: 456-569.

Lott, M. \& Spitznagel, E. (2010): Impulse für die berufliche Weiterbildung im Betrieb. IAB-Kurzbericht, 11. Nürnberg.

Lüthen, H. (2014): Rente und Reform: Lehren aus der Vergangenheit. DIW Roundup: Politik im Fokus, 14.

Merkel, S., Holman, D., Ruokolainen, M. \& Hess, M. (2020): Working longer in the professional HCS sector? In: Naegele, G. \& Hess, M. (Hrsg.): a.a.O.: 177-186.

Mladovsky, P., Allin, S., Masseria, C., Hernández-Quevedo, C., McDaid, D. \& Mossialos, E. (2009): Health in the European Union. Trends and analysis.

Observatory Series N. 19. Copenhagen: WHO.

Möhring, K. \& Bennett, J. (2015): Arbeitslosigkeit und Frührente älterer Personen in Europa - Die Rolle von Arbeitmarkt- und Rentenpolitik aus der Lebenslaufperspektive. Zeitschrift für Sozialreform, 61, 4: 379-402.

Naegele, G. (1992): Zwischen Arbeit und Rente. Augsburg: Maro.

Naegele, G. (2013a): Arbeit trotz Rente. In: Institut für Demoskopie Allensbach \& Generali Zukunftsfonds (Hrsg.): Generali Altersstudie 2013. Wie ältere Menschen leben, denken und sich engagieren. Frankfurt/M.: Fischer: 104-108.

Naegele, G. (2013b): Older workers and older worker policies in Germany. In: Taylor, P. (ed.): Older Workers in an Ageing Society. Critical Topics in Research and Policy. Cheltenham: $39-62$.

Naegele, G. (2015): Altes und Neues zur Erwerbsarbeit Älterer - mit besonderer Beachtung der betrieblichen Ebene. In: Igl., G., Welti, F. \& Eßer, M. (Hrsg.): Alter und Beschäftigungen. Arbeitssituation, Lebensentwürfe und soziale Sicherung der über 5ojährigen. Münster: LIT-Verlag: 17-32.

Naegele, G. (2017a): Altes und Neues zur 'Arbeit trotz Rente' - Weiter wachsende Rentnererwerbstätigkeit. In: Generali Deutschland AG (Hrsg.): Generali Altersstudie 2017. Wie ältere Menschen in Deutschland denken und leben. Heidelberg. Springer: 73-79.

Naegele, G. (2017b): Der demografische Wandel hat längst die Arbeitswelt erreicht - und was ist passiert? In: Hoose, F., Beckmann, F. \& Schönauer, A.-L. (Hrsg.): Fortsetzung folgt. Kontinuität und Wandel von Wirtschaft und Gesellschaft. Wiesbaden: Springer Fachmedien: 351-375.

Naegele, G. \& Schmähl, W. (2007): Materielle Ressourcen des Alters - Einkommen und Einkommenssicherheit im Alter. In: Bertelsmann Stiftung (Hrsg.): Alter neu denken. Gesellschaftliches Altern als Chance begreifen. Gütersloh: Verlag Bertelsmann Stiftung: 190-216.

Naegele, G., Leve, S. \& Sporket, M. (2009): 'Rente mit 67' - Voraussetzungen für die Weiterarbeitsfähigkeit älterer Arbeitnehmerinnen. Zeitschrift für Gerontologie und Geriatrie, 2009. 
Naegele, G. \& Bauknecht, J. (2017). Strategies ('Action Plan') for extending working lives, raising older workers' employment rates and intensifying Lifelong Learning in later working life. MoPAct Work Package 3, Task 5. Dortmund:

Forschungsgesellschaft für Gerontologie.

Naegele, G. \& Bauknecht, J. (2019): Extending working lives. In: Walker, A. (ed.): Ibid.: 107-142.

Naegele, G. \& Sporket, M. (2010): Perspektiven einer lebenslauforientierten ÄltereArbeitnehmer-Politik. In: Naegele, G. (Hrsg.): a.a.O.: 448-473.

Naegele, G., Anderson, J.G., Barkholdt, C., de Vroom, B. \& K. Krämer (2002): A new organisation of time throughout working life. European Foundation for the improvement of living and working conditions. Dublin.

Naegele, G. (Hrsg.) (2010): Soziale Lebenslaufpolitik. Wiesbaden: VS Verlag für Sozialwissenschaften.

Naegele, G. \& Hess, M. (2020) (Hrsg.): Neue und alte soziale Ungleichheiten beim Rentenübergang. Wiesbaden: SpringerVS.

Naegele, G. \& Hess, M. (2020): Social inequalities in realising extending working lives EXTEND `s conceptual framework. In: Naegele, G. \& Hess, M. (Hrsg.): 17-62.

Naegele, G. \& Hess, M. (eds.): Neue und alte soziale Ungleichheiten bei Berufsaufgabe und Rentenübergang. Wiesbaden: SpringerVS.

Neumann, L.F. (1979) (Hrsg.): Sozialforschung und soziale Demokratie. Festschrift für Otto Blume. Bonn: Verlag Neue Gesellschaft.

Ogg, J. \& Rasticova, M. (2020): Introduction: Key Issues and Policies for Extending Working Life. In: Leime, N. et al. (eds.): Extended Working Life Policies. International Gender and Health Perspectives. Wiesbaden: SpringerVS: 3-27.

Orloff, A.S. (1993): Gender and the Social Rights of Citizenship: The Comparative Analysis of Gender Relations and Welfare States. American Sociological Review, 58(3): 303-328.

Pott, E. (2017): Lebenserwartung und Lebensgefühl älterer Menschen in Deutschland. In: Generali Deutschland AG (Hrsg.): a.a.O.: 170-184.

Radl, J. (2007): Individuelle Determinanten des Renteneintrittsalters: Eine empirische Analyse von Übergängen in den Ruhestand/Individual Determinants of the Age of Retirement: An Empirical Analysis of Transitions to Old Age Pensions. Zeitschrift für Soziologie, 36(1): 43-64.

Radl, J. (2014): Retirement Timing and Social Stratification. A Comparative Study of Labour Market Exit and Age Norms in Western Europe. Berlin: De Gruyter Open.

Rigo, M. \& Hess, M. (2020): Economic evaluation of 'good practices' in the EXTEND context. In: Naegele, G. \& Hess, M. (Hrsg.): a.a.O.: 219-232. 
Reichert, M. (2016): Vereinbarkeit von Erwerbstätigkeit und Pflege - (k)ein Thema für Unternehmen? In: Naegele, G., Olbermann, E. \& Kuhlmann, A. (Hrsg.):

Teilhabe im Alter gestalten. Wiesbaden: SpringerVS: 251-264.

Reichert, M. (2020): Vereinbarkeit von beruflicher und häuslicher Pflege: 'Double Duty Carers' in Deutschland. In: Naegele, G. \& Hess, M. (Hrsg.): a.a.O.: 159-176.

Reichert, M. (2021): Vereinbarkeit von Pflege und Erwerbstätigkeit in Deutschland - Stand und Perspektiven. In: Kudo, H., Matsuda, T., Naegele, G. \& Waldenberger, F. (Hrsg.): Altern und Pflege als kommunale Aufgaben -

Deutsche und japanische Ansätze und Erfahrungen. Wiesbaden: SpringerVS (i.E.). Richter, G. (Hrsg.): Arbeit und Altern. Eine Bilanz nach 20 Jahren Forschung und Praxis. BAUA (Hrsg.): Baden-Baden: Nomos. Edition Sigma.

Rinklake, A. \& Buchholz, S. (2012): Increasing inequalities in Germany: Older people's employment lives and income conditions since the mid-1980s. In: Blossfeld, H. P., Buchholz, S. \& Kurz, K. (eds.): Ageing populations, globalization and the labour market. Comparing late working life and retirement in modern societies. Cheltenham: 35-64.

Romeu-Gordo L. \& Sarter, E.K. (2020): Chapter 20: Germany. In: Leime, N. et al. (eds.): Extended working life Policies. - International Gender and Health perspectives. Wiesbaden: SpringerVS: 271-280.

Rosenmayr, L. (1988): Arbeit und Freizeit im Lebenslauf. In: Rosenmayr, L- \& Kollan d, F. (Hrsg.): a.a.O.: 3-8.

Rosenmayr, L. \& Kolland, F. (Hrsg.): Arbeit - Freizeit - Lebenszeit. Neue Übergänge im Lebenszyklus. Wiesbaden: Westdeutscher Verlag.

Rürup, B. (2002): The German Pension System: Status Quo and Reform Options. University of Chicago Press. Chicago.

Schäufele, M. \& Hendlmeier, I. (2015): Erwerbstätigkeit und Pflege von Menschen mit Demenz: Ergebnisse einer Bevölkerungsstudie in Deutschland. Präsentation DGGG Mannheim, 17.09.2015.

Schmidt, B. (2009): Weiterbildung und informelles Lernen älterer Arbeitnehmer. Wiesbaden: VS Verlag für Sozialwissenschaften.

Singer, C. \& Toomet, O. (2013): On government-subsidized training programs for older workers, IAB-Discussion Paper, 21. Nürnberg.

Söhn, J. (2018): Migration: Erwerbsverläufe und Rentenansprüche von Zugewanderten bei der Gesetzlichen Rentenversicherung Deutschlands. FNA Abschlussbericht. FNA (Forschungsnetzwerk Alterssicherung) (Hrsg.): Heft 2/2018. Berlin.

Statistisches Bundesamt (2018): Arbeitsmarkt auf einen Blick. Deutschland und Europa. Wiesbaden. 
Stiemke, P., Hess, M. \& Naegele, G. (2020): Demografie-Tarifverträge in Deutschland - eine neue Gestaltungsoption. In: Naegele, G. \& Hess, M. (Hrsg.): a.a.O.: 211-218.

Tews, H.P. (1993): Neue und alte Aspekte des Strukturwandels des Alters. In: Naegele, G. \& Tews, H.P. (Hrsg.): Lebenslagen im Strukturwandel des Alters. Opladen: Westdeutscher Verlag: 15-42.

Tullius, K., Freidank, J., Grabbe, J., Kädtler, J. \& Schröder, W. (2012): Perspektiven alter(n)sgerechter Betriebs- und Tarifpolitik. WSI-Mitteilungen, 65 (2): 113 - 122.

Trischler, F. (2014): Erwerbsverlauf, Altersübergang, Alterssicherung. Zunehmende soziale Ungleichheit im Alter. Wiesbaden: VS Verlag für Sozialwissenschaften.

Vickerstaff, S., Loretto, W. \& White, P. (2007): The future for older workers: Opportunities and constraints. In: Loretto W., Vickerstaff S. \& White, P. (eds): The future for older workers: New perspectives. Bristol: Policy Press: 203-226 Walker, A. (2010): The Emergence and Application of Active Ageing in Europe. In: Naegele, G. (Hrsg.): a.a.O.: 585-601.

Walker, A. (2013). Understanding and combating unequal ageing. In: Bäcker, G. \& Heinze, R. (Hrsg.): Soziale Gerontologie in gesellschaftlicher Verantwortung. Wiesbaden: SpringerVS: 19-32.

Walker, A. (2019) (ed.): The Future of Ageing in Europe. London: Palgrave Macmillan.

Walker, A. (2020): Conclusion - Policy Priorities from EXTEND. In: Naegele, G. \& Hess, M. (Hrsg.): a.a.O.: 245-250.

Wang, M., Olson, D.A. \& Schultz, K.S. (2013): Mid and Late Career Issues: An Integrative Perspective. London and New York: Routledge.

Weber, M. (1978): Economy and society. University of California Press. 